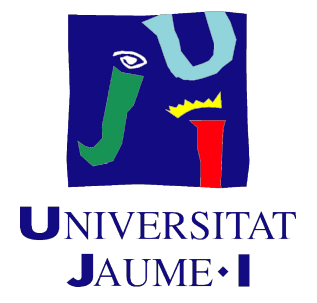

Programa de doctorado en Ciencias

Escuela de Doctorado de la Universitat Jaume I

\title{
Sistemas "single-pixel" para la obtención de imágenes a través de medios turbios. Aplicación en tejidos biológicos
}

Memoria presentada por Esther Irles Antón para optar al grado de doctora por la Universitat Jaume I

Doctoranda:

Esther Irles Antón
Directores:

Dr. Jesús Lancis Sáez

Dr. Vicente Durán Bosch 

Dedicado a mi familia 


\section{Agradecimientos}

Este es mi quinto año de tesis, debería haber terminado antes, pero por unas y otras circunstáncias he tardado más de la cuenta. En estos 5 años he vivido muchas cosas y he aprendido mucho de las personas que han estado conmigo, tanto a nivel profesional como personal, por ello me gustaría agradecer a cada persona que ha compartido conmigo momentos en esta etapa ilusionante, divertida, estresante, excitante, triste, entusiasmante... en definitiva, maravillosa.

Empezaré agradeciendo a Pedro Andrés que me propusiera ir a la Universitat Jaume I a realizar el experimento para mi trabajo de fin de grado, ya que ahí empezó todo. Los viajes en tren desde Valencia con Fernando, Enrique, Lluís y muchos otros trabajadores de la UJI fueron el inicio de esta aventura. Que quede claro que los retrasos en los horarios del cercanías y las siestas rompe-espaldas que me proporcionó renfe no son precisamente de agradecer. Sin embargo, quedan anécdotas, voy a decir 'graciosas', como aquél extraño hombre que me dijo, sin venir a cuento, que todo estaba hecho de mercurio y seguidamente se tiró una flatulencia allí en medio del vagón de tren.

Gracias a esos almuerzos con Ángel, Fernando, Merche y Vicente, entre otros, en los que he conocido (de oídas) más series y películas de las que probablemente veré; y a las comidas con Eva, Verónica (que nos abandonó por irse a la capital), Ángel, Fernando, Miguel y Carlos que desde luego te hacen desconectar del trabajo. Gracias a Omar, por convencernos con su don de palabra de formar el GOC. Gracias a la divulgación, los más jóvenes del GROC hemos compartido momentos de ocio fuera del trabajo y han surgido grandes amistades (además de borracheras con el Triple 1). Organizar un OSA IONS fue una gran experiencia (iViva la OSA!).

Gracias a Ben, Adrián, Silvestre y Pablo Artal por acogerme tan amablemente cuando he estado en el LOUM. Gracias también al aire acondicionado de su laboratorio aquél dia de verano que hizo un calor de infierno en Murcia (más del habitual). Y hablando de Murcia... gracias a Ángel por mantenernos al día de las novedades tecnológicas (sobre todo de Apple), y por ser el único 
que me entiende cuando le llamo 'fixo' al celo. A Jorge, que tiene la llave de Balsicas y que nos ha dejado frases como 'vais doblaos cabrones'. A Eva y Fernando, gracias por acogerme en vuestras casas y estar ahí cuando lo he necesitado, sois unos buenos amigos. A Eva gracias por invitarme a La Jana y por ser 'mala' y provocar situaciones cómicas en las que hay que explicarle el significado de 'coñ...' a un japonés (Miki), a una mexicana (Yessenia) y a un chileno (Eduardo, gracias por tus dibujos). A Yessenia con quien disfruté mucho en nuestro día de turismo por Roma. A Vicente (uno de mis directores de tesis), que jestá de moda! y además de ser muy buen mentor, es un gran compañero de cañas ¡viva el vino! Al dúo Carlos y Miguel: Miguel, que me encanta como cuenta las anécdotas que le ocurren en su vida diaria; y Carlos, el amante del glutamato, gracias por ser mi apoyo en las discusiones de las comidas y por el finde en tu casa con tu familia, a pesar de los mosquitos estuvo genial. Gracias a Fernando, aunque estudiamos el grado de Física en la misma clase, nuestra amistad comenzó en la UJI. Además de ser un buen investigador al que admiro, es un amigo que igual te pone en un aprieto con la cajera del mercadona, que te ayuda a limpiar el piso de alquiler al que te acabas de mudar...y la forma en la que modifica las historias es única (como lo del pollo, que en realidad fue él). Por cierto, ¿para cuándo el siguiente número de Proletarios Times?

Gracias a Enrique Tajahuerce, que es un trozo de pan, siempre quiere lo mejor para todos y aunque no conste como director de la tesis me ha ayudado como si lo fuese (además, lo del portátil en el baño fue top). A Jesús Lancis, mi otro director de tesis, que a pesar de sus preocupaciones como vicerrector siempre saca tiempo para estar al día y dar buenas ideas en la investigación. A Merche, mi tutora de tesis, que siempre aporta el protocolo correcto hasta para comer, ahora sabemos que al segundo plato no se espera. A Gladys por ser un ejemplo a seguir y organizar las cenas de chicas, donde, junto con Eva y Verónica, me ayudó a terminar el 'quién es quién' familiar. A Pere, que aunque sea pequeño sale caro invitarlo a comer, gracias por tu ayuda, sobre todo en programación. Y al resto del GROC, Lluís (que nos trae la mejor 'orxata'), Rocío (que tiene muy buen gusto para las camisas de los congresos), Omel y Vicent, con los que he compartido buenos momentos. El intercambio cultural con los visitantes (japoneses, iraníes, mexicanos, chilenos, etc.) también ha sido muy instructivo y divertido...ahora sé que darle dos besos a un japonés es casi como violarlo.

Cómo no, dar las gracias a las ayudas de garantía juvenil del ministerio por las que he podido trabajar durante dos años en el SCIC como técnico del microscopio confocal y el citómetro de flujo. Aunque ésta es una de las razones del retraso de mi tesis, no lo cambiaría por nada. Gracias a todos los trabajadores del SCIC y a los usuarios por apostar por mí. De estos 2 
años destaco el 'Holi!' de mi compi de despacho Ricard y la locura de Marc, con quien ha surgido mucho más que amistad y hemos compartido el proceso de escritura de nuestras respectivas tesis. Me gustaría mencionar a todas las personas que han estado conmigo en un momento $u$ otro de estos últimos 5 años (Rosa, Ana, la familia Bru, mis amigos de Elx y de 'lo' Xert, ...) pero no quiero aburriros antes de empezar a leer la tesis (si es que tenéis la intención).

Por último, y no por ello menos importante, agradecer a mi familia todo el apoyo que me ha dado, aún con $270 \mathrm{~km}$ de por medio. Sobre todo mi hermana Sandra, mis padres Tere y Jose $\mathrm{M}^{\mathrm{a}}$ y mi abuelo Pascual (que con 94 años es el que tiene más memoria de la familia). Destacar especialmente a la iaia Tonica y el tío Juanito, que, aunque no han podido ver el final de esta tesis, estarán siempre presentes en mis pensamientos.

A todos vosotros, gracias. 


\section{Resumen}

El ser humano siempre ha demostrado gran interés en la habilidad de ver a través de los objetos. En 1924 Joaquín María de Argamasilla, un joven español de 19 años, adquirió fama internacional al asegurar que tenía visión de rayos $\mathrm{X}$ y podía ver a través de los objetos. Hoy en día el mundo se ha vuelto más escéptico en cuanto a superpoderes, sin embargo, se pueden encontrar aplicaciones de teléfono móvil que te permiten 'ver a través de las cosas', basadas en la sensibilidad de las cámaras de éstos dispositivos a la radiación infrarroja. Desde el punto de vista científico, tener acceso, de una forma no invasiva, a imágenes de objetos ocultos tras un medio opaco o traslúcido, genera un interés casi tan grande como el reto que plantea. En el caso de medios traslúcidos, las imágenes formadas por métodos convencionales aparecen distorsionadas debido a la fuerte difusión a la que está sometida la radiación procedente de la muestra, es decir, no existe una correlación sencilla entre la dirección de los rayos de luz a la entrada y a la salida del medio. Ejemplos de estos medios, también llamados turbios o de scattering, son el humo, la niebla y el tejido biológico. Ver claramente objetos tras estos medios tiene importantes aplicaciones en los campos de la teledetección y el diagnóstico médico, entre otros.

La aparición de las tecnologías fotónicas en ciencias de la vida ha impulsado recientes avances sobre el control de la luz a través de medios turbios. Sin embargo, la difusión continúa siendo un gran inconveniente para la obtención de imágenes de tejido profundo. El objetivo de la presente tesis es diseñar y montar un sistema óptico capaz de obtener la imagen de un objeto a través de tejido biológico. Utilizando una técnica de iluminación estructurada y un sensor sin resolución espacial, de un solo píxel, se reconstruye la imagen del objeto. 


\section{Índice general}

\begin{tabular}{lll}
\hline Agradecimientos & III
\end{tabular}

Resumen VII

$\begin{array}{ll}\text { Lista de Acrónimos XI } & \text { XI }\end{array}$

$\begin{array}{ll}\text { 1. Introducción } & 1\end{array}$

2. Fundamentos teóricos $\quad 7$

2.1. Medios de scattering . . . . . . . . . . . . . . . . 8

2.2. Obtención de imágenes a través de medios de scattering. . . . 15

2.3. Sistemas single-pixel $\ldots \ldots \ldots \ldots \ldots \ldots$

3. Transmisión de imágenes a través de un medio difusor $\quad 27$

3.1. Objeto tras un medio difusor estático . . . . . . . . . . 35

3.2. Objeto tras un medio difusor dinámico . . . . . . . . . . . . 41

3.3. Objeto oculto tras un obstáculo . . . . . . . . . . . . . 43

4. Imagen de un objeto inmerso en tejido biológico 47

5. Sistema single-pixel para aplicaciones oftálmicas: imagen de la retina de un ojo sano y de un ojo artificial con catarata 59

5.1. Imagen single-pixel en configuración de reflexión en un ojo

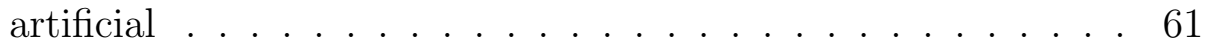

5.2. Imagen single-pixel en configuración de reflexión en un ojo humano in vivo . . . . . . . . . . . . . . . . . . . . 64

5.3. Imagen single-pixel en configuración de reflexión en un ojo artificial con cataratal . . . . . . . . . . . . . . 68

\begin{tabular}{ll}
\hline Conclusiones & 73
\end{tabular} 
\begin{tabular}{|ll}
\hline A. Moduladores espaciales de luz & 77
\end{tabular}

A.1. SLM de cristal líquido . . . . . . . . . . . . . . . . . . . . 78

A.2. SLM de microespejos . . . . . . . . . . . . . . . . . . . . . . . 79

\begin{tabular}{ll}
\hline B. Patrones de Walsh-Hadamard & 83
\end{tabular}

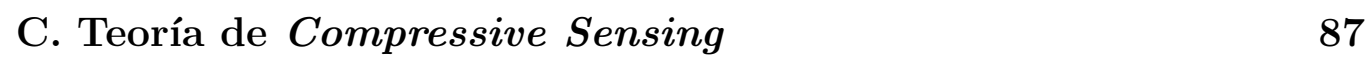

\begin{tabular}{lr}
\hline Bibliografía & 91
\end{tabular} 


\section{Lista de Acrónimos}

$\begin{array}{ll}\text { CCD } & \text { Charge Coupled Device } \\ \text { CMOS } & \text { Complementary Metal Oxide Semiconductor } \\ \text { CS } & \text { Compressive Sensing } \\ \text { CT } & \text { Computed Tomography } \\ \text { DMD } & \text { Digital Micromirror Device } \\ \text { DOT } & \text { Diffuse Optical Tomography } \\ \text { FLC } & \text { Ferroelectric Liquid Crystal } \\ \text { FPS } & \text { Frames Per Second } \\ \text { FWHM } & \text { Full Width at Half Maximum } \\ \text { GFP } & \text { Green Fluorescence Protein } \\ \text { LCD } & \text { Liquid Crystal Display } \\ \text { LCoS } & \text { Liquid Crystal on Silicon } \\ \text { LC-SLM } & \text { Liquid Crystal - Spatial Light Modulator } \\ \text { MFP } & \text { Mean Free Path } \\ \text { MRI } & \text { Magnetic Resonance Imaging } \\ \text { NIR } & \text { Near InfraRed } \\ \text { OCM } & \text { Optical Coherence Microscopy } \\ \text { OCT } & \text { Optical Coherence Tomography } \\ \text { PD } & \text { PhotoDiode } \\ \text { PET } & \text { Positron Emission Tomography } \\ \text { PMT } & \text { PhotoMultiplier Tube } \\ \text { PNLC } & \text { Parallel Nematic Liquid Crystal } \\ \text { SLM } & \text { Spatial Light Modulator } \\ \text { SNR } & \text { Signal-to-Noise Ratio } \\ \text { SPI } & \text { Single-Pixel Imaging } \\ \text { SRAM } & \text { Static Random Access Memory } \\ \text { TAC } & \text { Tomografía Axial Computarizada } \\ \text { TM } & \text { Transmission Matrix } \\ \text { TMFP } & \text { Transport Mean Free Path } \\ \text { TNLC } & \text { Twisted Nematic Liquid Crystal } \\ \text { W-H } & \text { Walsh-Hadamard } \\ \text { XGA } & \text { eXtend Graphics Array } \\ & \end{array}$




\section{Capítulo 1}

\section{Introducción}

El estudio de la luz y su uso para la formación de imágenes no es algo nuevo. Hace mil años el científico árabe Ibn al-Haytham (conocido como Alhacén) escribió uno de los tratados más influyentes en la historia de la física, Kitab al-Manazir conocido como Libro de Óptica. En él estudiaba la reflexión y la refracción de la luz, describía la formación de las imágenes en el ojo humano y explicaba el funcionamiento de la cámara oscura [1]. En la actualidad, el desarrollo de la ciencia y la tecnología de la luz sigue activa y es cada vez más relevante por su importancia para el futuro de áreas como la energía, la salud, la educación, la comunicación o el medio ambiente [2].

En la investigación científica, la radiación electromagnética, y en particular la luz, es muchas veces el único medio de obtener información de un objeto bajo estudio. Por ejemplo, en el campo de la astrofísica, no es posible viajar y tomar muestras de la inmensa mayoría de astros para analizar sus elementos y estudiar sus características. Por ello los investigadores han tenido que ingeniárselas para obtener información a partir de lo único que llega a la Tierra, la luz. Además de las fotografías que se consiguen con la óptica de los telescopios, la luz proporciona información sobre diversas características de las estrellas, como por ejemplo su composición química o la dirección y velocidad de su trayectoria, que se pueden conocer mediante técnicas espectroscópicas o empleando el efecto Doppler, respectivamente [3]. En el campo de la biomedicina, las biopsias son un procedimiento convencional de diagnóstico; no obstante, desde la aparición de los rayos X, se ha apostado por técnicas de imagen no invasivas que pretenden obtener información anatómica, fisiológica, celular o molecular del interior del cuerpo humano, con diferentes grados de resolución (macroscópica, mesoscópica y microscópica), usando para ello radiación electromagnética, positrones u ondas acústicas. Entre estas técnicas destacan la tomografía computarizada (CT, Computed Tomography), la imagen de resonancia magnética (MRI, Magnetic Resonance 
Imaging), los métodos basados en ultrasonidos, la tomografía de emisión de positrones (PET, Positron Emission Tomography), la microscopía de fibra óptica y la microscopía multifotón, por citar sólo algunas [4 6].

Un problema fundamental en el campo de la biomedicina es la obtención de imágenes nítidas a través de tejidos biológicos, ya que la luz difundida a través de ellos no permite alcanzar la profundidad de penetración que se requiere en numerosos estudios médicos [7 9]. Por ejemplo, en microscopía multifotón aplicada al cerebro se alcanza una profundidad de $\sim 1 \mathrm{~mm}$, que es sólo la cuarta parte de la anchura del córtex cerebral humano [10]. Los rayos $\mathrm{X}$, a diferencia de la luz, pueden penetrar el tejido, lo que permite producir imágenes de las estructuras internas; sin embargo, cuando se usan técnicas de diagnóstico con rayos $\mathrm{X}$, el cuerpo recibe una dosis de radiación que puede ser perjudicial para el paciente. Así, la exposición a la radiación proveniente de una radiografía de tórax es equivalente a la que se recibiría del entorno natural durante 10 días, una mamografía equivale a 7 semanas de exposición y un TAC (Tomografía Axial Computarizada) de abdomen y pelvis equivale a la radiación que se recibiría en 3 años [11].

Las técnicas fotónicas intentan solucionar estas desventajas y obtener información del interior del cuerpo de una forma no invasiva, pero usando para ello radiación a frecuencias ópticas (relativamente poco energética) para no dañar los organismos. Para que estas técnicas logren su propósito, se debe entender y controlar la propagación de las ondas luminosas en medios materiales, en los que se produce un intenso scattering aleatorio y múltiple de la luz. A nivel espacial, el scattering da lugar a los patrones de interferencia conocidos como moteado (speckle en inglés) y en el dominio temporal, un pulso corto que entra en un medio difusor sufre un amplio ensanchamiento.

Una estrategia que ha dado muy buenos resultados en obtención de imágenes a través de materiales difusores es aislar la pequeña cantidad de luz cuya dirección no cambia a pesar del scattering aleatorio. Esta fracción de la luz, compuesta por fotones llamados balísticos, es la predominante cuando se consideran medios delgados o poco difusores. Las técnicas que usan la componente balística para recuperar la imagen, como microscopía confocal [12], tomografía de coherencia óptica (OCT, del inglés Optical Coherence Tomography) [13] o microscopía no lineal [14], han demostrado un gran potencial en diferentes aplicaciones clínicas y biomédicas. Estas técnicas se pueden mejorar cuando se combinan con óptica adaptativa [15 17] y también con imagen computacional [18, 19]. Sin embargo, la estrategia basada en el uso de fotones balísticos no sirve a profundidades grandes de penetración o para medios en los que el scattering es muy intenso, ya que la fracción de fotones balísticos que atraviesa el medio es prácticamente nula.

Por otro lado, existen modelos de difusión para la propagación de fotones 
que permiten recuperar imágenes a grandes profundidades de penetración en los medios de scattering. La tomografía de proyección óptica, la tomografía fotoacústica o la tomografía de fluorescencia han contribuido ya a un gran número de estudios destinados a abordar una amplia gama de cuestiones biológicas 20 22]. Así, la tomografía de proyección óptica aplicada a la microscopía permite realizar imágenes 3D de muestras biológicas tratadas químicamente que midan hasta $15 \mathrm{~mm}$ de espesor (por encima de los límites de la microscopía confocal y OCT). De esta forma es posible realizar estudios de expresión génica en muestras biológicas, tales como un embrión de ratón. La tomografía fotoacústica, que aprovecha la ventaja de que el scattering ultrasónico es órdenes de magnitud menor que el óptico, mejora la transparencia de las muestras biológicas de 100 a 1000 veces y, en consecuencia, permite obtener imágenes de muestras biológicas in vivo a distintas profundidades. En estos métodos, el beneficio de acceder a profundidades mayores se paga con la pérdida de resolución espacial en las imágenes resultantes.

En los últimos años se han desarrollado con éxito varias técnicas de focalización y obtención de imágenes a través de medios fuertemente difusores. El objetivo es conseguir imágenes a profundidades de penetración donde los fotones balísticos ya no existen, manteniendo la propiedad de las técnicas balísticas de preservar una alta resolución espacial. La idea clave de algunas de estas técnicas es abandonar el intento de descripción a nivel microscópico del fenómeno de scattering y estudiar las propiedades físicas a nivel mesoscópico, con la finalidad de compensar la acción del medio de scattering predistorsionando el frente de onda incidente. Introduciendo conceptos básicos de la teoría mesoscópica que caracterizan el comportamiento de la luz a través de un medio difusor se consigue, por ejemplo, focalizar la luz tras el medio difusor [23]. Para modificar el frente de ondas incidente es fundamental disponer de un modulador espacial de luz (SLM, acrónimo del inglés Spatial Light Modulator), que permite controlar amplitud y fase de un campo óptico incidente, actuando de forma independiente sobre cada uno de los millones de píxeles de los que consta. Focalizar luz coherente a través de distintos medios turbios, usando frentes de onda modulados en fase que compensan el efecto del scattering de la luz, es un método elegante y versátil que fue propuesto hace una década por I. M. Vellekoop y A. P. Mosk 24.

Un enfoque más profundo para el estudio de los medios turbios radica en caracterizarlo en su conjunto mediante una matriz de transmisión (TM, del inglés Transmission Matrix). Este enfoque permite, si se manipula el frente de onda incidente siguiendo la prescripción de la matriz de transmisión, precompensar macroscópicamente las distorsiones ulteriores producidas por el medio. Los elementos de esta matriz son coeficientes complejos que relacionan los campos ópticos (en amplitud y fase) de entrada y salida del medio. 
Dichos coeficientes se pueden medir, por ejemplo, mediante un procedimiento interferométrico con la ayuda de un SLM. Teniendo en cuenta la TM del medio difusor, es posible focalizar un haz luminoso o formar imágenes con buena resolución a través de él [25, 26].

Algunas de las técnicas anteriormente mencionadas tienen limitaciones si se quieren aplicar en el ámbito de la biomedicina, ya que necesitan tener acceso al interior del medio. Para solventar este inconveniente aparecieron nuevos métodos de imagen a través de medios turbios basados en el llamado 'efecto memoria' óptico: aprovechando la correlación angular exhibida por los patrones de speckle dentro de un pequeño rango de ángulos, es posible ver a través de finas capas difusoras o detrás de las esquinas sin necesidad de caracterizar previamente el medio de scattering [27 29]. El mismo efecto se puede aprovechar para obtener la autocorrelación de un objeto de fluorescencia tras un medio difusor (mediante un procedimiento no invasivo) y, a partir de ella, reconstruir la imagen del objeto mediante un algoritmo iterativo [30,31. En algunos casos, la aleatoriedad exhibida por los medios difusores, que habitualmente se considera un inconveniente, ha sido aprovechada para formar imágenes con superresolución [32]. En el ámbito de la microscopía, por ejemplo, se ha realizado un sistema de fluorescencia, que emplea luz difusa, capaz de alcanzar una resolución por debajo del límite de difracción [33].

En paralelo a estas investigaciones, recientemente han aparecido cámaras formadoras de imágenes basadas en detectores de un solo píxel (SPI, del inglés Single-Pixel Imaging). El fundamento de la técnica SPI se basa en medir los coeficientes de una imagen cuando es transformada en una base de funciones dada (como, por ejemplo, la transformada discreta del coseno). Experimentalmente, el proceso de adquisición de datos se apoya en un SLM, que genera un conjunto de patrones de intensidad (o fase) a partir de la base elegida. Un detector sin resolución espacial mide la intensidad de la luz transmitida (o reflejada) correspondiente a los productos entre la imagen del objeto y la secuencia de funciones de la base. La imagen del objeto se recupera a partir de las funciones de la base y los correspondientes valores medidos de intensidad.

Como alternativa a los sistemas de imagen convencional, las técnicas de imagen basadas en cámaras single-pixel son especialmente útiles en regiones espectrales donde los sensores de imagen con estructura pixelada son inexistentes [34, 35], o el nivel de intensidad de la señal a detectar es extremadamente bajo [36]. Una característica notable de la técnica SPI es que puede proporcionar información, no sólo acerca de la intensidad de la señal original, sino también sobre otras propiedades del campo incidente, como su amplitud y fase, dependiendo de las características del procedimiento de detección [37 40]. Adicionalmente, la sustitución del fotodiodo típico, usado en 
las primeras cámaras monopíxel, por otro detector como un espectrómetro de fibra o un polarímetro de haz, permite conseguir imágenes con información de otros parámetros físicos como imágenes hiperespectrales o polarimétricas, respectivamente [41, 42].

Como se ha visto en los párrafos anteriores, en la actualidad existen varias técnicas de adquisición de imágenes a través de medios turbios a distintas escalas (microscopía confocal, tomografía computarizada, fotoacústica, etc.). Sin embargo, estas tecnologías suelen ser caras, aparatosas, y se encuentran restringidas fundamentalmente al ámbito académico. El desarrollo de nuevas técnicas, más simples y accesibles para su uso como herramientas de análisis, diagnóstico o investigación, sigue siendo un campo activo. En ese contexto, el objetivo concreto de esta tesis es explorar la técnica de imagen single-pixel para diseñar y desarrollar experimentos con medios de scattering, especialmente tejidos biológicos. La estrategia de combinar iluminación estructurada y detección integrada, a diferencia de los sistemas de escaneo punto a punto, es adecuada para sistemas en los que se dispone de niveles bajos de señal de radiación, de forma que las imágenes mejoran su relación señal-ruido respecto a las que se obtendrían con sistemas convencionales. Así, técnicas como por ejemplo la imagen Raman pueden incorporar este tipo de detección para aumentar sus prestaciones [43]. La relativa simplicidad de los sistemas single-pixel ofrece ventajas, no sólo en términos de eficiencia, sino en la libertad a la hora de elegir el tipo de detector sin resolución espacial. Esta libertad abre un abanico de posibilidades utilizando sensores que miden características de la luz distintas a la intensidad (tales como la longitud de onda o la polarización). Además, como se ha mencionado anteriormente, los sistemas single-pixel ofrecen la posibilidad de trabajar en regiones espectrales con longitudes de onda largas (infrarojo, terahercio, microondas) donde los detectores con resolución espacial son caros o simplemente no existen. En estas regiones del espectro los efectos del scattering sobre la propagación de radiación se ven atenuados, lo que puede beneficiar la obtención de imágenes a través de medios turbios. Tal como se demuestra a lo largo de esta tesis, la arquitectura de los sistemas single-pixel, por un lado, hace posible la transmisión de imágenes a través de un medio de scattering sin necesidad de tener información previa sobre dicho medio. Por otro lado, el proceso de reconstrucción usado en SPI facilita la aplicación de técnicas de muestreo compresivo (Compressive Sensing) para reducir de forma significativa el tiempo total de medida y el volumen de datos [44]. Estos hechos son esenciales en aplicaciones reales en las que los objetos de estudio son dinámicos, y se requieren sistemas ópticos lo bastante rápidos para que el tiempo de medida sea considerablemente menor que la escala temporal a la que se producen los cambios en el sistema. En esta tesis se demuestra la capacidad de 
los sistemas single-pixel para obtener imágenes por transiluminación de un objeto incrustado en un tejido biológico de grosor milimétrico, así como para tomar imágenes de la retina de un ojo in vivo. El oftalmoscopio single-pixel resulta especialmente prometedor en el caso de pacientes con cataratas, cuyo cristalino se va volviendo difusor de forma progresiva.

Esta tesis se estructura en seis capítulos, de los que esta introducción es el primero y el sexto corresponde al capítulo de conclusiones. En el capítulo2 se explica, por un lado, el comportamiento general de la luz cuando pasa por un medio turbio, es decir, la manera en que un medio de scattering perturba la luz y cómo es posible obtener imagen a través de él; a continuación, se presentan las bases de la técnica de imagen basada en detección single-pixel, poniendo énfasis en sus ventajas respecto a la imagen convencional. En el capítulo 3, se demuestra que es posible usar la técnica SPI para transmitir imágenes a través de un medio turbio estático y también dinámico. Además se muestra experimentalmente cómo la difusión de la luz puede ser una ventaja para la transmisión de imágenes de objetos parcial o totalmente ocultos por un obstáculo. En el capítulo 4 se realiza un experimento con tejido biológico de grosor milimétrico como medio turbio y se consigue la imagen por transmisión de un objeto inmerso en él. En el capítulo 5 se diseña un sistema single-pixel por reflexión para aplicarlo a un caso de interés práctico, el de obtener la imagen de la retina de un ojo in vivo. Seguidamente, se emplea un ojo artificial para demostrar la capacidad del sistema diseñado para obtener imágenes en presencia de un medio difusor. En éste último experimento, el medio difusor simula un cristalino con catarata y la configuración en reflexión permite que sea un método no invasivo. 


\section{Capítulo 2}

\section{Fundamentos teóricos}

El problema general de 'ver' a través de medios turbios se puede abordar de distintas formas. Un método consiste en aplicar un tratamiento al propio medio difusor para que deje de difundir la luz; por ejemplo, en el caso de tejido biológico, existe la técnica llamada optical clearing, que usa procesos químicos para volver transparente el tejido [7]. En este caso, la luz ya no sufre distorsión y es posible capturar la imagen del objeto tras el medio de scattering modificado. La idea es hacer transparentes las primeras capas para visualizar más fácilmente los tejidos profundos. Esta forma de abordar el problema presenta varias desventajas, ya que para cada medio turbio se necesitaría un proceso distinto para volverlo transparente, y plantea más preguntas que respuestas sobre cómo producir de forma segura y reproducible los tejidos biológicos transparentes. Otra forma de abordar el problema es mediante el estudio del comportamiento de la luz a través de los medios de scattering y éste es el que se tratará en este trabajo. Entender y controlar la propagación de las ondas luminosas en medios materiales difusores es un tema puntero en investigación. La comprensión de este proceso despierta gran interés en campos tan dispares como la acústica (medios policristalinos) [45], las telecomunicaciones (la distribución de los edificios en las ciudades afecta a las redes inalámbricas) [46] o la óptica [23]. En este último ámbito, la presencia de un medio con núcleos difusores causa que la luz procedente de las estructuras microscópicas de la materia sea altamente difundida. Un objetivo primordial en teoría de scattering es describir cómo modifica un medio difusor la luz que incide sobre él.

Por otro lado, todos los sistemas formadores de imagen tienen un elemento clave común: los sensores ópticos. Gracias a la introducción de la tecnología digital CCD (Charge-Coupled Device) y CMOS (Complementary Metal Oxide Semiconductor), los sensores ópticos más comunes (los de las cámaras) han mejorado notablemente en los últimos tiempos. Además, la constante mi- 
niaturización de los componentes electrónicos ha hecho posible la existencia de detectores con una resolución espacial altísima: cualquier cámara digital comercial tiene una matriz de sensores con varios megapíxeles. Esta tecnología está al alcance de todos gracias a que el material semiconductor que se usa para la integración electrónica a gran escala (silicio) también transforma fácilmente señales luminosas en señales eléctricas. Pero esto sólo ocurre en el rango del visible: la obtención de imágenes a longitudes de onda fuera del rango visible es considerablemente más complicada y costosa.

La tecnología actual permite diseñar dispositivos que superan las capacidades del ojo humano. Hoy en día, es posible construir sistemas que aumentan la dimensionalidad de las imágenes, es decir, que permiten obtener imágenes con información de distintos parámetros físicos, como por ejemplo, información espectral, información de fase o polarización. El conocimiento de esta información es útil en campos tan dispares como medicina [6], telecomunicaciones [47], astronomia [48], teledetección [49], robótica [50], etc. Esto justifica el esfuerzo actual en la búsqueda de nuevos materiales, sensores y sistemas de control para construir sistemas capaces de obtener imágenes multidimensionales con mayores prestaciones.

\subsection{Medios de scattering}

En la naturaleza se pueden encontrar distintos tipos de medios cuyas propiedades pueden cambiar el comportamiento de la luz que los atraviesa. En un medio homogéneo se puede aplicar un modelo de propagación rectilínea de la luz. El aire que nos rodea se comporta en muchas ocasiones como un medio homogéneo, y así, en un día claro, se pueden distinguir fácilmente objetos que están a kilómetros de distancia, porque la luz se propaga sin apenas pertubaciones.

A diferencia de un medio homogéneo, un medio difusor, también llamado turbio o de scattering, es una densa concentración de partículas que causa inhomogeneidades aleatorias, lo que evita una propagación rectilínea de la luz. Un frente de ondas proveniente de un objeto, el cual está situado detrás o dentro de un medio turbio, sufre múltiples eventos de scattering quedando fuertemente distorsionado y evitando que la imagen del objeto sea distinguible. Caminando al aire libre en un día de niebla, por ejemplo, se puede observar cómo la dispersión múltiple de la luz limita la capacidad de identificar los objetos del entorno (véase figura 2.1).

Los medios difusores de luz se pueden clasificar en dos grupos: los difusores superficiales, que suelen ser superficies con distintos grados de rugosidad, con protuberancias aisladas (regular o aleatoriamente distribuidas) o bien 


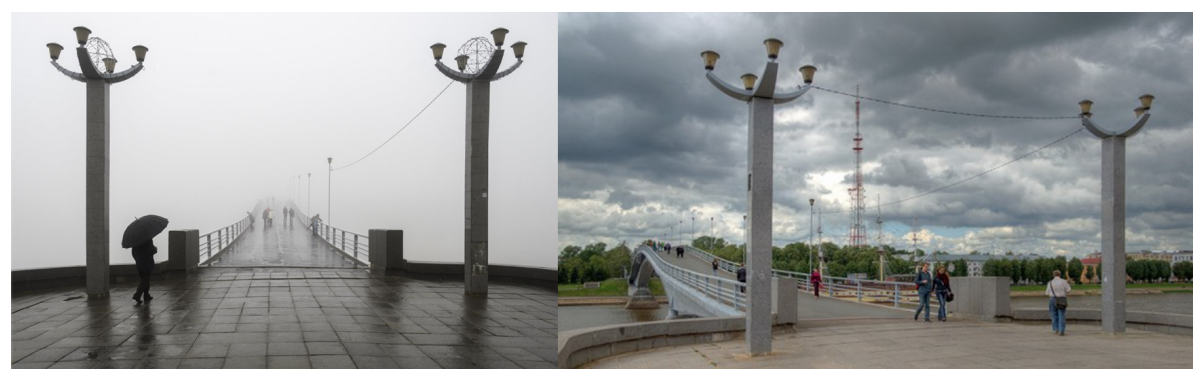

Figura 2.1 - Imagen de un puente con y sin niebla [51,52]. En la imagen de la izquierda se observa que, a medida que el grosor del medio de scattering (niebla) aumenta, es más difícil o imposible obtener una imagen de los objetos mediante una cámara convencional (por ejemplo una CCD). En la imagen de la derecha se observa el mismo puente en un día sin niebla.

con distintos tipos de defectos; y los difusores en volumen, como la atmósfera, la niebla, el humo o el tejido biológico, en los que se producen múltiples eventos de scattering. Los tejidos biológicos son medios ópticamente inhomogeneos, pero también son absorbentes. La propagación de la luz a través de éstos depende de las propiedades de difusión y absorción de sus componentes (tales como células, orgánulos celulares y varias estructuras de fibra). La difusión múltiple y la absorción son los responsables del ensanchamiento del haz de luz que entra en el medio y de la disminución de la intensidad de éste a medida que se desplaza a través del tejido. La difusión múltiple, además, es responsable de una gran parte de la radiación difundida hacia atrás (backscattering).

La propagación de la luz en un medio turbio es un proceso complejo. Una forma de abordar su estudio es suponer que la amplitud y la fase de las ondas de luz que se propagan fluctuan de forma aleatoria temporal y espacialmente. En este modelo se consideran los dos fenómenos principales de la interacción luz-materia: absorción y difusión. El primero es el fenómeno relacionado con las bandas de absorción de las moléculas constituyentes del medio. Cuando un electrón dentro de una molécula es excitado por la absorción de un fotón, el electrón pasa a niveles energéticos superiores. El proceso de relajación al estado fundamental puede darse o bien mediante un proceso no radiativo, que permite la transferencia de energía en forma de calor, o bien mediante un proceso radiativo con la emisión de luz. Un ejemplo de proceso radiativo es la luminiscencia, en la que el electrón se relaja al estado fundamental con la emisión de un fotón. Este fotón no puede tener una frecuencia mayor que el fotón absorbido y puede continuar su propagación a través del medio. Ejemplos de luminiscencia son la fluorescencia, caracterizada por un tiempo de vida relativamente corto $\left(10^{-9}-10^{-7} \mathrm{~s}\right)$, y la fosforescencia, que es un 
proceso lento $\left(10^{-3}-\left\{10^{2}-10^{4}\right\} \mathrm{s}\right)$. Sin embargo, los procesos radiativos no serán considerados aquí.

La difusión, por su parte, es el resultado de la interacción entre las ondas electromagnéticas incidentes y la materia que hace que los fotones se desvíen hacia nuevas direcciones de propagación. Si la energía del fotón difundido es la misma que el fotón incidente, entonces la interacción fotón-molécula se denomina scattering elástico (un ejemplo es la difusión Rayleigh, que ocurre cuando la luz se propaga a través de medios gaseosos). Si, por el contrario, la energía del fotón difundido cambia respecto a la del fotón incidente, la interacción se denomina scattering inelástico (la difusión Raman es un ejemplo de ello). El caso que aquí se considera es el scattering elástico; por tanto, la energía, y en consecuencia la frecuencia, de los fotones difundidos permanece constante.

Los fotones, a medida que penetran en el medio, pueden ser difundidos o absorbidos por las moléculas que conforman dicho medio. Para cuantificar cómo el medio absorbe o difunde la luz se pueden definir los coeficientes de absorción y difusión, $\mu_{a} \mathrm{y} \mu_{s}$, respectivamente. Estos coeficientes determinan la probabilidad de que ocurra un evento de absorción o de difusión en una distancia infinitesimal. Por ello tienen unidades de $\left[\mathrm{m}^{-1}\right]$, y se definen como la razón entre potencia absorbida o difundida por unidad de volumen y potencia incidente por unidad de área. Los fotones difusos, resultantes de eventos de scattering, pueden tener una dirección privilegiada en su propagación; por ello algunos materiales tienen más scattering en transmisión, es decir, predominan los fotones difusos que pasan a través del medio. Esta característica queda determinada mediante la función de scattering, $p\left(\hat{s}, \hat{s^{\prime}}\right)$, que tiene unidades de $\left[s r^{-1}\right]$ y carateriza un evento de scattering elemental como la probabilidad de que un fotón que viaja en la dirección $\hat{s}$ sea difundido dentro del ángulo sólido unidad alrededor de la dirección $\hat{s}^{\prime}$ (véase figura 2.2. .

Si el scattering producido es simétrico respecto a la dirección de la onda incidente, entonces la función de scattering depende únicamente del ángulo $\theta$ entre las direcciones $\hat{s}$ y $\hat{s}^{\prime}$, es decir, $p\left(\hat{s}, \hat{s}^{\prime}\right)=p(\theta)$. Considerando centros difusores distribuidos aleatoriamente en un medio, entonces se asume la siguiente normalización para la función de scattering:

$$
\int_{0}^{4 \pi} p\left(\hat{s}, \hat{s^{\prime}}\right) d \Omega^{\prime}=\int_{0}^{2 \pi}\left\{\int_{0}^{\pi} p(\theta) \sin \theta d \theta\right\} d \varphi=2 \pi \int_{0}^{\pi} p(\theta) \sin \theta d \theta=1 .
$$

En la equivalencia de la ecuación $2.1, d \Omega^{\prime}[s r]$ es el diferencial de ángulo sólido sobre la dirección $\hat{s}^{\prime}$. Expresado en coordenadas esféricas puede escri- 


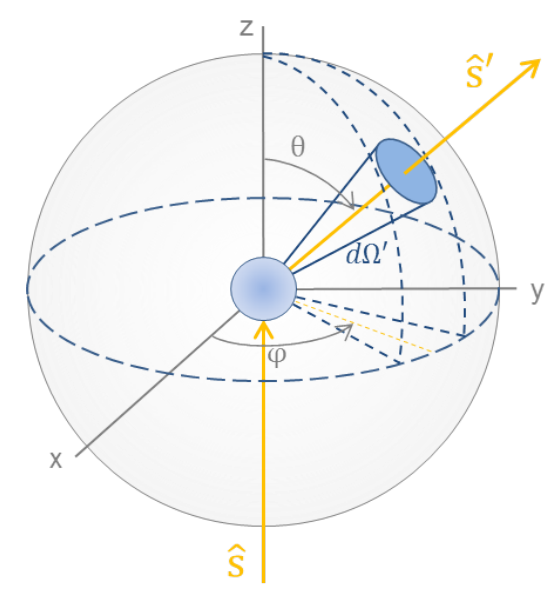

Figura 2.2 - Diferencial de ángulo sólido alrededor de la dirección de difusión en un evento de scattering. La probabilidad de que un fotón que viaja en la dirección $\hat{s}$ sea difundido dentro del ángulo sólido unidad alrededor de la dirección $\hat{s}^{\prime}$ queda caracterizado por la función de scattering $p\left(\hat{s}, \hat{s^{\prime}}\right)$.

birse de la siguiente manera: $d \Omega^{\prime}=d S^{\prime} / r^{2}=\left(r^{2} \sin \theta d \theta d \varphi\right) / r^{2}$, donde $d S^{\prime}$ es el diferencial de superficie para $r$ constante.

Cuando predomina la difusión múltiple en la propagación a través del medio, se define el llamado factor de anisotropía $g$, promedio del coseno del ángulo de scattering:

$$
g \equiv\langle\cos \theta\rangle=2 \pi \int_{0}^{\pi} \cos (\theta) p(\theta) \sin \theta d \theta .
$$

Este parámetro puede variar en el rango de -1 a 1 , siendo $g=0$ correspondiente a un scattering isotrópico (de Rayleigh), $g=1$ corresponde a un scattering total transmitido (Mie, scattering de partículas grandes), y $g=-1$ corresponde a un scattering total hacia atrás [53]. Para tejidos biológicos el valor de $g$ suele estar comprendido entre 0.8 y 1 [8]. La potencia total obtenida después de los procesos de absorción y scattering se puede describir mediante el coeficiente de extinción o coeficiente total de atenuación, que no es más que la suma de los coeficientes de absorción y scattering:

$$
\mu_{t}=\mu_{a}+\mu_{s} .
$$

Este coeficiente se usa para calcular la profundidad de penetración de un haz colimado, $l=1 / \mu_{t}$. Este valor es comúnmente conocido como recorrido libre medio (MFP, del inglés Mean Free Path). 


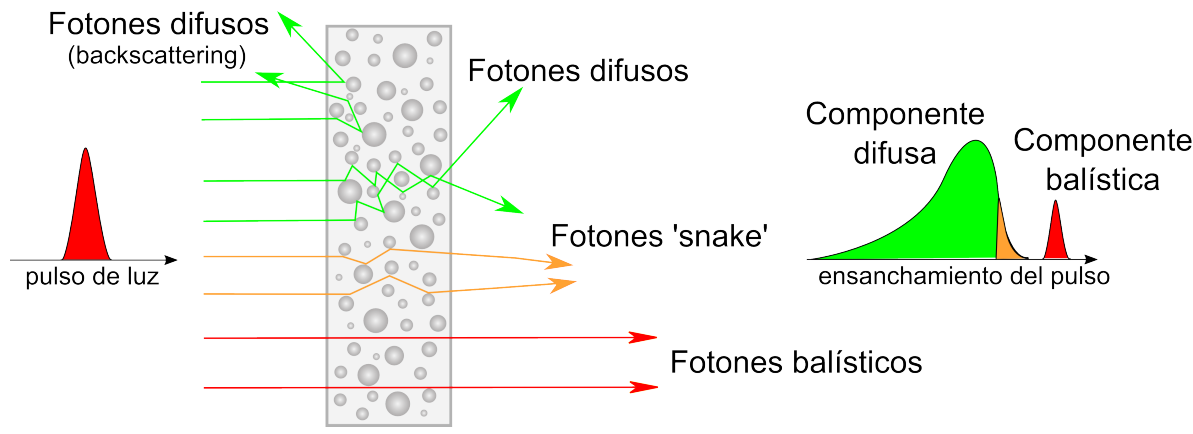

Figura 2.3 - Comportamiento de un pulso de luz cuando atraviesa un medio turbio. La componente balística no interacciona con el medio por eso es la primera que lo atraviesa. Los fotones snake y difusos interacionan con el medio turbio desviándose poco o mucho de su dirección inicial y retrasando así su salida a través del medio. El ensanchamiento temporal también se produce en el haz reflejado (de backscattering) donde existen los tres tipos de fotones descritos. Figura adaptada de [53].

Cuando la luz incidente en el medio turbio se propaga a lo largo de la dirección $z$ la variación entre la potencia a la salida y a la entrada del medio depende del coeficiente de extinción y del grosor $d z$ del medio:

$$
d P(z)=-\mu_{t}(z) P(z) d z .
$$

Integrando la ecuación 2.4 se obtiene la Ley de Lambert-Beer:

$$
P(z)=P_{0} e^{-\mu_{t} z}
$$

donde $P_{0}=P(z=0)$ es la potencia incidente en $z=0$ y se ha considerado que el coeficiente total de atenuación es constante en el medio de scattering. La Ley de Lambert-Beer describe la caída exponencial de la potencia del haz de luz cuando se propaga a través del medio turbio [54,55] y también puede expresarse en términos de la intensidad de la señal: $I(z)=I_{0} e^{-\mu_{t} z}$. El factor exponencial de la ecuación es el espesor óptico del medio (cantidad adimensional) atravesado por el haz.

Cuando un pulso láser se propaga a través de un medio difusor, sufre un ensanchamiento temporal, tal como se muestra en la figura 2.3. Este ensanchamiento se puede explicar por el comportamiento difuso de los fotones cuando atraviesan el medio [53. Una fracción de ellos no interacciona con el medio y viaja en la dirección inicial; otra fracción de fotones, llamados snake, colisiona sólo unas pocas veces con los centros difusores del medio y su trayectoria se desvia muy ligeramente de la dirección inicial; y el resto de fotones forman una componente difusa que pierde totalmente su dirección 


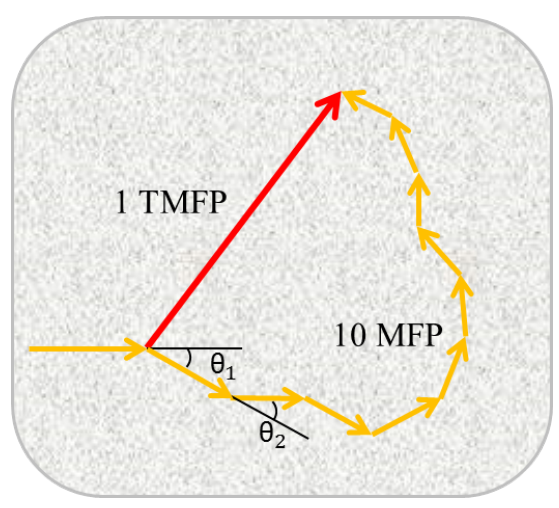

Figura 2.4 - Scattering múltiple. Ilustración del camino aleatorio que sigue un fotón dentro de un medio turbio en una distancia de un TMFP (señalado con la flecha roja). El factor de anisotropía $g$ es el resultado de promediar el coseno del ángulo de dispersión $\left(<\cos \theta>\right.$, con $\left\langle\theta>\approx \theta_{1} \approx \theta_{2} \approx \ldots \approx \theta_{10}\right)$. Figura adaptada de [53].

inicial. Los fotones no difundidos, que forman la componente balística, y el grupo de fotones snake son los primeros fotones que atraviesan el medio. Por otro lado, el pulso reflejado por el medio está constituido por fotones que se reflejan en las primeras capas del medio (los balísticos) y una componente difusa (de fotones snake y difusos) que vuelve por el mismo lado del medio por el que incidieron (fotones de backscattering).

Si el fenómeno de scattering domina sobre la absorción $\left(\mu_{s}>>\mu_{a}\right)$, como ocurre en la mayoría de tejidos biológicos, la distancia media recorrida por un fotón entre dos eventos de scattering, es decir, el valor del MFP, se puede escribir simplemente como $l=1 / \mu_{s}$. La distancia que en promedio recorren los fotones antes de perder por completo su dirección inicial se llama recorrido libre medio de transporte (TMFP, del inglés Transport Mean Free Path), y se define como $l^{*}=1 / \mu_{s}^{\prime}$, donde $\mu_{s}^{\prime}=\mu_{s}(1-g)$ es el coeficiente de scattering reducido, que se define mediante el factor de anisotropía, $g$ (véase figura 2.4.

Teniendo en cuenta las definiciones anteriores, se pueden distinguir tres regímenes a medida que la luz se propaga por un medio de scattering (véase figura 2.5). El primero, el régimen balístico, se da a profundidades menores que el MFP y en él sólo una pequeña fracción de fotones se ha difundido. Cuando la profundidad es mayor que el TMFP, predomina el régimen difuso, ya que la componente balística prácticamente se ha extinguido y los fotones describen trayectorias aleatorias (random walk). Para profundidades entre el MFP y el TMFP, existe un régimen intermedio, en el que coexisten una fracción de fotones balísticos, que va disminuyendo con la distancia de penetración; una fracción de fotones snake, que han interaccionado con el medio 


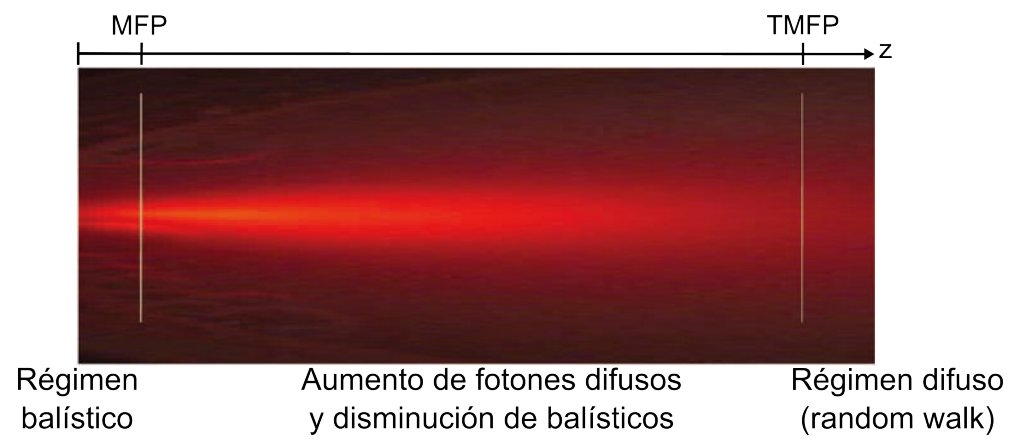

Figura 2.5 - Comportamiento de la luz a medida que avanza en un medio turbio. Se distinguen tres regímenes caracterizados por la cantidad de fotones que han sido difundidos. También se observa el ensanchamiento espacial del haz de luz a medida que penetra en el medio. Figura adaptada de la referencia 8 .

pero aún no han perdido su dirección inicial; y una fracción creciente de fotones difundidos. Esta última región sigue la ley de la ecuación 2.5 usando el coeficiente de scattering reducido, $\mu_{s}^{\prime}$ [56].

El problema para la componente difusa puede describirse como un haz de luz que sigue una trayectoria en la que el vector campo eléctrico va cambiando (en amplitud y fase) de forma independiente y aleatoria. La suma de todos los vectores da lugar a una amplitud y fase resultantes cuyas propiedades estadísticas sirven para caracterizar un medio difusor. Una suma de fasores aleatorios se puede describir matemáticamente como:

$$
\mathbf{A}=A e^{j \vartheta}=\frac{1}{\sqrt{N}} \sum_{n=1}^{N} a_{n} e^{j \varphi_{n}}
$$

donde $N$ representa el número de fasores que forman el random walk. Para estos fasores aleatorios se asumen las siguientes hipótesis:

1. Las amplitudes y fases $a_{n} \mathrm{y} \varphi_{n}$ son estadísticamente independientes de $a_{m}$ y $\varphi_{m}$ donde $n \neq m$. Es decir, los valores de amplitud y/o fase de un componente de la suma no están relacionados con la amplitud y/o fase de otro componente de la misma suma.

2. Para cualquier $n, a_{n} \mathrm{y} \varphi_{n}$ son estadísticamente independientes uno del otro. Esto significa que conocer la fase de un fasor no implica que se conozca el valor de la amplitud del mismo fasor, y viceversa.

3. Las fases $\varphi_{m}$ están uniformemente distribuidas en el intervalo $(-\pi, \pi)$. Esto implica que todos los valores de la fase son igualmente probables.

Aceptando estas premisas y cogiendo un número $N$ muy grande de fasores en la suma, se obtendrá un fasor complejo resultante (A en la ecuación 2.6) cuya función de probabilidad sigue una distribución gaussiana circular. Esto 
significa que, por un lado, la amplitud $(A=|\mathbf{A}|)$ tiene una función densidad de probabilidad de Rayleigh, es decir,

$$
p_{A}(A)=\frac{A}{\sigma^{2}} \exp \left\{-\frac{A^{2}}{2 \sigma^{2}}\right\}
$$

donde $\sigma$ está relacionado con la distribución de caminos elementales que conectan el campo óptico a la entrada con el campo óptico a la salida. Por otro lado, la fase resultante de la suma $(\vartheta=\arg (\mathbf{A}))$ tiene una función densidad de probabilidad constante, es decir, la probabilidad de obtener un valor de fase $\vartheta$ es igual en todo el intervalo de $(-\pi, \pi)$,

$$
p_{\vartheta}(\vartheta)=\frac{1}{2 \pi}
$$

Una explicación más detallada de estos resultados se encuentra en la Ref. [57].

Las propiedades descritas en esta sección determinan el comportamiento de la luz en el medio difusor a escala mesoscópica y permiten explicar la posibilidad de obtener imágenes a través de dicho medio, como se verá a continuación.

\subsection{Obtención de imágenes a través de me- dios de scattering}

Conseguir la imagen de un objeto a través de un medio de scattering no es una tarea fácil. En un sistema de imagen convencional, un haz de luz ilumina el objeto del que se quiere obtener la imagen y un sistema de lentes forma una imagen sobre el sensor, normalmente una cámara pixelada. Cuando el objeto está detrás o dentro de un medio turbio, la luz que proviene del objeto y pasa a través del medio turbio tiene una componente balística y otra compuesta por los fotones difusos (véase figura 2.6), que al ser capturados por la cámara degradan la imagen del objeto. Los fotones que no se desvían de su dirección inicial y que forman la imagen del objeto sobre el sensor sufren una atenuación exponencial con el espesor del medio turbio (tal como se ha explicado en el apartado 2.1, ecuación 2.5). A cierto espesor de medio turbio los fotones difusos inundarán la imagen emborronando la medida realizada con un detector convencional y ocultando la imagen del objeto.

En la actualidad existen varios métodos para resolver el problema de obtener imágenes a través de medios de scattering. Aunque esta tecnología tiene un amplio rango de aplicación en diversos campos, uno de los más activos es el de la imagen biomédica. La obtención de imágenes a grandes profundidades 


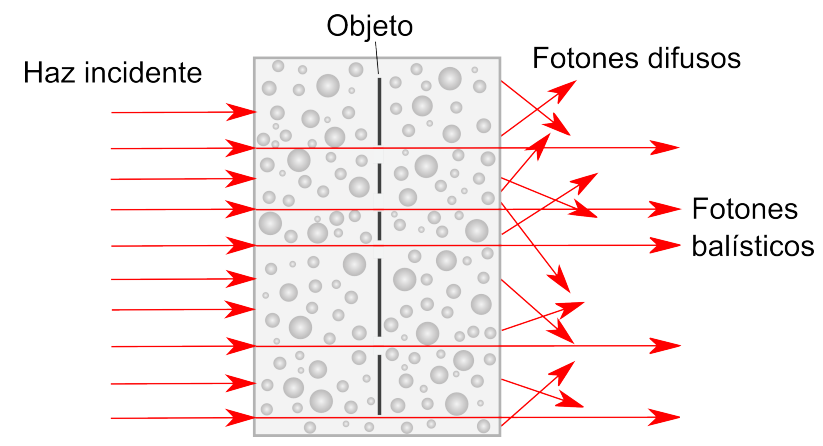

Figura 2.6 - Representación de un objeto inmerso en un medio turbio iluminado en transmisión por un haz colimado. A la salida del medio se obtienen unos pocos fotones balísticos que forman la imagen del objeto y muchos fotones difusos que emborronan y ocultan la imagen del objeto cuando es capturada con una cámara convencional.

de penetración en el tejido, generalmente se ha basado en técnicas no ópticas como tomografía computarizada $(\mathrm{CT})$ de rayos X, imagen de resonancia magnética (MRI), ultrasonido, tomografía por emisión de positrones (PET) y tomografía por emisión de un fotón. Sin embargo, el desarrollo de técnicas ópticas para el estudio de sistemas biológicos es un campo que ha crecido enormemente en los últimos años. Las técnicas empleadas en la actualidad permiten obtener, o bien muy buena resolución a poca profundidad, o bien permiten alcanzar mucha profundidad a baja resolución. Por ello la obtención de imágenes de alta resolución a profundidades mayores que 1 TMFP utilizando métodos ópticos es un reto en el que se continúa trabajando hoy en día. En este apartado se discuten las tecnologías actuales que se usan en el campo de la biomedicina, clasificando las diferentes técnicas de imagen en relación a la profundidad de penetración en el medio difusor (tejido biológico) y la resolución que son capaces de alcanzar (véase figura 2.7).

En la gráfica de la figura 2.7 se diferencian tres regiones de trabajo: la microscópica, en la que se obtienen resoluciones muy por debajo del límite del ojo humano para imagen de muestras in vivo (del orden de centenas de $\mathrm{nm}$ ) y la profundidad de penetración se encuentra por debajo de 1 TMFP la macroscópica, en la que se obtiene profundidades de penetración mayores de 10 TMFP (aproximadamente $>1 \mathrm{~cm}$ ) y resoluciones bajas (del orden de centenas de $\mu \mathrm{m}$ o mayores); y por último la región mesoscópica, situada entre las dos anteriores, tanto en resolución como en profundidad de penetración (de $0,5 \mathrm{~mm}$ a $1 \mathrm{~cm}$ ). A continuación se hace una discusión de las tecnologías

\footnotetext{
${ }^{1}$ Para tejidos biológicos el MFP es del orden de $100 \mu \mathrm{m}$ y el TMFP es $0,5-1 \mathrm{~mm}$, dependiendo del tejido 8 .
} 


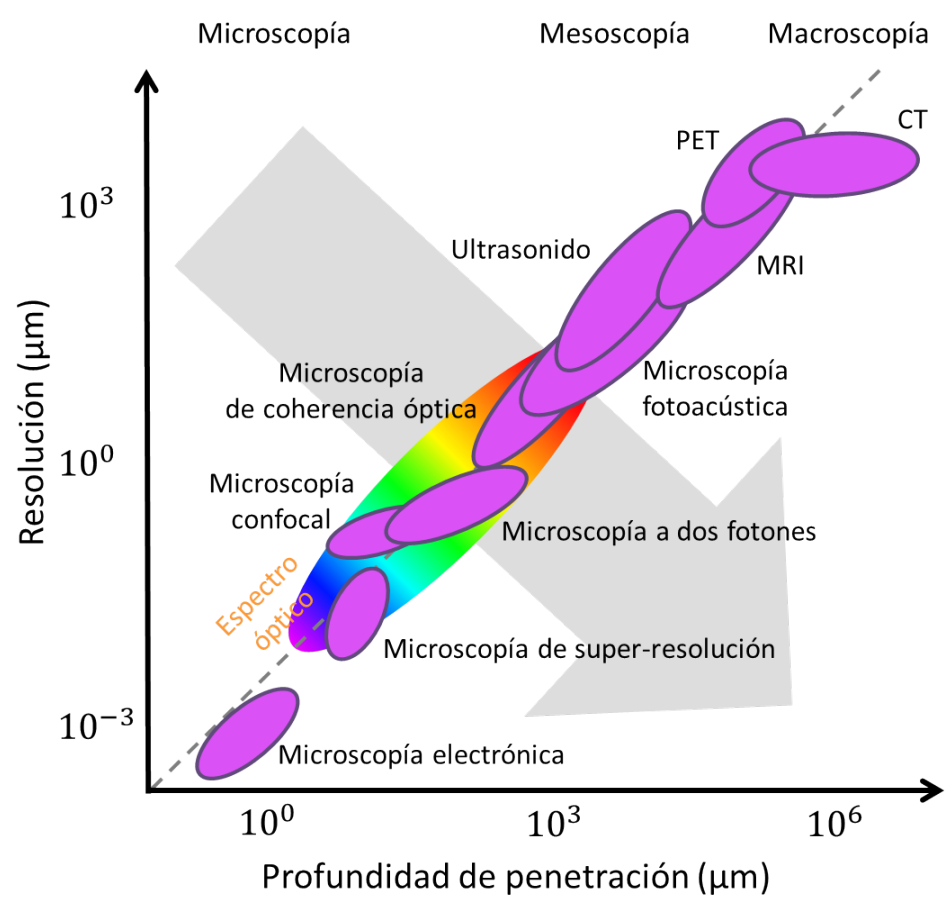

Figura 2.7 - Clasificación de distintas técnicas de imagen por su resolución y profundidad de penetración en medios turbios. La flecha indica la meta que se pretende conseguir en el estudio de nuevas técnicas de imagen. La elipse con los colores del espectro electromagnético del visible sirve para marcar las técnicas de imagen que usan radiación en el rango óptico del espectro. Gráfica adaptada de 8,58 .

más relevantes que usan radiación en el rango óptico del espectro.

En microscopía, la capacidad para obtener imagen depende, en muchos sistemas, de la focalización de la luz en la muestra mediante el uso de lentes. El scattering producido por el medio disminuye la capacidad de las técnicas microscópicas de focalizar luz dentro de una muestra difusora y, por tanto, de obtener imagen. Mientras que la microscopía convencional sólo proporciona imagen de resolución micrométrica de muestras delgadas, limitando la profundidad de penetración en el tejido al orden del MFP, la microscopía confocal [59] y microscopía a dos fotones (o multifotónica) 60] son comunmente usadas para sobrepasar dicho límite de profundidad manteniendo una resolución submicrométrica en sus imágenes. Estas técnicas se utilizan típicamente para estudios en el campo de la biología y medicina mediante el uso de marcadores fluorescentes en las muestras.

El microscopio confocal de barrido láser es una técnica de obtención de imágenes de alta resolución con capacidad de seccionado óptico, es decir, 
capacidad para adquirir imágenes en foco a distintas profundidades de la muestra. Mientras que un microscopio convencional captura información procedente de las múltiples capas de la muestra en una sola imagen, el microscopio confocal puede obtener imagen con información de una sola capa. En este tipo de microscopio se realiza un barrido punto a punto sobre un plano de la muestra utilizando radiación láser y estos puntos formarán la imagen 2D reconstruida en un ordenador; si se miden distintos planos de profundidad de la muestra se podrán reconstruir imágenes 3D. Esto es posible gracias al uso de un pinhole (pequeña apertura) que elimina la información fuera de foco, es decir, los fotones desenfocados y difusos, en cada punto de la imagen. Aunque el pinhole haga disminuir considerablemente la cantidad de fotones, con el uso de fuentes de luz de gran intensidad y detectores muy sensibles como tubos fotomultiplicadores, se captan suficientes fotones balísticos para reconstruir la imagen. La utilidad de la técnica está limitada a unos pocos MFP de penetración en la muestra, ya que el scattering produce una disminución de la señal confocal con el aumento de profundidad de penetración. Se han obtenido imágenes de alta resolución a profundidades de $300-500$ $\mu \mathrm{m}$, dependiendo del tipo de tejido, e incluso a través de tejido in vivo 61. Idealmente, si se aumentara la intensidad del láser de iluminación, se podría mejorar la calidad de las imágenes o incluso llegar a medir a profundidades mayores; sin embargo, la realidad es que hay un límite máximo de nivel de intensidad sobre el tejido biológico, ya que éste podría resultar dañado al aplicar potencia por encima de un cierto umbral.

Por otro lado, la microscopía a dos fotones o multifotón tiene el mismo principio de funcionamiento que la microscopía confocal pero sigue un proceso no lineal para la obtención de fluorescencia en la muestra. La fuente de luz es un láser pulsado ultracorto que permite focalizar el punto de luz en un plano de la muestra sin excitar la fluorescencia en los planos anteriores o posteriores, es decir, sin que se produzca emisión de fotones en capas fuera de foco. Por tanto, no requiere el uso de un pinhole. Esta característica supone una ventaja respecto a la microscopía confocal en cuanto a la resolución. Por otro lado, usando radiación en el infrarojo cercano (NIR, del inglés Near-InfraRed) como fuente de luz se pueden alcanzar mayores profundidades de penetración. El coeficiente de scattering disminuye a mayor longitud de onda, por tanto el MFP aumenta. La profundidad de penetración en tejido para la microscopía a dos fotones (usando luz infraroja) es el doble o el triple que la profundidad para microscopía confocal (usando luz visible) [8, 14,62]. El inconveniente de esta tecnología es que está restringida a muestras fluorescentes.

Una técnica que no depende de la fluorescencia es la tomografía de coherencia óptica (OCT), capaz de obtener imagen a profundidades en un tejido de grosor milimétrico con resolución de decenas de micras. Existen diversas 
modalidades de OCT. La primera que se aplicó a tejido biológico [13 opera en el dominio temporal, usando una fuente de baja coherencia para iluminar la muestra, y analiza la interferencia de los fotones de backscattering con una señal de referencia. Los cambios en el índice de refracción del material producen reflexiones en las interfases y son mostrados en un interferograma, permitiendo imágenes de planos a distintas profundidades de tejido. La radiación en el NIR se usa normalmente para aumentar la profundidad de penetración. Aunque la técnica OCT se demostró en primer lugar para imagen retiniana 63], ha sido aplicada en otras áreas de imagen biomédica convirtiéndose en una herramienta de diagnóstico médico con un gran potencial [64 66]. La combinación de un microscopio confocal y la técnica de interferometría de baja coherencia, llamada microscopía de coherencia óptica (OCM, Optical Coherence Microscopy), tiene un gran potencial para el diagnóstico médico, ya que permite realizar imagen no invasiva a través de medios fuertemente difusores. Esta adaptación de OCT puede conseguir imagen a profundidades hasta tres veces mayor que un microscopio confocal convencional [67].

Para conseguir mayor penetración en el tejido se pueden usar técnicas híbridas como la fotoacústica, en la que un pulso de nanosegundo ilumina una región de interés en la muestra y algunos de los fotones son absorbidos. Las moléculas que absorben los fotones aumentan su energía produciendo una expansión térmica y creando una onda de presión que viaja a través del tejido. Esta onda es detectada por trasductores acústicos y el tiempo de llegada de diferentes ondas acústicas determina la distancia a la fuente. Como las ondas acústicas no son difundidas por el medio de scattering, es posible resolver su localización, y por tanto obtener la imagen, mediante un algoritmo. La razón de que la profundidad de penetración en el tejido sea mayor en esta técnica es que cualquier fotón difundido que es absorbido cuenta para la creación de una señal fotoacústica. Un ejemplo de imagen fotoacústica es la vasculatura, usando la hemoglobina en sangre como medio de absorción [68.

Además de las técnicas de imagen consolidadas que se explican en los párrafos anteriores, han aparecido nuevas metodologías para conseguir imagen a través de medios de scattering. En concreto, muchas de ellas se basan en la posibilidad de controlar la amplitud y fase de un campo óptico incidente píxel a píxel mediante un modulador espacial de luz (SLM). Cuando un medio difusor es iluminado con luz coherente, a la salida se genera una imagen de speckle. El campo de entrada se puede representar como una matriz (imagen) de $N$ celdas (píxeles). Considerando que cada píxel es una función de la base canónica, se llamarán modos de entrada a los píxeles del campo de entrada. En la figura 2.8 se representa el comportamiento de un solo modo de entrada cuando atraviesa el medio difusor. Este modo sufre múltiple scattering y a la salida la información transmitida está distribuida en todos 


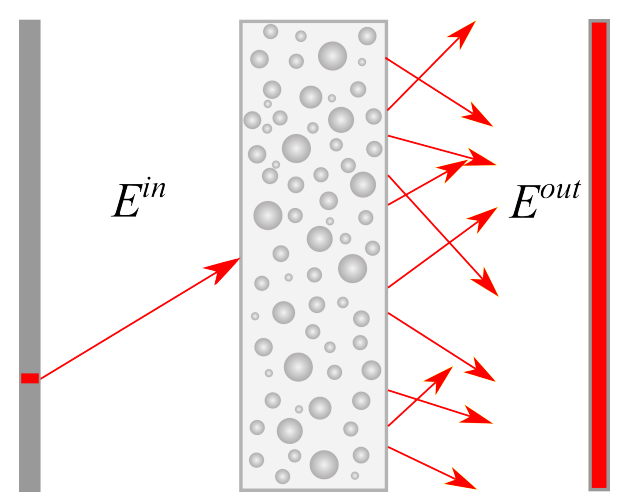

Figura 2.8 - Acción de un medio turbio sobre un modo de entrada del campo incidente en el régimen difuso.

los modos de la imagen del campo de salida. El comportamiento del medio difusor es lineal y la interferencia de todos los modos de salida da lugar a la imagen de speckle. Otra forma de describir este fenómeno sería que un modo de salida contiene información de todos los modos de entrada.

Si el campo de entrada $\left(E^{\text {in }}\right)$ y el de salida $\left(E^{\text {out }}\right)$ se redimensionan como vectores de $N$ elementos, el operador matemático que los relaciona es la matriz de transmisión (TM) del medio turbio. Se define la TM mesoscópica de un sistema óptico, para una longitud de onda dada, como la matriz $\mathbf{K}$ de coeficientes complejos $k_{m n}$ que conecta (en amplitud y fase) cada elemento $m$ del campo óptico de salida al elemento $n$ de entrada. En esencia la TM da la relación entre los modos de entrada y salida a una frecuencia dada, independientemente de la complejidad de la propagación, para un medio estacionario.

$$
E_{m}^{o u t}=\sum_{n=1}^{N} k_{m n} E_{n}^{i n} .
$$

La linealidad del proceso de scattering se ha aprovechado para diseñar métodos de focalización, proyección de una imagen tras un medio turbio o incluso detección de objetos desconocidos tras un medio difusor [23]. Una de las técnicas se basa en construir un algoritmo iterativo que calcula un patrón que, al implementarlo en un SLM, permite predistorsionar el frente de onda incidente, precompensando así las distorsiones introducidas por el medio turbio. De esta forma, se puede focalizar la luz en un punto o formar imágenes tras el medio de scattering [24,69]. Otra forma de conseguir el mismo resultado es determinando la TM del medio cuyos elementos (coeficientes complejos) se pueden medir mediante un procedimiento interferométrico con la ayuda de un SLM [70,71]. El método de focalización a través de un medio turbio ha sido implementado en microscopía de fluorescencia con el obje- 
tivo de conseguir una mayor profundidad de penetración en las muestras difusoras [33, 72]. Otro método de imagen no invasivo que detecta objetos fluorescentes tras una capa difusora delgada consiste en aprovechar la correlación angular de los patrones de speckle, conocida como 'efecto memoria', para detectar la señal proveniente del objeto con una configuración en reflexión [30]. Una evolución de este método consiste en aprovechar la correlación que existe entre de las imágenes de speckle reflejada y transmitida por un medio turbio dinámico para obtener la imagen de un objeto fluorescente [73]. La combinación del efecto memoria y el conformado de frentes de ondas con un SLM ha permitido también 'ver detrás de las esquinas' 29, 31].

\subsection{Sistemas single-pixel}

Las cámaras single-pixel obtienen imágenes empleando fotodetectores sin resolución espacial, a diferencia de las cámaras convencionales que utilizan un sensor matricial constituido por millones de fotodetectores. En la figura 2.9 están representadas esquemáticamete ambas técnicas. En las cámaras convencionales, la luz que emite o refleja un objeto se hace pasar por un sistema óptico, mediante el cual se proyecta dicha luz sobre el plano del detector (un sensor CCD, por ejemplo). De este modo, se obtiene la imagen del objeto, esto es, la distribución bidimensional de intensidades procedentes del mismo. La cámara single-pixel, sin embargo, funciona proyectando secuencialmente un conjunto de patrones luminosos directamente sobre el objeto (iluminación estructurada) o, alternativamente, muestreando secuencialmente la imagen del objeto empleando un conjunto de máscaras (detección estructurada). La primera configuración de SPI se emplea a lo largo de esta tesis (véase figura 3.7, por ejemplo) y la segunda se muestra en la figura 2.9 b. En ambos casos, los patrones generados están relacionados con una base de funciones, de manera que lo que mide el fotodetector son las proyecciones del objeto en esa base. A partir de las funciones de la base y las intensidades medidas se recupera la imagen del objeto.

Matemáticamente se puede identificar la imagen obtenida por un sistema óptico convencional como un vector $\mathbf{x}$ del espacio real que consta de $N$ elementos (tantos como número de píxeles tenga el sensor) y que contiene información sobre la distribución bidimensional de intensidad de la luz. En un sistema óptico que usa la técnica de imagen single-pixel se proyecta el objeto (x) sobre un conjunto de funciones $\left\{\phi_{j}\right\}_{j=1}^{N^{\prime}}$. La medida experimental de cada una de estas proyecciones se corresponden con los valores que forman el vector $\mathbf{y}$ (véase figura 2.10). Este proceso se puede escribir en forma 

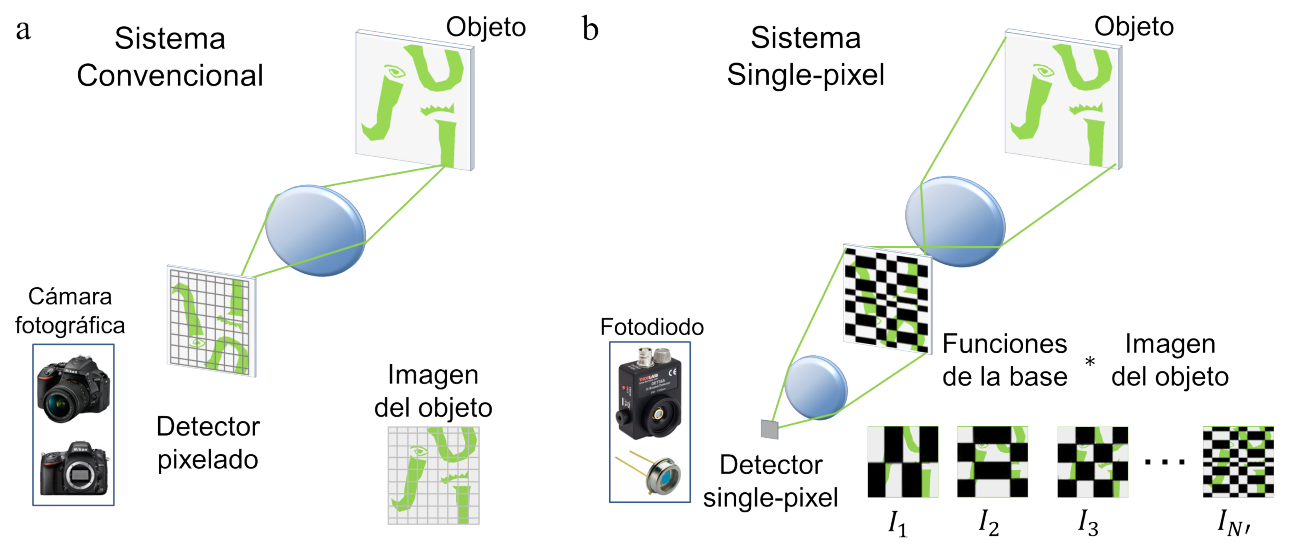

Figura 2.9 - a. Proceso de captura de imagen de una cámara convencional: cada punto del objeto se corresponde con un píxel de la imagen. b. Proceso de adquisición de una cámara single-pixel: se miden las intensidades de la superposición de cada función de la base con el objeto $\left(I_{1}, I_{2}, \ldots\right)$, y con estos valores y las funciones de la base se reconstruye la imagen del objeto. Figura adaptada de 35 .

matricial como

$$
\mathbf{y}=\Phi \mathbf{x}
$$

donde $\mathbf{y}$ es un vector columna de $N^{\prime}$ elementos, $\mathbf{x}$ es un vector columna de $N$ elementos, y se define una matriz $(\boldsymbol{\Phi})$, que se considerará ortogonal y se llamará matriz de muestreo. Esta matriz consta de $N^{\prime}$ filas de funciones ${ }^{2} \phi_{j}$ por $N$ columnas (su dimensión). Cada medida que se realiza corresponde a la superposición de una de las funciones fila de la matriz de muestreo con el objeto bajo estudio (x). La intensidad integrada detectada con el sensor monopíxel es proporcional al elemento correspondiente del vector $\mathbf{y}$, es decir, $\mathbf{y} \propto\left(I_{1}, I_{2}, \ldots I_{N^{\prime}}\right)$ (véase la figura 2.9 b y la figura 2.10.

En la figura 2.10 se muestra una representación esquemática del proceso de medida. A la izquierda se representan las superposiciones de los patrones con el objeto, siendo los patrones funciones de la base Walsh-Hadamard (véase apéndice B). En la gráfica de la misma figura se representan los coeficientes (pesos) de cada patrón empleado en el proceso de adquisición y que se corresponden con las medidas de $\mathbf{y}$. Para obtener la imagen del objeto, simplemente se sebe calcular la inversa de la matriz de muestreo y multiplicarla

\footnotetext{
${ }^{2}$ El hecho de considerar $N^{\prime}$ funciones en la matriz de muestreo, con $N^{\prime} \leq N$, se explica por la posibilidad de aplicar Compressive Sensing (véase apéncice C y los siguientes párrafos).
} 


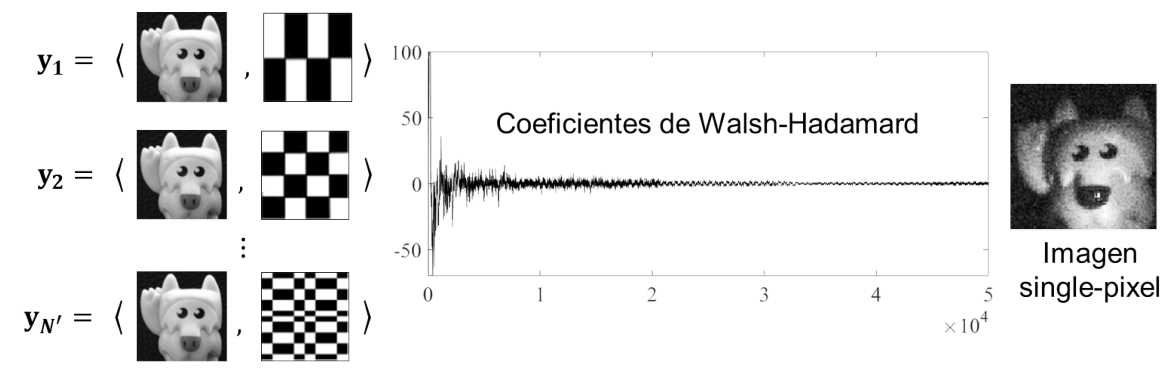

Figura 2.10 - A la izquierda se ve la imagen del objeto original con los patrones (funciones de la base elegida) y a la derecha la imagen reconstruida experimentalmente por single-pixel $(256 \times 256$ píxeles $)$. La gráfica muestra los pesos (coeficientes) de cada función de la base Walsh-Hadamard, obtenidos con los valores medidos de $\mathbf{y}$.

por el vector medido $\mathbf{y}$, quedando:

$$
\mathbf{x}=\Phi^{-1} \mathbf{y}
$$

En el caso concreto de la base Walsh-Hadamard ocurre que la matriz de muestreo es igual a su inversa $\left(\boldsymbol{\Phi}^{-\mathbf{1}}=\boldsymbol{\Phi}\right.$, si $\left.N^{\prime}=N\right)$. Y en general, para bases ortogonales se puede obtener la imagen sumando los productos de cada medida de intensidad por el patrón correspondiente.

En resumen, una cámara de un solo píxel no es más que un sistema que mide secuencialmente el producto escalar entre la imagen de un objeto y un conjunto de funciones bidimensionales de muestreo. En las primeras aplicaciones de cámara single-pixel, las funciones de la base se construían mediante tarjetas perforadas que se movían mecánicamente [74]. El hecho de proyectar numerosas funciones, además de usar tarjetas móviles, fue un obstáculo en los inicios del desarrollo de la cámara single-pixel [75,76]. Aunque la idea básica de esta cámara ya se propuso en 1949 por el profesor Marcel Golay [77] en los laboratorios Bell, hasta la aparición de los moduladores espaciales de luz esta técnica no fue práctica. Los SLMs permiten generar patrones bidimensionales de luz mediante millones de píxeles, cada uno de los cuales se puede controlar individualmente. La alta resolución espacial, las elevadas frecuencias de refresco y la facilidad de control de estos dispositivos hacen que el SLM sea un componente fundamental de la cámara single-pixel (véase apéndice A).

Una cámara single-pixel no puede competir con una cámara convencional en aplicaciones cotidianas. Sin embargo, existen aplicaciones específicas en las que pueden aportar ventajas. Entre ellas están la adquisición de imágenes en el rango espectral de las ondas milimétricas [34, 35], de infrarojo [78], con niveles de iluminación inferiores al pico-watt [36], imágenes polarimétricas [42, 79, imágenes y video 3D 80, 81] o imágenes de fase [82. Además, la 
detección integrada de la luz en la cámara single-pixel hace que el proceso de detección sea invariante ante las posibles variaciones del frente de ondas (por ejemplo, variaciones debidas a las aberraciones de las lentes). Esto permite conseguir imágenes con resolución por debajo del límite de difracción [83 y resulta beneficioso para conseguir la imagen de objetos inmersos en medios turbios (como se trata en esta tesis).

Muchas de las aplicaciones mencionadas en el párrafo anterior son multidimensionales. Aumentar la dimensionalidad de las imágenes supone un incremento sustancial en la cantidad de datos a adquirir, procesar y almacenar, de ahí el interés en desarrollar algoritmos de compresión de imágenes. En concreto, fue en la Universidad de Rice (USA) donde se desarrolló el primer prototipo de cámara single-pixel basada en la técnica de muestreo compresivo o Compressive Sensing (CS) [84]. Esta técnica, introducida por el profesor Emmanuel Candés en Caltech, permite comprimir las imágenes durante el proceso de adquisición de datos, reduciendo significativamente el tiempo de medida 85].

Para entender mejor el funcionamiento de la técnica de CS en el ámbito de los métodos de SPI se considera el vector objeto (x) expresado como una combinación lineal de elementos de una base ortonormal, obteniendo

$$
\mathbf{x}=\sum_{i=1}^{N} \alpha_{i} \psi_{i}
$$

donde $\alpha_{i}$ son los coeficientes del desarrollo y $\left\{\psi_{i}\right\}_{i=1}^{N}$ son los vectores de la base (de dimensión $N$ ). Expresando la ecuación 2.12 con notación matricial se puede trabajar de forma sencilla y útil agrupando los vectores de la base por filas (formando una matriz de dimensión $N \times N$ ) y los coeficientes en un vector columna de longitud $N$. Los vectores-fila son las funciones de la base ortonormal $\boldsymbol{\Psi}=\left[\psi_{1} ; \psi_{2} ; \ldots ; \psi_{N}\right]$. Con esta notación la imagen se expresa como el producto entre la matriz $\boldsymbol{\Psi}$ (matriz de cambio de base) y el vector $\boldsymbol{\alpha}$ (vector de coeficientes),

$$
\mathrm{x}=\Psi \alpha .
$$

Si en la ecuación 2.13 se expresa $\mathbf{x}$ en el espacio transformado, se puede reescribir la ecuación 2.10 de la forma

$$
\mathrm{y}=\Phi \Psi \alpha
$$

El caso más simple sería aquel en el que los elementos de $\boldsymbol{\Phi}$ son precisamente $N^{\prime}$ funciones de la base $\boldsymbol{\Psi}$. Teniendo en cuenta que las funciones de la base considerada son ortonormales, entonces el producto de las matrices $\boldsymbol{\Phi}$ y $\boldsymbol{\Psi}$ será una matriz de tamaño $N^{\prime} \times N$ en la que todos los elementos de 
cada fila son nulos excepto uno de valor unidad, que se obtiene al hacer el producto escalar de una fila y una columna correspondientes al mismo vector de la base. De este modo, los valores medidos de $\mathbf{y}$ corresponden a los coeficientes de las funciones de la base $\boldsymbol{\Psi}$ y se puede obtener la imagen del objeto simplemente con una suma de los productos de los coeficientes por las funciones de la base proyectada.

En el caso de que el número de funciones empleadas, $N^{\prime}$, fuese menor que la longitud del vector $\boldsymbol{\alpha}$ de coeficientes, $N$, la ecuación 2.14 indicaría que el conjunto de medidas corresponde a una selección de los coeficientes del espacio transformado. Esto es precisamente lo que hace el algoritmo de CS (véase apéndice C). Si bien existe un gran número de bases distintas (wavelet, Fourier, etc.), no todas son adecuadas para usar CS. Para que esta técnica pueda aplicarse deben darse dos condiciones: la primera es que la señal tratada debe ser sparse, es decir, debe admitir una representación concisa en una base adecuada de funciones. De esta forma sólo un número reducido de coeficientes de la expansión es significativamente distinto de cero, tal como se ha visto en la gráfica de la figura 2.10 con la base de funciones WalshHadamard. Cuando una señal cumple esta condición, se pueden descartar los coeficientes más pequeños sin tener una pérdida relevante de información. Éste es el procedimiento que emplean los algoritmos de compresión habituales, como por ejemplo las compresiones estándard JPEG y JPEG-2000: una vez se han calculado todos los coeficientes en una determinada base, se almacenan sólo los más relevantes. Medir sólo esos coeficientes equivaldría a realizar un "muestreo compresivo". Esto, en principio, no es posible, ya que 'a priori' se desconoce qué coeficientes son los más significativos. Sin embargo, CS impone una segunda condición, y es que las dos bases utilizadas para medir y reconstruir el objeto deben ser incoherentes, es decir, los objetos que tienen una representación sparse o compresible en una determinada base deben exhibir una "representación extensa" en el dominio en que son adquiridos. Si se cumplen las condiciones anteriores, la teoría de CS afirma que si se efectúa un submuestreo aleatorio en el espacio correspondiente a una de las bases, y se reconstruye siguiendo un proceso de optimización en la otra, se puede recuperar la imagen con un alto grado de fidelidad.

Además de CS, se han desarrollado otras técnicas basadas en algoritmos adaptativos capaces de conseguir imágenes de alta resolución con menos medidas de las que serían necesarias a priori [86 88]. La aplicación de estas técnicas junto con los avances en optoelectrónica permite que las imágenes multidimensiones sean capturadas a velocidad de vídeo [78, 81. 


\section{Capítulo 3}

\section{Transmisión de imágenes a través de un medio difusor}

En un esquema de formación de imágenes convencional en el que un objeto es iluminado por un haz monocromático, la luz procedente del objeto es capturada con una cámara digital CCD o CMOS en el plano donde se forma la imagen del mismo. Sin embargo, si un medio difusor está situado entre el objeto y el sensor, la misma técnica de detección no es capaz de formar su imagen en ningún plano. El efecto del medio difusor sobre la luz hace que aparezca una imagen de speckle en lugar de la imagen del objeto. Como ya se ha visto, cualquier medio difusor limita la observación óptica debido a las variaciones aleatorias del índice de refracción, que deforman los frentes de onda emergentes del objeto bajo estudio. En este capítulo se demuestra que se puede recuperar la imagen de un objeto tras un medio difusor mediante la técnica de imagen single-pixel (SPI).

Para explicar la transmisión de imágenes a través de un medio difusor, se tomarán conceptos ya presentados en la sección 2.2, y se utilizará el concepto de modos del campo eléctrico $E$. En el caso de un sistema de imagen convencional, cada modo es el valor de la amplitud compleja del campo en una determinada posición espacial (píxel)1․ Además, cada modo del campo incidente se corresponde con un modo del campo transmitido, quedando limitada esta correspondencia, en el caso ideal, por la difracción. Cuando se añade un medio de scattering al sistema de imagen, la relación entre los modos de entrada y salida sufre los efectos del random walk que experimentan

\footnotetext{
${ }^{1}$ Siempre se considera un número finito de modos, igual al número de píxeles (celdas unidad) del detector (CCD). En cada píxel se tiene una amplitud y fase del campo constantes. Cuando se considera un número discreto de posiciones espaciales, cada modo se puede expresar como una matriz (o, reescalando, como un vector) cuyos elementos son nulos salvo uno, correspondiente al píxel considerado.
} 
los fotones y, como resultado, la información espacial de un modo de entrada está mezclada y repartida en todos los modos de salida (véase la figura 2.8). Alternativamente, se puede decir que un modo de salida (un píxel de la imagen que mediría una CCD) contiene información de todos los modos del campo de entrada. Experimentalmente, el patrón de speckle que se observa a la salida del medio difusor no es más que el resultado de la interferencia de todos los modos de entrada que han sido mezclados de forma aleatoria por acción del scattering. Por tanto, la intensidad de un área cualquiera del patrón de speckle que incluya muchos granos (esto es, en la que se promedien muchas interferencias constructivas y destructivas) acaba simplemente siendo proporcional a la suma de las intensidades de todos los modos de entrada.

Una cámara convencional no puede proporcionar una imagen nítida de un objeto tras un medio turbio, ni siquiera si se trata de una capa difusora delgada. Sin embargo, un sistema de imagen single-pixel, que usa un detector sin resolución espacial (un fotodiodo con una cierta área de detección) para realizar las medidas de intensidad del campo transmitido, sí permite recuperar la imagen del objeto, tal como se ha explicado de forma intuitiva en el párrafo anterior. La distribución de irradiancias a la salida del medio difusor tiene una intensidad total que es la suma de las intensidades en cada posición espacial (modo):

$$
I^{\text {out }}=\sum_{m=1}^{M} I_{m}^{\text {out }}
$$

En la ecuación 3.1, $M$ es el número de modos de salida en el área de detección considerada. Teniendo en cuenta que el medio de scattering se caracteriza a escala mesoscópica mediante la matriz de transmisión de coeficientes complejos $k_{m n}$, se puede calcular el campo de salida de acuerdo con la ecuación 2.9. Así, la intensidad correspondiente al modo $m$ de salida se expresa de la siguiente forma:

$$
I_{m}^{\text {out }}=\left|E_{m}^{\text {out }}\right|^{2}=\left|\sum_{n=1}^{N} k_{m n} E_{n}^{\text {in }}\right|^{2}=\sum_{n=1}^{N}\left|k_{m n} E_{n}^{\text {in }}\right|^{2}+\sum_{n=1}^{N} \sum_{n^{\prime} \neq n}^{N} k_{m n}^{*} k_{m n^{\prime}} E_{n}^{\text {in* }} E_{n^{\prime}}^{\text {in }},
$$

donde el subíndice $n$ hace referencia a los modos de entrada en el medio de scattering.

Si en el área activa del fotodetector se detectan todos los modos de salida, entonces ocurre el caso ideal de $M=N$, siendo $N$ el número total de modos de la base. Sin embargo, puesto que el campo a la salida del medio difusor viaja en todas direcciones debido al scattering, no todos los modos de salida entran en el área del sensor; por tanto, se considerará el caso de $M<N$. 
Cuando se realiza el sumatorio de los $M$ modos sobre los términos de la ecuación 3.2 se tiene que:

$$
\begin{aligned}
I^{\text {out }} & =\sum_{m=1}^{M} I_{m}^{\text {out }}=\sum_{m=1}^{M} \sum_{n=1}^{N}\left|k_{m n}\right|^{2}\left|E_{n}^{i n}\right|^{2}+\sum_{m=1}^{M} \sum_{n=1}^{N} \sum_{n^{\prime} \neq n}^{N} k_{m n}^{*} k_{m n^{\prime}} E_{n}^{i n *} E_{n^{\prime}}^{i n} \\
& =\sum_{n=1}^{N}\left(\sum_{m=1}^{M}\left|k_{m n}\right|^{2}\right)\left|E_{n}^{i n}\right|^{2}+\sum_{n=1}^{N} \sum_{n^{\prime} \neq n}^{N}\left(\sum_{m=1}^{M} k_{m n}^{*} k_{m n^{\prime}}\right) E_{n}^{i n *} E_{n^{\prime}}^{i n}
\end{aligned}
$$

Asumiendo que la estadística de los coeficientes de la TM se rige por el fenómeno clásico de random walk (como se vio en la sección 2.1), a continuación se demostrará que para un número $M$ suficientemente grande de modos de salida detectados en el área del sensor se tiene que:

$$
I^{\text {out }} \propto \sum_{n=1}^{N}\left|E_{n}^{i n}\right|^{2} .
$$

La ecuación anterior indica que todos los modos de entrada contribuyen de forma idéntica, con el mismo factor de peso, a la señal detectada y que, además, las contribuciones de los diferentes modos de entrada son independientes entre sí. Por tanto, se puede formular el proceso de obtención de imágenes a través del medio difusor como un proceso lineal en intensidades. Esto implica que la presencia de un medio de scattering entre un objeto y el detector no impide medir la proyección de una serie de patrones sobre el objeto y, en consecuencia, es posible recuperar la imagen del objeto situado tras un medio de scattering con la técnica SPI.

Para comprobar la veracidad de la ecuación 3.4 se ha realizado primero una simulación y después un experimento. A continuación se muestran los razonamientos y resultados obtenidos.

En la figura 3.1 se muestra el resultado de la simulación de la distribución de probabilidad tanto para la amplitud $\left(\left|k_{m n}\right|\right)$ como para la fase $\left(\arg \left(k_{m n}\right)\right)$ de los coeficientes complejos de una TM. Cada término $k_{m n}$ resulta de la suma de las contribuciones de muchas desviaciones elementales aleatorias dentro del medio, que conecta los modos de entrada y salida. Como resultado, se dice que el fasor complejo resultante $k_{m n}$ sigue una distribución gaussiana

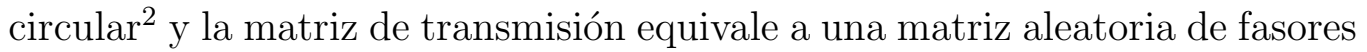
independientes e idénticamente distribuidos con estadística gaussiana [89]. En

\footnotetext{
${ }^{2}$ Las partes real e imaginaria siguen una distribución gaussiana, lo que hace que la amplitud venga descrita por una densidad de probabilidad de Rayleigh y la fase tenga una distribución constante (sección 2.1).
} 

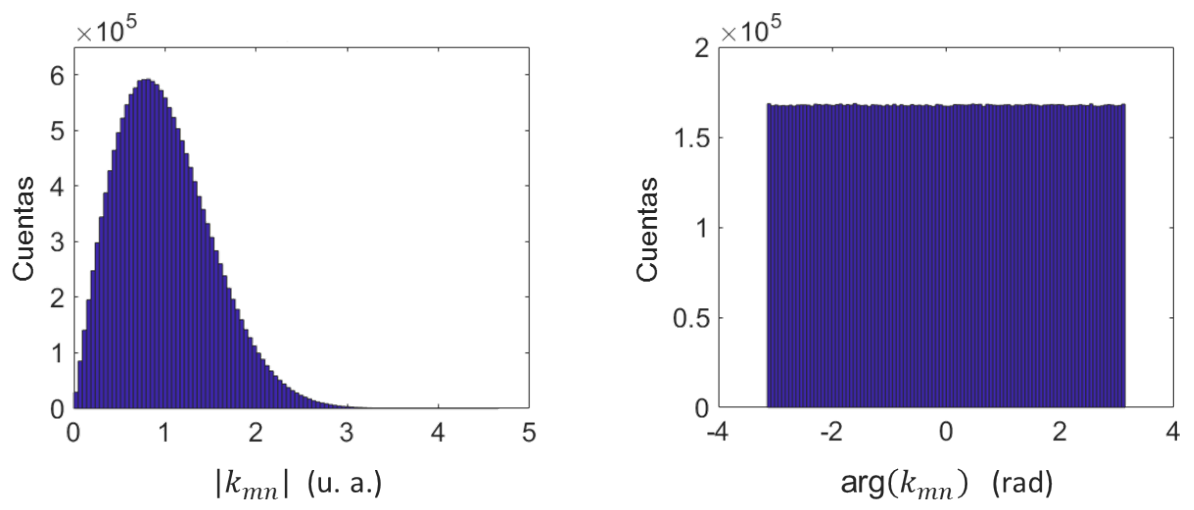

Figura 3.1 - A la izquierda se muestra una distribución de Rayleigh al representar el histograma de la amplitud de los coeficientes complejos $k_{m n}$ simulados. A la derecha se representa la distribución de probabilidad para un valor de la fase de los coeficientes de la misma TM. Dicha distribución es uniforme entre $(-\pi, \pi)$. Para realizar esta representación se han escogido 4096 modos de entrada $(64 \times 64$ píxeles $)$, y 4096 modos de salida.

esta simulación los valores de $\left|k_{m n}\right|$ siguen una distribución de Rayleigh y la fase está distribuida uniformemente entre $(-\pi, \pi)$.

Partiendo de la ecuación 3.3 para el cálculo de $I^{\text {out }}$, se puede escribir:

$$
I^{\text {out }}=\sum_{n=1}^{N} A_{n}\left|E_{n}^{\text {in }}\right|^{2}+\sum_{n}^{N} \sum_{n^{\prime} \neq n}^{N} B_{n, n^{\prime}} E_{n}^{\text {in* }} E_{n^{\prime}}^{i n},
$$

donde $A_{n}=\sum_{m=1}^{M}\left|k_{m n}\right|^{2}$ y $B_{n, n^{\prime}}=\sum_{m=1}^{M} k_{m n}^{*} k_{m n^{\prime}}$.

A consecuencia del comportamiento estadístico de los coeficientes de la matriz de transmisión, para un determinado número $M$ de modos a la salida, los términos que dependen de $A_{n}$ y $B_{n, n^{\prime}}$ siguen una distribución de probabilidad gaussiana, como se muestra en la figura 3.2. En esta figura se observa que todos los posibles valores de $A_{n}$ son positivos mientras que el término correspondiente a $B_{n, n^{\prime}}$ tiene una distribución gaussiana centrada en cero con valores positivos y negativos. Al realizar los sumatorios para el cálculo de $I^{\text {out }}$ se obtiene que, la contribución del término $B_{n, n^{\prime}}$ es mucho más pequeña que la contribución del término $A_{n}$, por lo que se puede considerar despreciable. En la gráfica 3.2 a se ha representado el histograma correspondiente a los valores de $A_{n}$ y en la gráfica $3.2 \mathrm{~b}$, la parte real de los valores de $B_{n, n^{\prime}}$. Además, en la figura 3.2 c se representa, en función del número de modos a la salida, la razón entre la desviación estándard y el valor medio del histograma correspondiente a los términos $A_{n}$. A partir de esta representación es fácil deducir que la contribución de los diferentes modos de entrada a la señal detectada 
Capítulo 3. Transmisión de imágenes a través de un medio difusor

a

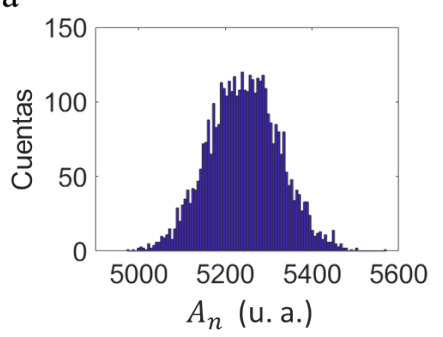

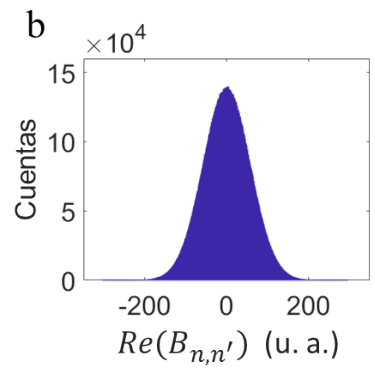

$\mathrm{c}$

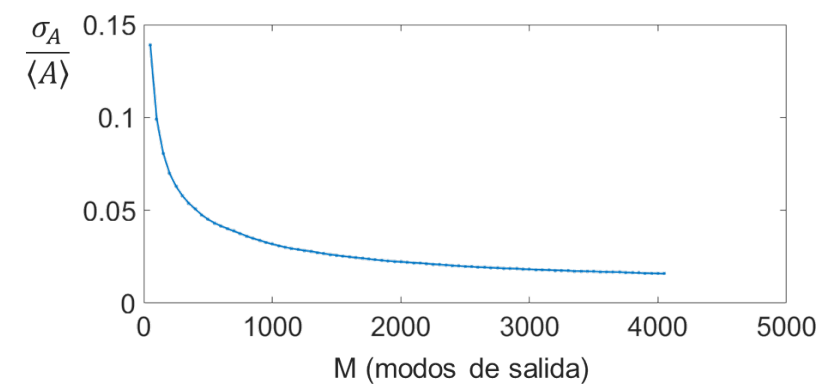

Figura 3.2 - a. Histograma asociado a la distribución de los valores de $A_{n}$ calculados. b. Histograma asociado a la distribución de los valores calculados de la parte real de $B_{n, n^{\prime}}$. c. Representación gráfica en función del número $M$ de modos de salida del ancho relativo de la distribución de coeficientes $A_{n}$.

por el sensor es igual siempre que el número de modos detectados a la salida exceda un cierto valor relacionado con el tamaño del grano de speckle. En otras palabras, el término $A_{n}$ se mantiene constante para todos los modos de entrada $n$ siempre que el número $M$ de modos de salida detectados sea suficientemente grande. Con esta simulación, por tanto, queda comprobada la validez de la ecuación 3.4 .

A continuación, se explica la prueba experimental llevada a cabo con el objetivo de comprobar que el medio de scattering utilizado en este capítulo realmente sigue la estadística mostrada en la simulación. Para ello se envían $N$ modos de entrada, es decir, se proyectan las funciones de la base sobre el objeto, y después de atravesar el medio difusor se captura con una cámara CCD la imagen de speckle resultante de cada proyección. Cada imagen de speckle capturada se reescala al tamaño de los modos de entrada (es decir, al número de píxeles de las imágenes proyectadas) para que pueda existir una correspondencia píxel a píxel mediante una matriz de transferencia. El valor de cada píxel de la imagen de speckle corresponde a un valor de intensidad, es decir, lo que se ha medido es $I_{m}^{\text {out }}=\left|E_{m}^{\text {out }}\right|^{2}$. Experimentalmente sólo se obtiene información de la amplitud, por tanto para obtener el valor del campo $E_{m}^{\text {out }}$ se debe añadir la fase. Puesto que las imágenes recuperadas por 
la CCD son imágenes de speckle, se asume que todos los valores de la fase son igualmente probables entre $\{0,2 \pi\}$ [57]. Así, para conseguir el valor del campo, se añade una fase aleatoria entre dichos valores al módulo de cada modo de salida, siendo éste $\left|E_{m}^{\text {out }}\right|=\sqrt{I_{m}^{\text {out }}}$.

En el tratamiento digital de imágenes es habitual considerar la imagen bidimensional como un vector unidimensional. De esta manera, las filas de la imagen están concatenadas formando un único vector columna de $N$ elementos. Expresando cada imagen como un vector, se puede escribir $E^{\text {out }}=K E^{i n}$, donde $E^{\text {in }}$ y $E^{\text {out }}$ son las imágenes de entrada y salida, respectivamente, y $K$ es la matriz TM.

Si los modos de entrada se correspondiesen con los vectores de la base natural de un sensor pixelado, es decir, los que dan la posición de cada píxel, entonces se obtendrían directamente los coeficientes de la TM, tal como se muestra en el siguiente ejemplo para $N=4$. La expresión para el primer modo de entrada quedaría:

$$
\left(\begin{array}{l}
E_{1}^{\text {out }} \\
E_{2}^{\text {out }} \\
E_{3}^{\text {out }} \\
E_{4}^{\text {out }}
\end{array}\right)=C\left(\begin{array}{llll}
k_{11} & k_{12} & k_{13} & k_{14} \\
k_{21} & k_{22} & k_{23} & k_{24} \\
k_{31} & k_{32} & k_{33} & k_{34} \\
k_{41} & k_{42} & k_{43} & k_{44}
\end{array}\right)\left(\begin{array}{l}
1 \\
0 \\
0 \\
0
\end{array}\right)=C\left(\begin{array}{c}
k_{11} \\
k_{21} \\
k_{31} \\
k_{41}
\end{array}\right),
$$

donde $C$ es una amplitud compleja que es constante y representa el valor del campo incidente en el píxel considerado. La imagen de speckle capturada con una CCD y dispuesta en forma de vector para el primer modo de entrada resultaría ser, salvo constantes, directamente la primera columna de la matriz de transmisión. Para el segundo modo de entrada, se obtendría la segunda columna de coeficientes y así sucesivamente hasta obtener todos los $k_{m n}$. Esta forma de medir se traduce en realizar un escaneo punto a punto del plano de entrada, es decir, del objeto. En un sistema experimental, sin embargo, un modo correspondiente a un píxel es dispersado por el medio de scattering antes de llegar al detector, de forma que la cantidad de luz detectada es tan pequeña que no se puede obtener una relación señal ruido (SNR) aceptable. Para solucionar este problema, en este trabajo se usan las funciones de Walsh-Hadamard (W-H) para los modos de entrada. Estas funciones permiten considerar para cada modo distintas posiciones espaciales (de hecho, la mitad de los píxeles, véase apéndice B). Así se mejora la SNR de las imágenes.

El hecho de usar otra base de funciones no es un problema, simplemente se deben transformar los modos de salida capturados con la CCD a la base de Walsh-Hadamard mediante la matriz de cambio de base $H$ :

$$
\begin{aligned}
E^{i n} & =H^{-1} E^{i n_{H}} \\
E^{\text {out }} & =H^{-1} E^{\text {out }}{ }_{H} .
\end{aligned}
$$


Capítulo 3. Transmisión de imágenes a través de un medio difusor

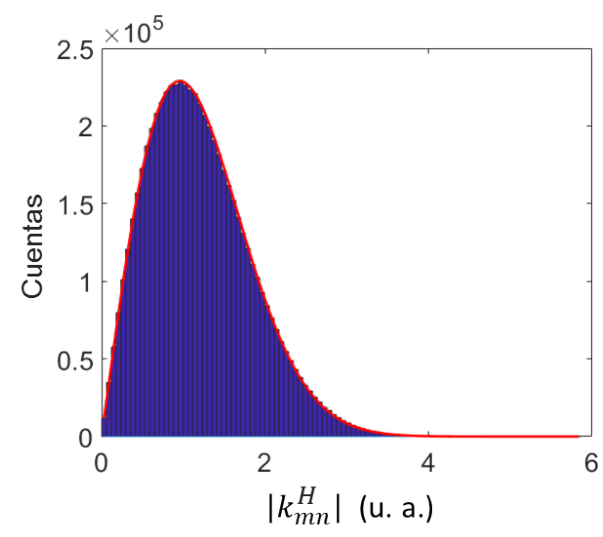

Figura 3.3 - Histograma de la amplitud de los coeficientes complejos $k_{m n}^{H}$ en el espacio de Walsh-Hadamard calculados experimentalmente. La curva roja es la distribución de Rayleigh teórica con un parámetro de valor $\sigma=0.97$.

Sustituyendo estas expresiones en $E^{\text {out }}=K E^{\text {in }}$ y multiplicando $H$ por la izquierda queda:

$$
E^{\text {out }} t_{H}=H K H^{-1} E^{\text {in }_{H}} \rightarrow E^{\text {out }} t_{H}=K^{H} E^{i n_{H}} .
$$

Los hiperíndices $H$ indican que los vectores o matrices se encuentran en la base Walsh-Hadamard. Una vez se ha cambiado todo al espacio de WalshHadamard, los modos de entrada están en su base natural, por lo que directamente se pueden obtener los valores de los coeficientes de la $K^{H}$ realizando la misma operación que en el ejemplo de la ecuación 3.6. En el caso experimental realizado se han tomado imágenes de speckle correspondientes a 1500 patrones de la base W-H (modos de la base), cuya resolución es de $64 \times 64$ píxeles. En la figura 3.3 se muestra la distribución de amplitud de los $4096 \times 1500$ coeficientes de $K^{H}$ calculados. La distribución de Rayleigh teórica, representada por la curva roja de la gráfica 3.3, se ajusta a los valores experimentales con un coeficiente de correlación de 0.99. Por tanto, esta distribución se identifica, al igual que en la simulación (figura 3.1), con una distribución de Rayleigh que corresponde al comportamiento de un random walk. Puesto que la estadística del comportamiento de $K$ no depende de la base en la que se exprese y que, además, coincide en ambos casos, en la simulación y en los resultados experimentales, queda comprobado que el modelo de scattering presentado es correcto para el medio turbio usado experimentalmente.

Un esquema general que engloba los montajes experimentales utilizados en este capítulo se muestra en la figura 3.4. Por un lado, la iluminación consiste en proyectar secuencialmente sobre el plano del objeto tantos patrones de 


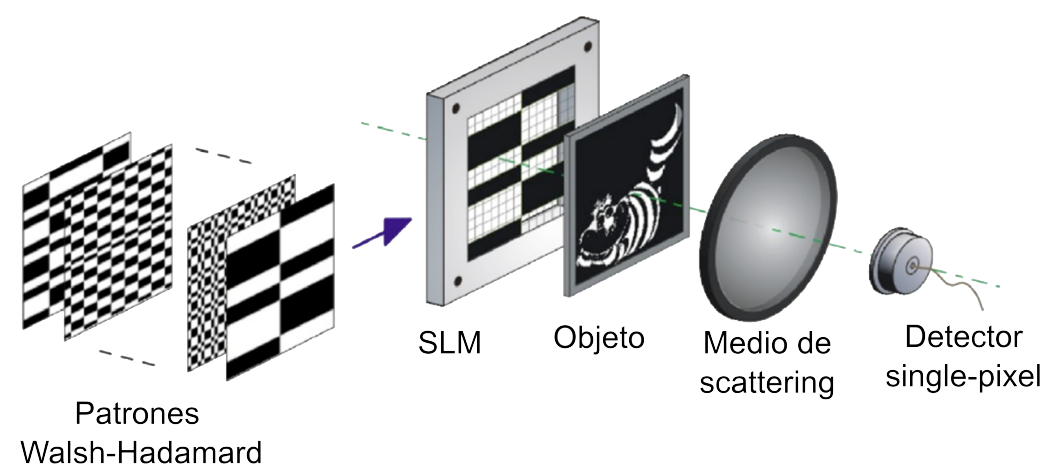

Figura 3.4 - Montaje experimental general. El SLM proyecta patrones de Walsh-Hadamard superpuestos al objeto y esta superposición es detectada por un detector sin estructura espacial a través de un medio turbio [90].

luz (funciones de la base de Walsh-Hadamard) como píxeles tenga la imagen que se quiere obtener. Aunque las matrices de $\mathrm{W}-\mathrm{H}$ tienen valores -1 y 1 , en la práctica se opta por proyectar patrones de luz con valores de 0 y 1 (dos patrones complementarios por cada función de $\mathrm{W}-\mathrm{H}$, véase apéndice B]. La razón de este cambio se debe principalmente a que el SLM es un modulador de amplitud binario, que no puede representar el valor -1 . Por otro lado, la detección consiste en medir la señal asociada a cada una de las proyecciones, que pasan a través del medio de scattering, con un sensor sin resolución espacial. Puesto que el área activa del detector debe medir un número suficientemente grande de modos del campo de salida, normalmente se emplean lentes para focalizar la luz transmitida dentro del sensor. Para recuperar la imagen del objeto de interés, se realiza una suma de los productos de cada patrón de luz con su valor de señal medida.

Los dispositivos utilizados en los experimentos presentados en este capítulo se controlan mediante un código informático escrito en Matlab. Este código permite controlar el sistema, realizar las medidas necesarias y procesar los datos para reconstruir la imagen del objeto de interés. El SLM utilizado en los experimentos de este capítulo es de cristal líquido, funciona por reflexión y puede alcanzar como máximo $75 \mathrm{~Hz}$ de frecuencia de refresco. Para implementar los patrones en el modulador de cristal líquido, el código utilizado transforma la imagen asignándole valores en escala de grises entre 0 y 255 . Como los patrones son imágenes binarias, sólo se emplean dos valores, que corresponden, respectivamente, a una extinción máxima y a la máxima reflexión. Una descripción más detallada sobre el funcionamiento del SLM de 


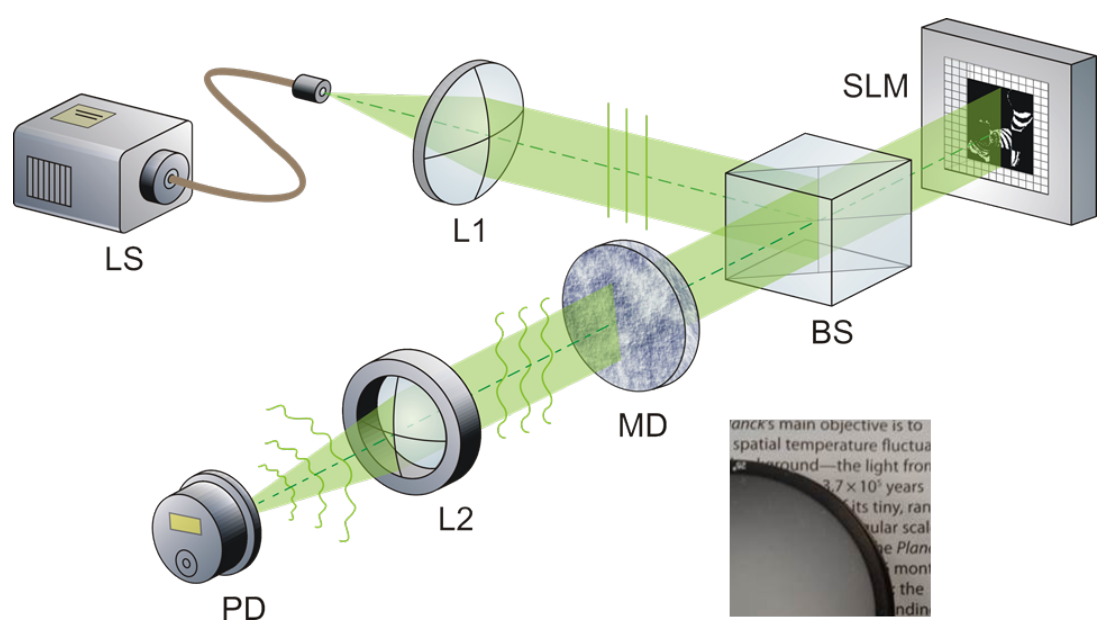

Figura 3.5 - Montaje experimental. Objeto implementado en la pantalla del SLM. La luz emergente del difusor se focaliza en el fotodiodo mediante una lente. La foto situada al lado del medio de scattering (MD) muestra la lámina difusora comercial utilizada.

cristal líquido se encuentra en el apéndice A

El tiempo de adquisición y reconstrucción depende también de la resolución empleada, ya que a mayor resolución, el volumen de las matrices a procesar y el número de medidas a realizar aumenta. Una forma sencilla de disminuir el tiempo de adquisición es usar el método de Compressive Sensing mencionado en capítulos anteriores y explicado en el apéndice C. El algoritmo de CS empleado para la reconstrucción de las imágenes presentadas en este capítulo es la función lleq-pd del software l1-magic [91].

\subsection{Objeto tras un medio difusor estático}

Para demostrar que la técnica SPI es capaz de recuperar la imagen de un objeto a través de un medio turbio, en primer lugar se considera una configuración del sistema en transmisión con un medio turbio estático. Tal como se muestra en el esquema experimental de la figura 3.5, el medio de scattering está situado entre el objeto y el sensor. El objeto utilizado es la versión binaria de una imagen del gato 'Cheshire', de Alicia en el país de las maravillas, y está codificado directamente en la pantalla del SLM. El medio de scattering estático consiste en una lámina difusora comercial (Edmund Optics T54-497), cuya foto se muestra en la figura 3.5.

La iluminación utilizada es un láser de estado sólido monocromático (Oxxius SLIM-532) con una fibra acoplada y longitud de onda en el rango del 

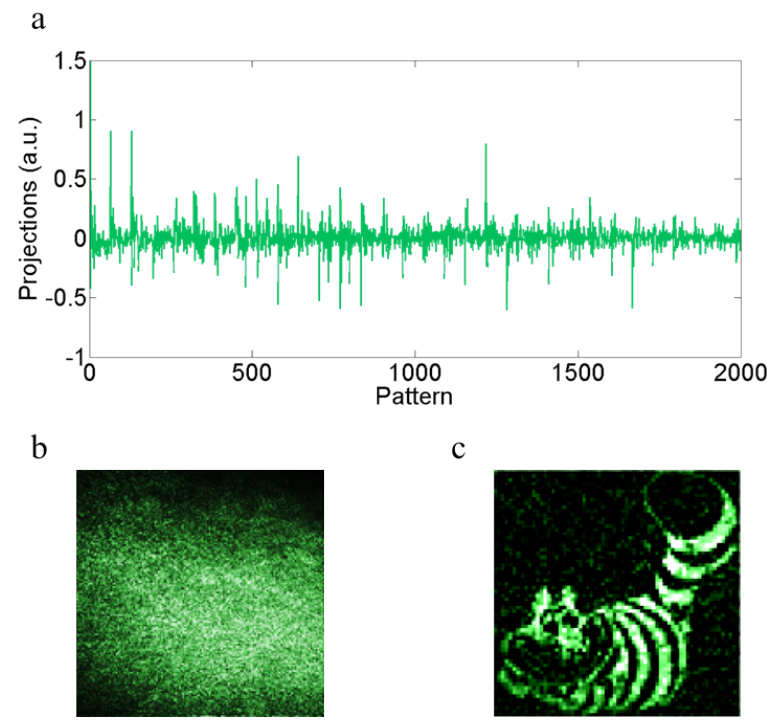

Figura 3.6 - a. Coeficientes de la imagen del objeto en la base de WalshHadamard. b. Imagen de speckle capturada con una CCD. c. Imagen reconstruida con la técnica SPI a través del medio de scattering $(128 \times 128$ píxeles) 90 .

verde $(532 \mathrm{~nm})$. La luz procedente de la fuente pasa a través de una lente colimadora (L1) y de un separador de haz (BS, acrónimo de beamsplitter) que permite iluminar el SLM que funciona por reflexión en incidencia normal. Los patrones de Walsh-Hadamard se codifican en la pantalla del SLM directamente superpuestos al objeto. El SLM utilizado es de cristal líquido (TN LC-R 2500 de Holoeye) y está formado por $1024 \times 768$ píxeles (XGA) cada uno de los cuales tiene un tamaño de $19 \mu m \times 19 \mu m$. Este dispositivo se basa en la tecnología LCoS (acrónimo de Liquid-Crystal-on-Silicon) y requiere el uso de dos polarizadores lineales cruzados (no mostrados en la figura) para lograr una modulación espacial de la intensidad 92]. La luz emergente del modulador pasa a través del medio difusor (MD) y de una lente condensadora (L2), que colecta la luz transmitida para ser recogida por un fotodiodo ( $\mathrm{PD}$, photodiode) de Thorlabs, DET36A, con una área activa de $3.6 \mathrm{~mm} \times 3.6 \mathrm{~mm}$. La señal detectada es digitalizada mediante un conversor analógico-digital (controlador PRO8000(-4)/PRO800 con módulo PDA8000, Thorlabs Instrumentation).

Para recuperar la imagen del objeto a través de la lámina difusora, se situa el fotodiodo en la posición donde capture un gran número de granos de speckle (cuyo tamaño medio, calculado al final de esta sección, es $12.9 \mu \mathrm{m}$ ) y se mide la intensidad de la superposición del objeto con cada patrón. Una 
vez se han obtenido todas las intensidades, se calculan los coeficientes que se corresponden con los pesos de los patrones de Walsh-Hadamard en el objeto. Los primeros 2000 coeficientes se muestran en la figura 3.6 a, donde se puede observar que muchos de ellos tienen valor nulo o muy cercano al cero, lo que significa que la señal del objeto es sparse y por tanto se puede aplicar CS. El objeto tiene una resolución de $128 \times 128$ píxeles, donde cada píxel de la imagen se corresponde con un píxel de la pantalla del SLM. La imagen obtenida con un sistema óptico convencional se ha tomado con una cámara CCD (cámara progresiva de tipo Stingray F-145, Allied Vision Technologies, cuyos píxeles tienen $6.45 \mu \mathrm{m}$ de lado). A través de la lámina difusora, la imagen obtenida con la CCD es una imagen de speckle, tal como se muestra en la figura 3.6 b. La reconstrucción del objeto mediante CS se muestra en la figura $3.6 \mathrm{c}$, utilizando solamente un $20 \%$ del total de medidas $\left(N^{\prime}=0.2 \mathrm{~N}\right.$, donde $N$ es el número total de medidas correspondiente al número de píxeles de la imagen).

En el experimento que se acaba de explicar el objeto utilizado está codificado en la pantalla del SLM. Para comprobar que la técnica SPI a través de medios turbios funciona también con objetos reales, se ha realizado un experimento utilizando una muestra de epidermis de cebolla ${ }^{3}$ como objeto de interés. Este tipo de muestras son muy comunes para observar células vegetales por un microscopio. Para reconstruir una imagen de la epidermis de cebolla en la que se puedan observar sus células se han de proyectar los patrones de Walsh-Hadamard en una región muy pequeña de la muestra (cubriendo del orden de 10 células). Por tanto se necesita un objetivo de microscopio que sea capaz de proporcionar dicha disminución. Un objetivo con aumento de $4 \times$ y apertura numérica (NA) de 0.1 basta para realizar esta medida.

El montaje experimental utilizado es el mismo que el del experimento anterior, añadiendo nuevos elementos (figura 3.7). Después del BS1 se situa una lente de $250 \mathrm{~mm}$ de focal (L3) seguida del objetivo de microscopio (OM), de focal $62.5 \mathrm{~mm}$. Ambas lentes están separadas entre sí una distancia igual a la suma de sus distancias focales (procesador 4-f). Este sistema de lentes

\footnotetext{
${ }^{3}$ Este objeto, al ser una muestra biológica, lleva el siguiente proceso de preparación: se limpia una cebolla de las hojas exteriores secas; se separa una de las hojas internas y se desprende la tenue membrana que está adherida por su cara interna cóncava; si el trozo desprendido fuese muy grande, se corta con unas tijeras una porción más pequeña y se coloca sobre el portaobjetos con una gota de agua. Seguidamente, se añaden unas gotas de azul de metileno (nombre científico, cloruro de metiltionina) y se deja actuar el colorantefijador durante unos pocos minutos. Se coloca el cubre y se observa la muestra por el microscopio. Las células de la epidermis de cebolla tienen forma alargada y su tamaño es del orden de centenares de micras ( $500 \mu \mathrm{m}$ en la muestra usada). Las paredes celulares se destacan claramente debido a la tinción por el colorante.
} 


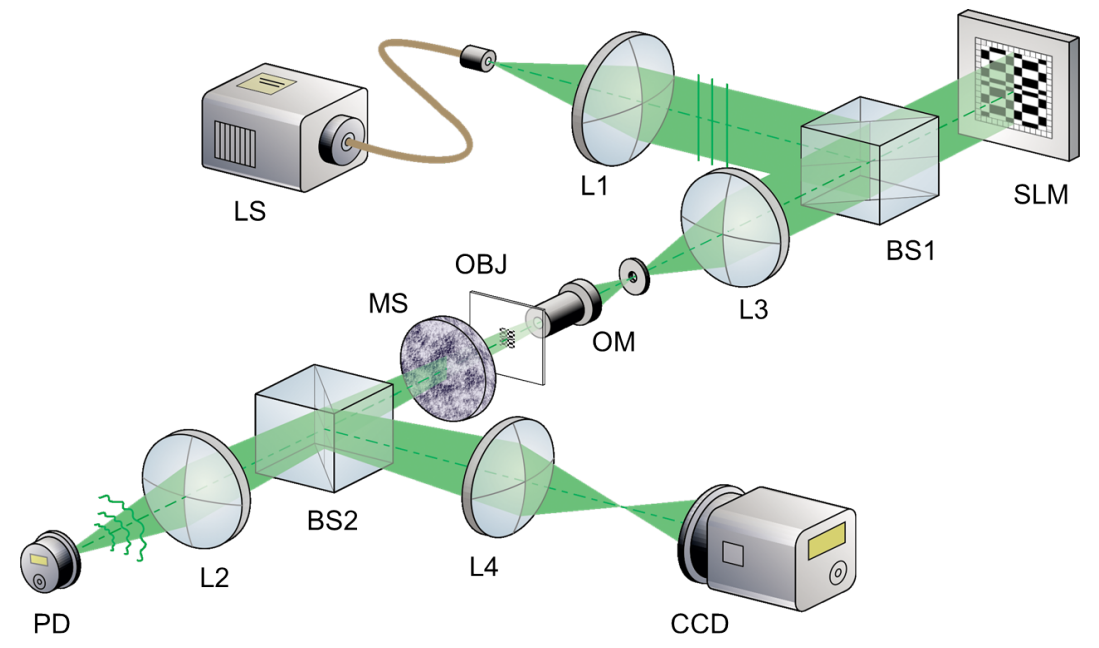

Figura 3.7 - Montaje experimental con un objeto real microscópico 90 . En este caso los patrones de luz se proyectan sobre el objeto (iluminación estructurada) y mediante el separador de haz que hay después del difusor el sistema permite capturar imágenes con CCD y medir las intensidades de cada proyección con un fotodiodo.

afocal proyecta los patrones implementados en la pantalla del SLM sobre una pequeña zona del objeto (OBJ). La estructura pixelada del SLM es filtrada mediante un pinhole situado en el plano focal común (plano de Fourier) entre L3 y OM. En el sistema de colección de luz tras el medio de scattering (MS), se ha añadido un segundo beamsplitter (BS2) que divide el haz en dos caminos ópticos: el haz transmitido es detectado por el fotodiodo igual que en el montaje anterior; y el haz reflejado pasa a través de una lente (L4) que forma la imagen del objeto sobre la pantalla de la cámara digital CCD.

Los resultados obtenidos para este experimento se muestran en la figura 3.8: las imágenes a y b corresponden al sistema convencional que utiliza como sensor una CCD, y las imágenes c y d son el resultado de la técnica SPI que mide con el fotodiodo. Con estas imágenes se hace una comparación directa de ambos métodos, convencional y single-pixel, en dos situaciones distintas. En la primera, sin medio difusor, la imagen obtenida por una CCD (figura 3.8 a) tiene ventajas respecto a la imagen single-pixel (figura $3.8 \mathrm{c}$ ), ya que permite obtener muy buena calidad de imagen en una sola captura, mientras que la técnica single-pixel necesita realizar muchas medidas experimentales para obtener la misma resolución. En segundo lugar, se considera la configuración en la que hay un medio difusor entre el objeto y el sensor. En ese caso con la CCD sólo se puede obtener una imagen de speckle (figura $3.8 \mathrm{~b}$ ), mientras que con la técnica SPI la imagen obtenida muestra el objeto oculto (figura 

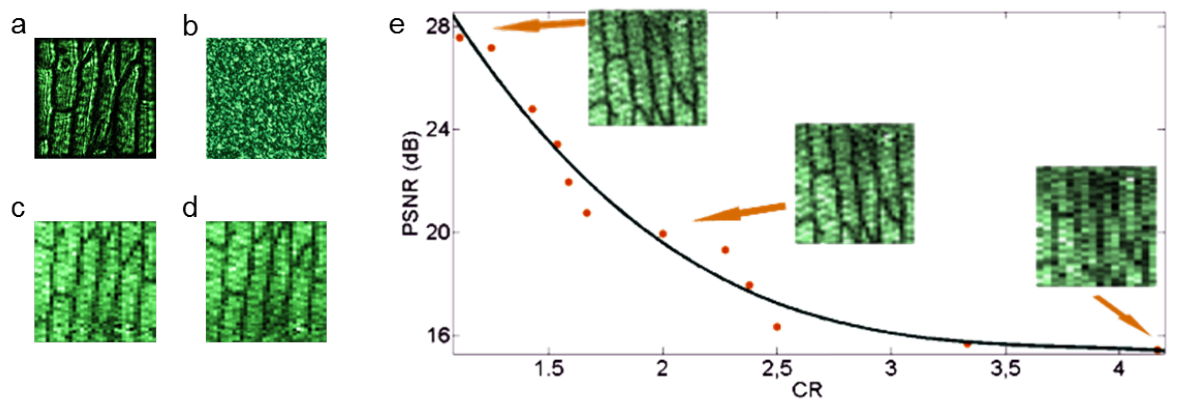

Figura 3.8 - Resultados experimentales con un objeto microscópico 90. a. Imagen convencional (con CCD) del objeto en el sistema sin difusor; b. Imagen convencional del plano del objeto obtenida con difusor; c. Imagen single-pixel (con fotodiodo) del objeto sin difusor; d. Imagen single-pixel del objeto con difusor. Las imágenes reconstruidas con la técnica SPI tienen una resolución de $64 \times 64$ píxeles. e. Estimación de la calidad de las imágenes a través de la medida del PSNR en función del grado de compresión (CR) usando el método de CS.

3.8 d). Comparando las imágenes de la figura 3.8 c y d se puede afirmar que el sistema es capaz de 'ver' a través de medios difusores con una calidad similar a la que se obtendría si no hubiese ningún medio perturbando la imagen del objeto.

En la reconstrucción por SPI de las imágenes de la figura 3.8 se ha usado una resolución de $64 \times 64$ píxeles, donde cada píxel de la imagen corresponde a $2 \times 2$ píxeles en la pantalla del SLM. Después de pasar por el sistema de lentes (L3 y OM) el tamaño de los patrones proyectados sobre el objeto es un cuarto de la imagen en el SLM. Al ser una muestra biológica de tamaño muy pequeño, la intensidad que mide el fotodiodo es muy baja, por tanto se obtiene una señal más ruidosa que en experimentos anteriores. Este hecho es relevante a la hora de aplicar CS para realizar un número de medidas $N^{\prime}<N$ (en este caso $N=4096$ ). Con la finalidad de determinar el valor óptimo de $N^{\prime}$ se reconstruye la imagen del objeto para diferentes valores de $N^{\prime}$ [42]. Para evaluar la calidad de cada una de las reconstrucciones se calcula la denominada relación señal-ruido de pico (PSNR, Peak Signal-toNoise Ratio) 93, 94]. El PSNR se define como la relación entre la potencia máxima posible de una señal y la potencia de ruido que afecta a la fidelidad de su representación:

$$
\mathrm{PSNR}=10 \log \left(\frac{I_{\max }^{2}}{\mathrm{MSE}}\right)=20 \log \left(I_{\max }\right)-10 \log (\mathrm{MSE}),
$$

donde MSE es el error cuadrático medio (MSE, Mean Square Error); definido 

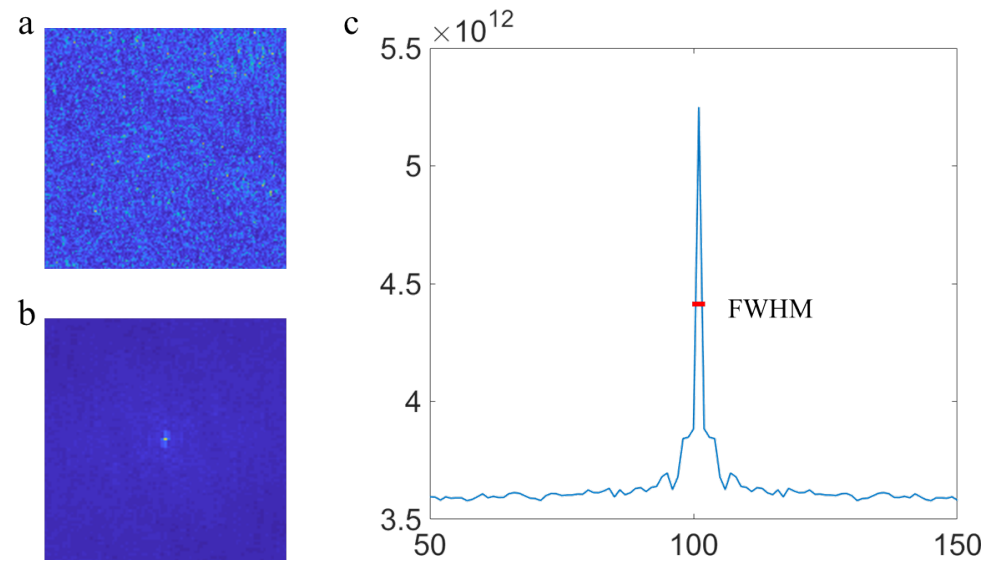

Figura 3.9 - a. Imagen de speckle de resolución $512 \times 512$ píxeles; b. Autocorrelación de la imagen de speckle a; c. Representación del pico de autocorrelación en el eje $\mathrm{x}$.

como

$$
\mathrm{MSE}=\frac{1}{N} \sum_{i} \sum_{j}\left[I(i, j)-I_{r e f}(i, j)\right]^{2},
$$

siendo $I_{r e f}(i, j)$ la imagen de referencia. Aquí, $I_{\max }$ es el máximo valor posible del píxel de la imagen de referencia. Las imágenes de referencia están representadas por $2^{8}$ niveles de gris, por lo que $I_{\max }=255$. Los valores típicos de PSNR están en el rango de 20 y 40 dB para imágenes de 8 bits (píxel con valor $[0,255]$ ) [95]. Cuando el PSNR baja de este rango de valores, la calidad de la imagen disminuye de forma acusada.

En la gráfica de la figura 3.8 e se representa el PSNR en función de la razón de compresión ( $C R=N / N^{\prime}$, Compression Ratio) para la muestra de epidermis de cebolla a través de la lámina difusora. La imagen tomada como referencia para el cálculo del MSE es la imagen single-pixel reconstruida con el $100 \%$ de los patrones $(\mathrm{CR}=1)$ y con un procesado de imagen consistente en un suavizado del ruido y un pequeño ajuste de contraste. La calidad de la imagen mejora a medida que disminuye $\mathrm{CR}$. Para $\mathrm{CR}=2, \mathrm{PSNR}=$ $20 \mathrm{~dB}$, valor para el que se considera una calidad aceptable de la imagen reconstruida. Por tanto, se ha tomado un $50 \%$ del total de medidas.

Finalmente, para comprobar que se puede tomar como válida la teoría explicada al principio de este capítulo, se ha realizado un cálculo del número de granos de speckle que entran en la superficie del fotodiodo cuando se usa el difusor empleado en los experimentos anteriores. Para ello se ha tomado una imagen del speckle con la CCD en la posición donde el fotodiodo mide las intensidades y se ha escogido una zona cuadrada de $512 \times 512$ píxeles 
(figura 3.9 a). A esta nueva imagen se le aplica una técnica convencional de autocorrelación (figura 3.9 b) para encontrar la anchura a mitad de la altura máxima del pico (FWHM, acrónimo de Full Width at Half Maximum) que dará un valor aproximado del tamaño medio del grano de speckle. En la figura 3.9 se muestra la representación en el eje de las $x$ (figura 3.9 c) para el valor de $y$ correspondiente al máximo del pico de la autocorrelación. En rojo está marcada la mitad del pico. El valor del tamaño medio del grano de speckle en este caso es $12.9 \mu \mathrm{m}$. Como resultado, el número de granos de speckle que entran en la superficie activa del fotodiodo usado como detector monopíxel (con área activa de $3.6 \mathrm{~mm} \times 3.6 \mathrm{~mm}$ ) es del orden de $10^{5}$. Es decir, el número de modos de salida $M$ detectados es razonablemente alto, de forma que se puede asumir la validez de la ecuación 3.4 en las medidas experimentales.

\subsection{Objeto tras un medio difusor dinámico}

Existen medios turbios que cambian sus propiedades con el tiempo debido al movimiento de los centros de scattering. Ejemplos de medios turbios dinámicos pueden ser el humo, la atmósfera cuando hay turbulencias, o las células sanguíneas, que están en constante movimiento. En un medio de scattering dinámico se crean a cada instante nuevos caminos aleatorios de difusión y, como consecuencia, la intensidad del speckle en cualquier punto del plano de un detector convencional cambia con el tiempo. Esto produce que la matriz de transmisión cambie también con el tiempo, de modo que la mayoría de las técnicas descritas en el apartado 2.2, que se utilizan para obtener imagen a través de medios de scattering, no son útiles cuando el scattering es dinámico. Sin embargo, la técnica de SPI presentada en los experimentos anteriores es válida, siempre que el número de granos de speckle que incidan sobre el área activa del detector sea lo suficientemente grande.

Para comprobar que una cámara basada en SPI es capaz de reconstruir la imagen del objeto a través de un medio de scattering dinámico se usa un montaje experimental similar al de la figura 3.5. El objeto tras el medio difusor está implementado en la pantalla del SLM y se trata de un test de resolución típico (test USAF). En este experimento el medio difusor consiste en una capa de polipropileno caracterizada por su textura de piel de naranja, con un grosor de $89 \mu \mathrm{m}$ y un perfil de rugosidad de $4 \mu \mathrm{m}$. El movimiento del scattering del medio se consigue agitando la capa difusora mediante una corriente de aire que incide sobre el difusor y genera un speckle variable sobre el plano imagen del sistema.

En la figura 3.10 a se muestra una captura del movimiento del speckle, 
a

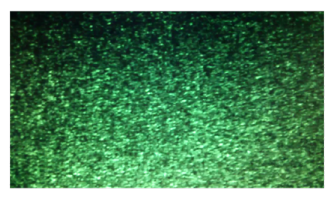

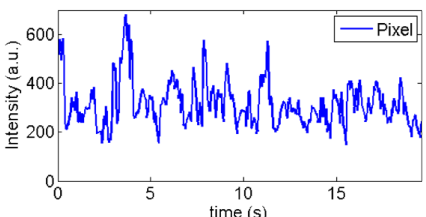

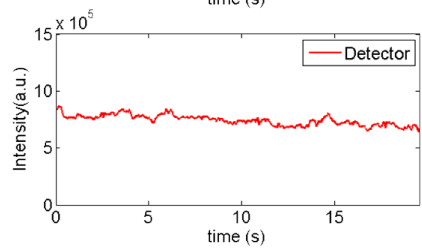

$\mathrm{b}$

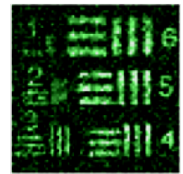

Figura 3.10 - Resultados experimentales con un objeto codificado en el SLM y un medio de scattering dinámico [90]. a. Imagen capturada con un detector convencional (CCD) del speckle producido en el plano imagen del sistema. Las gráficas muestran la variación de intensidad con el tiempo en un píxel de la imagen capturada con CCD (curva azul) y la variación de la intensidad integrada de una área correspondiente al área del objeto sin difusor (curva roja). b. Imagen resultante del objeto (test de resolución USAF) a través del medio turbio dinámico obtenida con el sistema SPI, con $64 \times 64$ píxeles de resolución.

grabado con una cámara CCD, producido por el difusor dinámico. La curva azul de la gráfica superior muestra la variación con el tiempo de la intensidad medida en un píxel de la cámara CCD. La curva roja, por su parte, muestra la variación en el tiempo del valor de la intensidad integrada de todos los píxeles de una área de la imagen de speckle correspondiente al área de la imagen del objeto sin difusor. Esta sería la medida que proporcionaría aproximadamente un fotodiodo que integrara la luz incidente en esa misma área. De la curva azul se comprueba que, efectivamente, el efecto del movimiento del medio difusor produce grandes variaciones de intensidad en aproximadamente un grano de speckle. Las variaciones de intensidad que se aprecian en la curva roja, sin embargo, son muy pequeñas para considerarse significativas y pueden ser debidas, en este caso, a la fluctuación de la intensidad de la fuente y al ruido electrónico de los equipos. Aunque pueda parecer que la curva roja tiene fluctuaciones similares a la curva azul pero en otra escala, el valor del cociente entre la desviación típica y el promedio de las intensidades es efectivamente mayor en la curva azul. De esto se deduce que el valor de intensidad integrada de todos los granos de speckle (curva roja) se mantiene aproximadamente constante en el tiempo, y que el movimiento del medio de scattering no afecta significativamente al valor de las medidas realizadas por el fotodiodo. La demostración experimental de que el sistema SPI funciona con un medio de scattering dinámico se puede ver en la figura $3.10 \mathrm{~b}$, donde se 


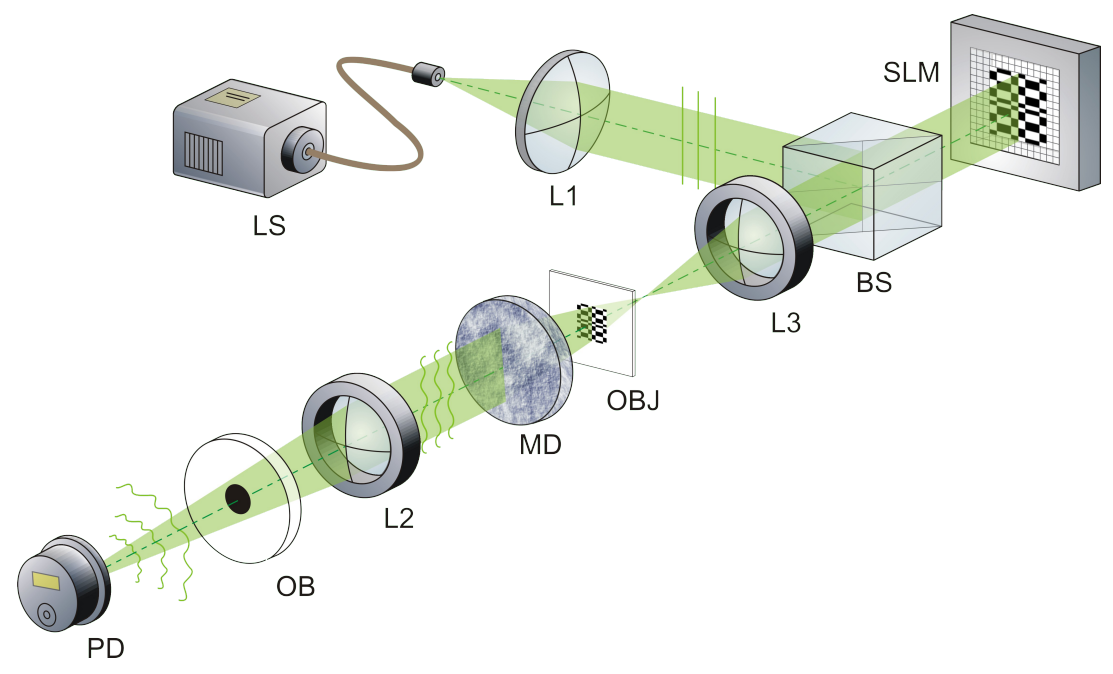

Figura 3.11 - Montaje experimental para recuperar la imagen de un objeto oculto por un obstáculo.

muestra la reconstrucción de la imagen del test USAF con resolución $64 \times 64$ píxeles.

\subsection{Objeto oculto tras un obstáculo}

En este apartado se presenta un sistema formador de imagen en el que existe un obstáculo (otro objeto opaco situado entre el objeto de interés y el detector) que dificulta o impide la visión del objeto. En estas condiciones, la luz transmitida por el objeto está bloqueada por el obstáculo causando que, ni en un sistema convencional con CCD ni en un sistema SPI con un fotodiodo, se pueda detectar la señal proveniente del objeto. En esta situación es posible aprovechar las propiedades de los medios de scattering para conseguir la imagen del objeto de interés. Con el montaje experimental de la figura 3.11 se consigue recuperar la imagen de un objeto, cuya visión está parcial o totalmente obstaculizada, mediante el uso de un medio de scattering.

Un láser monocromático ilumina el SLM mediante L1 y BS. La luz reflejada en el modulador, donde están implementados los patrones de WalshHadamard, pasa por una lente (L3) que proyecta los patrones en el plano del objeto (iluminación estructurada). La lente L2 se puede usar para guiar la luz a un fotodiodo (PD) o para formar la imagen en una CCD (situación no mostrada en la figura 3.11). Después de L2 se sitúa el obstáculo (OB) que dificulta la obtención de la imagen del objeto. Para resolver este problema se utiliza la técnica SPI añadiendo un medio difusor (MD) entre el objeto y 
L2. El difusor provoca que la información espacial procedente del objeto de interés se mezcle aleatoriamente. Como consecuencia, se crea una imagen de speckle que es mayor que la imagen del objeto que se forma sin medio turbio para el mismo plano. El sistema basado en la técnica SPI y un medio difusor es capaz de reconstruir la imagen del objeto completo porque el obstáculo en esta nueva configuración no impide el avance de la información de todo el objeto. La luz procedente de cada punto del objeto está mezclada por la acción del medio difusor, por tanto la porción de luz que consigue avanzar después del obstáculo contiene información de todas las partes del objeto y ésta es detectada por el fotodiodo. En este montaje es importante que el obstáculo no sea demasiado grande, debe ajustarse a las dimensiones del objeto para que, al poner el medio difusor, al menos una parte del campo de speckle llegue al detector. El proceso seguido para obtener la imagen de un objeto que está tapado parcial y/o totalmente por un obstáculo es el mismo que para 'ver' a través de medios turbios. Todo el proceso de adquisición de datos se realiza en condiciones de oscuridad máxima, apagando las luces y evitando la influencia de luz exterior.
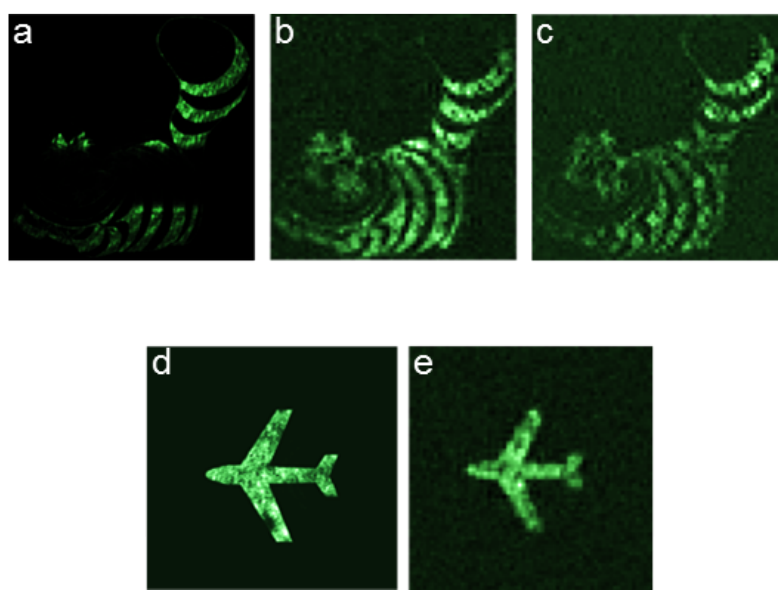

Figura 3.12 - Resultados con un objeto codificado en el SLM (a, b, c) y un objeto real (d, e). a. Imagen del objeto obstaculizado parcialmente obtenida con un sistema convencional (CCD). b. Imagen del objeto obstaculizado parcialmente obtenida con la técnica SPI situando un medio difusor entre el objeto y el obstáculo. c. Imagen del objeto totalmente obstaculizado obtenida con la técnica SPI y un medio difusor. d. Imagen con CCD de una transparencia de vidrio con la imagen de un avión, sin obstáculos. e. Imagen del objeto obstaculizado totalmente recuperada con la técnica SPI y un medio difusor. La imagen con CCD del objeto totalmente oculto no se muestra ya que es una imagen completamente negra. 
Los resultados experimentales se muestran en la figura 3.12. En un primer experimento, se usa el objeto implementado en el SLM del apartado 3.1 (el dibujo de 'Cheshire Cat') para recuperar la imagen del objeto parcial y totalmente oculto (véase figuras 3.12 a, b y c). El sistema experimental utilizado en este caso es el de la figura 3.5 añadiendo el obstáculo del mismo modo que en la figura 3.11. La imagen parcialmente oculta captada por una CCD con el sistema convencional se muestra en la figura 3.12 a. Si se añade el medio de scattering (capa de polipropileno utilizada para implementar el difusor dinámico) se reconstruye la imagen completa del objeto (figura 3.12 b) mediante la técnica SPI. Cuando el obstáculo impide la observación de todas las partes del objeto mediante la cámara convencional, de nuevo la técnica SPI consigue reconstruir la imagen completa del dibujo (figura 3.12 c). El obstáculo usado es una barra metálica en posición horizontal para tapar parcialmente la imagen del objeto de interés y un círculo de cartulina negra sujetada a la barra para taparlo totalmente. En un segundo experimento se usa un objeto real, consistente en una lámina opaca con una zona transparente en forma de avión, que mide $0.5 \mathrm{~cm}$ aproximadamente, tanto en anchura como en altura. En la figura 3.12 e se puede observar la imagen del objeto recuperada mediante el montaje de la figura 3.11, cuando el obstáculo evita la observación directa de todas las partes del objeto. Al igual que el caso del gato Cheshire, añadiendo como medio difusor la capa de polipropileno y midiendo con la técnica de imagen single-pixel, el sistema es capaz de recuperar la imagen oculta. Las imágenes c y e de la figura 3.12 tienen menos contraste y más ruido que las demás. Esto es debido a que el obstáculo tapa completamente el objeto y, como consecuencia, la cantidad de granos de speckle recogidos en la ventana del fotodiodo se reduce, empeorando así la SNR.

En este capítulo se ha comprobado la ventaja de la cámara basada en SPI cuando se tiene un medio turbio entre el objeto y el detector. Sin embargo, en los sistemas que se han presentado se tiene acceso directo al objeto por la parte en la que se ilumina. Este escenario no se da en aplicaciones reales, de modo que en el siguiente capítulo se aborda una situación más real en la que el objeto está inmerso en un medio turbio. 


\section{Capítulo 4}

\section{Imagen de un objeto inmerso en tejido biológico}

La absorción y difusión de la radiación no ionizante que se produce en los tejidos biológicos constituye un problema básico en el campo de la biofotónica. Ambos fenómenos dificultan la visualización mediante métodos no invasivos de estructuras internas en presencia de tejidos. Tal como se discutió en el capítulo 2, las técnicas ópticas que proporcionan la mejor resolución espacial son aquellas que emplean fotones balísticos, aunque a costa de limitar la penetración en el tejido a una distancia máxima por debajo del TMFP $(0.5-1 \mathrm{~mm})$. Las técnicas basadas en los modelos de difusión, como la tomografía óptica difusa (DOT, Diffuse Optical Tomography), permiten penetraciones mucho mayores, pero con una resolución espacial mucho menor (del orden de milímetros) [96, 97]. En este capítulo se usa una técnica híbrida, es decir, se usan fotones balísticos y difusos, para conseguir la imagen de un objeto inmerso en un tejido biológico.

El esquema general del sistema propuesto se muestra en la figura 4.1. donde se pueden diferenciar dos partes: el sistema de iluminación y el sistema de detección. En el sistema de iluminación, una serie de patrones de luz son proyectados sobre el objeto con la ayuda de un modulador espacial de luz (SLM). En esta configuración, la luz debe atravesar un determinado espesor de medio difusor, de forma que buena parte de los fotones sufrirá scattering antes de llegar al objeto, y solo una pequeña componente balística mantendrá la estructura espacial de los patrones e interactuará con el objeto. Al ir variando los patrones, esa interacción hará fluctuar la intensidad transmitida por el objeto. Tal como se ha demostrado en el capítulo anterior, la presencia de una segunda capa difusora entre el objeto y el detector no impide la medida de esas fluctuaciones (siempre que se promedie un área lo suficientemente grande del patrón difuso que se detecta). Por tanto, en el sistema de detección 


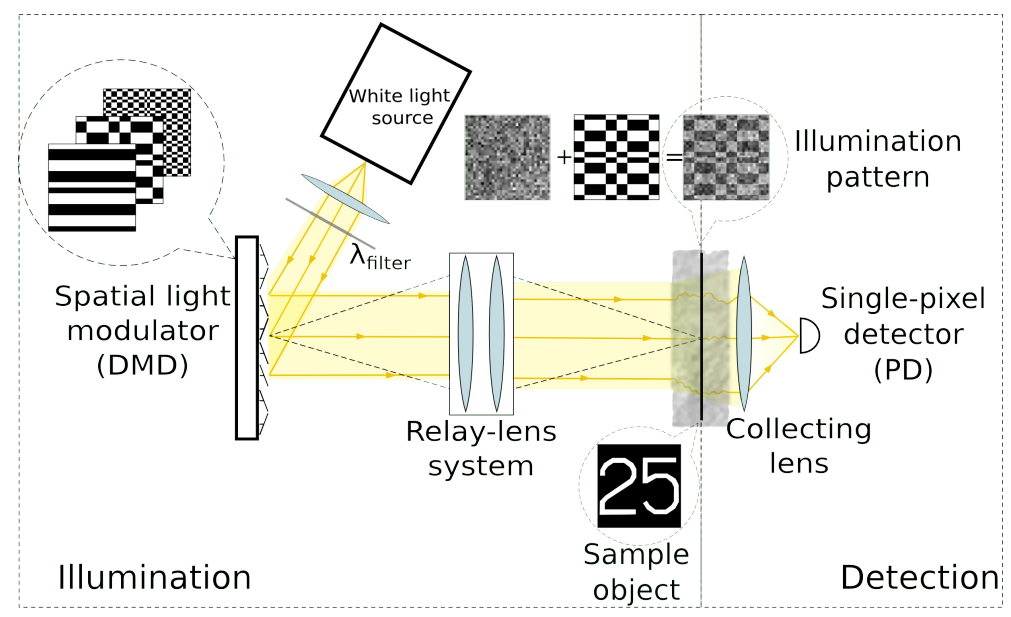

Figura 4.1 - Esquema del montaje experimental [98]. El círculo a trazos de la parte superior izquierda muestra ejemplos de los patrones de $\mathrm{W}-\mathrm{H}$ usados en la proyección. El círculo a trazos de la parte superior derecha muestra la superposición del fondo difuso y el patrón de luz formado por la luz balística. La contribución balística se ha realzado artificialmente para hacerla visible. El círculo a trazos en la parte inferior de la figura muestra el objeto de amplitud binaria usado, que es transparente en la parte blanca del dibujo.

no es necesaria la presencia de fotones balísticos.

En el montaje experimental, la fuente de luz es una lámpara de xenon de alta potencia (Modelo 66002, Oriel Corporation). El SLM utilizado en los experimentos de este capítulo es un DMD (Digital Micromirror Device), es decir, un dispositivo compuesto por una matriz de microespejos controlables electrónicamente que pueden modular el campo de luz incidente en amplitud (para más detalle véase el apéndice A). El modelo utilizado (DLP Discovery 4100, Texas Instruments) tiene un tamaño de píxel (microespejo) de 13.68 $\mu \mathrm{m}$ de lado. Los patrones modulados en la pantalla del DMD tienen una celda unidad que corresponde a $4 \times 4$ píxeles del DMD. Sin embargo, sobre el plano del objeto adquieren un tamaño mayor debido al aumento de $\times 2.7$, producido por el par de lentes que proyectan los patrones en el plano del objeto. Por tanto, el tamaño final de la celda unidad es $148 \mu \mathrm{m}$. El sistema de detección consiste en dos lentes condensadoras $(25.4 \mathrm{~mm}$ Diameter $\times 25.4 \mathrm{~mm}$ FL Condenser Lens, Edmund) que permiten que la mayor parte de luz transmitida entre en el área del sensor $\left(13 \mathrm{~mm}^{2}\right)$. En este caso el detector single-pixel es un fotodiodo (DET36A Si Biased Detector, Thorlabs). La señal detectada por el fotodiodo es digitalizada mediante un conversor analógico-digital (NI USB-6003, National Instruments) para poder procesar los valores de fotocorriente medidos y reconstruir la imagen del objeto. El proceso de medida 
a

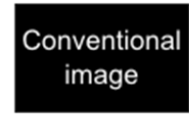

Single-pixel image
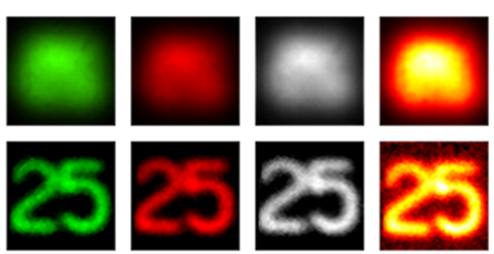

$\mathrm{b}$

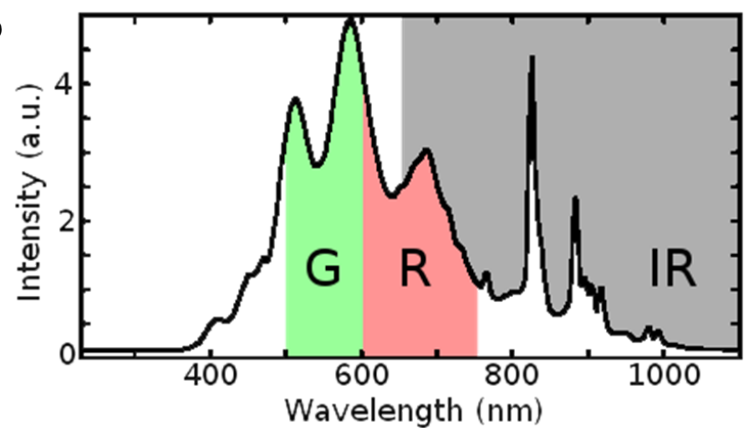

Figura 4.2 - a. Conjunto de imágenes capturadas por métodos convencionales (fila superior) y por la técnica single-pixel (fila inferior) cuando el objeto está situado entre dos capas difusoras comerciales. La última columna de imágenes corresponde a la reconstrucción con todo el espectro de la fuente (sin filtros), mientras que las demás imágenes pseudocoloreadas corresponden a las distintas bandas espectrales: verde $(G)$, roja (R) e infrarroja (IR), respectivamente. b. Espectro de potencia de la lámpara de Xe usada experimentalmente. Se usaron distintas combinaciones de filtros dicroicos para seleccionar diferentes bandas espectrales 98 .

se controla mediante un software programado en LabVIEW con scripts de Matlab.

Para comprobar la capacidad de la técnica propuesta, en primer lugar se recupera la imagen de un objeto binario cubierto por ambos lados con láminas difusoras holográficas comerciales (Edmund Optics \#T48-002 y \#T54-497). El objeto es una zona cuadrada, de $1 \mathrm{~cm}$ de lado, perteneciente a una tarjeta de resolución (NBS 1963A). Los patrones de amplitud proyectados sobre el objeto son una versión desplazada y reescalada de las matrices de WalshHadamard (véase apéndice B). El número total de patrones W-H utilizados es $N=4096$, de modo que la resolución de las imágenes reconstruidas es de $64 \times 64$ píxeles. Para ver qué se obtiene en un sistema convencional, se retira el sistema de detección de single-pixel, es decir, las lentes condensadoras y el fotodiodo; y en su lugar se añade un objetivo fotográfico (Nikkor $28 \mathrm{~mm}$ f/2.8, Nikon) que proyecta el plano del objeto sobre una cámara digital (UI3480CP-M, Imaging Development Systems). Tanto las imágenes obtenidas con la técnica single-pixel como las obtenidas por el sistema convencional se 

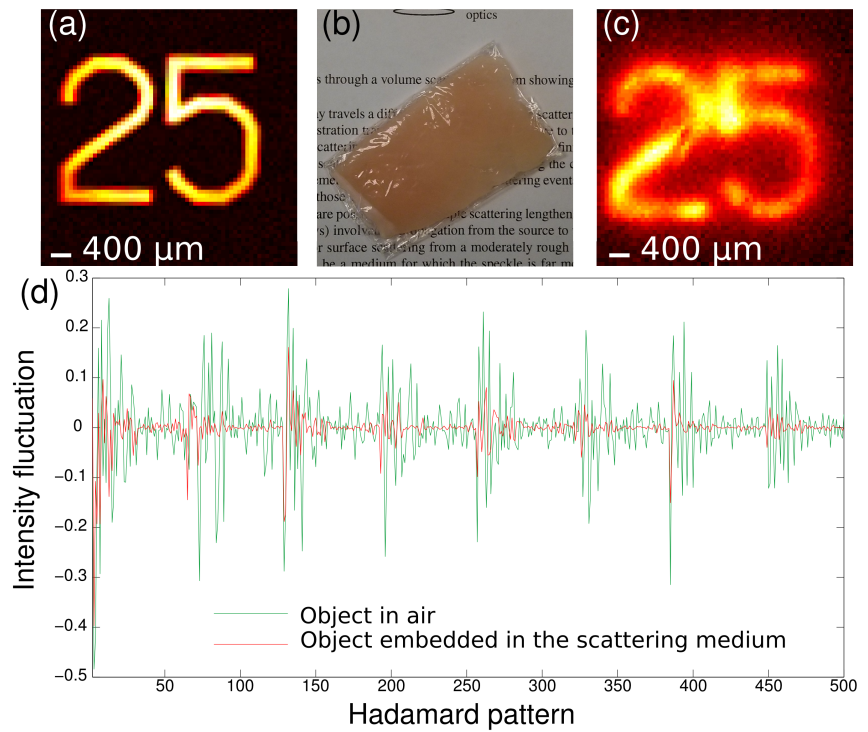

Figura 4.3 - Resultados experimentales para un objeto inmerso en tejido biológico [98]. a. Reconstrucción del objeto de interés por la técnica SPI sin difusores. b. Fotografía del medio difusor empleado experimentalmente: una capa de tejido de pechuga de pollo de $3 \mathrm{~mm}$ de espesor. c. Imagen reconstruida cuando el objeto se sitúa entre dos capas de tejido de aproximadamente $3 \mathrm{~mm}$ cada una. d. Fluctuaciones de intensidad normalizadas correspondientes a los 500 primeros patrones $\mathrm{W}-\mathrm{H}$ usados en la reconstrucción de las imágenes a y c.

muestran en la figura 4.2 a.

La figura 4.2 b muestra el espectro de la fuente de luz utilizada. Las bandas espectrales marcadas en la gráfica son los espectros de la fuente cuando se usan los filtros dicroicos: verde (Green Dichroic Filter \#46-139, Edmund), rojo (Red Dichroic Filter \#30-634, Edmund) e infrarrojo (Colored Glass Filter RDG665, Melles Griot). En la figura 4.2 a se puede observar que en las imágenes convencionales, aunque tienen mayor resolución espacial (el tamaño del píxel de la cámara es de $2.2 \mu m \times 2.2 \mu \mathrm{m}$ ), el halo originado por los difusores hace imposible recuperar la información espacial de la escena. Sin embargo, la técnica de imagen single-pixel permite recuperar la información del objeto. En esta figura se ha realizado un estudio del comportamiento espectral del difusor mediante los filtros dicroicos mencionados. El resultado es que, para las láminas difusoras empleadas, la técnica SPI permite recuperar la información del objeto en los tres canales con una calidad muy parecida.

Una vez se ha comprobado que la configuración experimental funciona para láminas difusoras, se intenta recuperar la imagen del objeto cubierto por un difusor en volumen. En este experimento, se ha elegido tejido de 

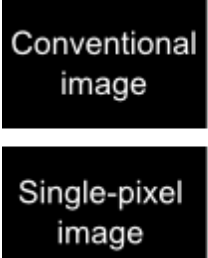
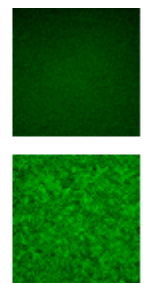
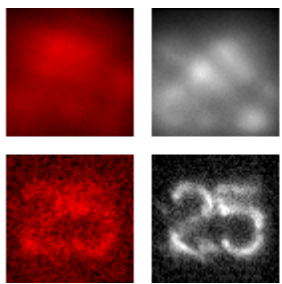

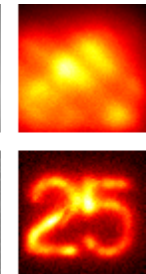

Figura 4.4 - Estudio espectral del tejido biológico utilizado [98]. Las imágenes pseudocoloreadas desde la columna izquierda hacia la derecha son imágenes reconstruidas con SPI para las bandas verde, roja e infraroja. La columna de la derecha corresponde a la imagen obtenida usando todo el espectro de la fuente en la iluminación.

pechuga de pollo como medio de scattering biológico. El resultado obtenido se muestra en la figura 4.3. La imagen recuperada por SPI del objeto cuando no hay medios difusores se muestra en la figura 4.3 a. El objeto se situa entre dos capas de tejido de pechuga de pollo de grosor $2.84 \mathrm{~mm}$ y $2.92 \mathrm{~mm}$, respectivamente. Ambas capas no han sido sometidas a procesos químicos o mecánicos, simplemente se han plastificado con una película transparente para fijarlas y manipularlas más fácilmente, tal como se muestra en la figura 4.3 b. La imagen recuperada por SPI se muestra en la figura 4.3 c. En la figura 4.3 d se representan las fluctuaciones de señal obtenida para los primeros 500 patrones de $\mathrm{W}-\mathrm{H}$ tanto del objeto inmerso en aire (señal verde) como del objeto inmerso en tejido biológico (señal roja). Tal como se observa, aunque la señal con difusor tiene valores más pequeños y una SNR menor, los valores medidos son proporcionales a los de la señal sin difusor. Estas fluctuaciones hacen posible la reconstrucción de la imagen del objeto de interés.

En el ejemplo anterior, los fotones están sometidos a scattering múltiple y absorción a medida que se adentran en el tejido. A diferencia de los resultados obtenidos con láminas difusoras holográficas, ahora la imagen resultante varía a lo largo del espectro. En este caso, el parámetro de scattering reducido $\left(\mu_{s}^{\prime}\right.$, inversa del TMFP) disminuye suavemente al aumentar la longitud de onda utilizada [99], lo que produce una degradación progresiva de la imagen recuperada para las longitudes de onda más cortas del espectro visible. Además, el tejido es algo más absorbente para longitudes de onda en la banda cromática verde, como se verá a continuación. Los resultados se muestran en la figura 4.4. En las imágenes reconstruidas se observa una clara mejora a partir de la longitud de onda de $650 \mathrm{~nm}$ aproximadamente, coincidiendo con la ventana óptica del tejido $(650-1350 \mathrm{~nm})$, donde la luz alcanza su máxima profundidad de penetración [53, 100].

Para el grosor milimétrico de tejido que se está considerando en el expe- 


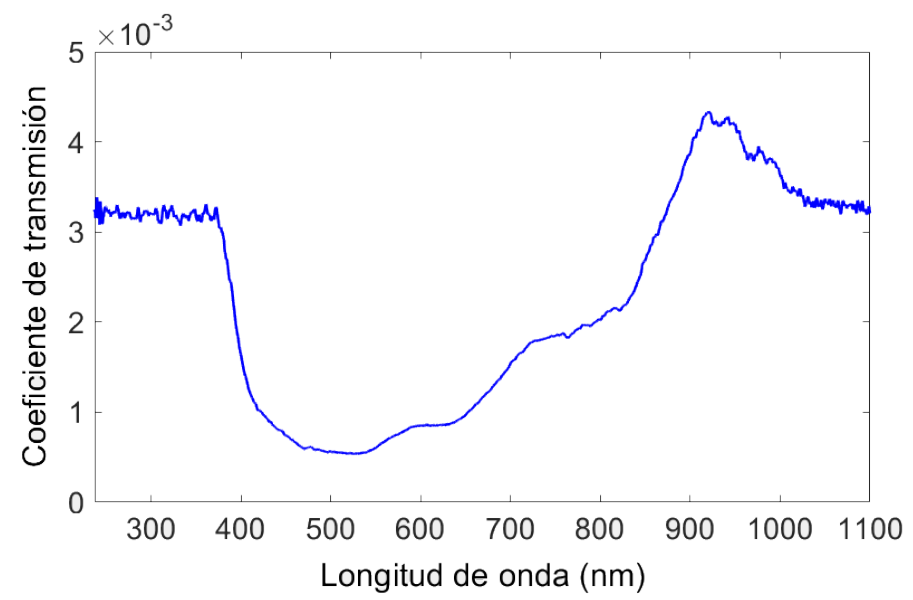

Figura 4.5 - Espectro de transmisión del tejido biológico usado en este capítulo. El coeficiente de transmisión es el cociente de la intensidad de la radiación transmitida e incidente.

rimento, el scattering domina sobre la absorción (lo que significa que un haz colimado que incide sobre el tejido es fundamentalmente difundido), aunque en los resultados experimentales hay también algo de absorción. Para comprobar esto último, se realiza un cálculo de la transmisión de la muestra. La figura 4.5 se obtiene a partir del espectro de la fuente y del espectro medido a través de una muestra de tejido de pechuga de pollo. El espectrómetro de fibra es un BLACK-Comet de StellarNet Inc, con un rango espectral UVVIS-NIR.

Como puede observarse en la figura 4.5, a partir de $600 \mathrm{~nm}$ aproximadamente, la transmisión aumenta hasta alcanzar un máximo sobre los $900 \mathrm{~nm}$. Esto coincide con los resultados experimentales obtenidos en las imágenes reconstruidas y también con la bibliografía. Por tanto, la mejor radiación para penetrar en el tejido es la infraroja cercana (NIR).

La teoría de Compressive Sensing puede ser aplicada también en este montaje experimental. Con el método de CS se puede reducir considerablemente el tiempo de medida del objeto oculto en un medio de scattering. En la figura 4.6 a se muestra un análisis de la calidad de la imagen recuperada. En la gráfica está representado el valor de PSNR ${ }^{1}$ obtenido para cada imagen con respecto a la razón de compresión utilizada. Para ello, se han usado las láminas difusoras holográficas como medio difusor que envuelve el objeto y se ha iluminado el objeto con todo el espectro de la fuente. Tal como

\footnotetext{
${ }^{1}$ Para calcular el valor de PSNR de las imágenes, primero se debe calcular el MSE de cada una de ellas con respecto a la imagen de mayor calidad, tal como se describe en el capítulo 3, sección 3.1.
} 
a

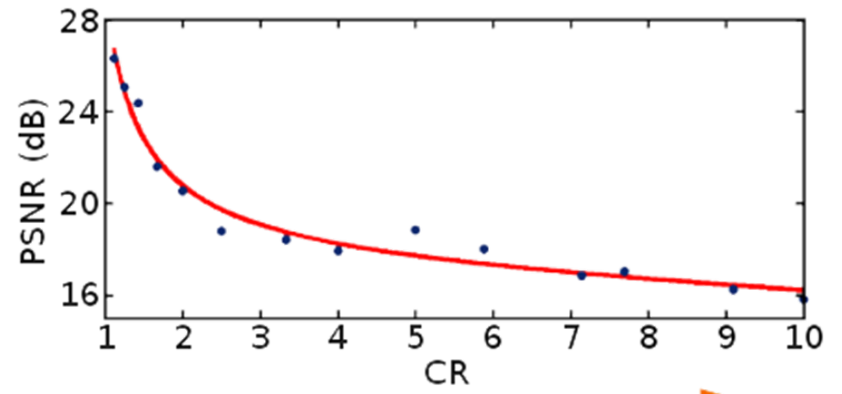

b

INCREASING COMPRESSION RATIO

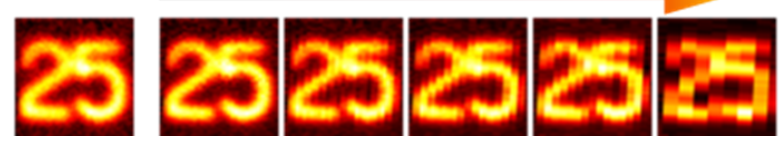

Figura 4.6 - Aplicación de Compressive Sensing 98. a. Representación de la calidad de las imágenes reconstruidas, mediante los valores del PSNR en dB, en función de la razón de compresión (CR) aplicada. b. Comparación entre la imagen de referencia (sin compresión) y cinco imágenes con distintos valores de CR. De izquierda a derecha: imagen de referencia, $C R=2, C R=2.5$, $C R=3.3, C R=5$, y $C R=10$.

puede apreciarse en la figura $4.6 \mathrm{~b}$, la imagen reconstruida proyectando sólo la mitad de las funciones de la base $(C R=2)$ tiene una calidad aceptable $(\mathrm{PSNR}>20 \mathrm{~dB})$.

Cada medio turbio tiene unas propiedades distintas de scattering. Para caracterizar de un modo sencillo los difusores utilizados en este capítulo se ha realizado un cálculo del porcentaje de fotones balísticos que pasan a través de las capas difusoras e inciden sobre el objeto. La figura 4.7 muestra el montaje experimental usado para obtener este porcentaje.

El sistema consiste en un haz de luz colimado que pasa por dos diafragmas de apertura conocida $(\emptyset=4 \mathrm{~mm})$, D1 y D2 en la figura 4.7. Después del diafragma D2 se detecta el haz de salida con un detector single-pixel, en este caso un medidor de potencia, Coherent FM-GS Field Master con un sensor de alta sensibilidad. El cálculo de los fotones balísticos se realiza en dos pasos, correspondientes a los esquemas a y b de la figura 4.7. En un primer paso se mide la potencia total del haz luminoso colimado después del segundo diafragma. En el segundo paso se añade el medio difusor entre los dos diafragmas. Así, la potencia detectada disminuye respecto a la medida en la primera etapa. Cuando la luz atraviesa el medio difusor, los fotones sufren el efecto del scattering y el haz a la salida del medio se ve ensanchado. Al llegar al segundo diafragma, éste elimina prácticamente todos los fotones difusos, que han perdido la dirección inicial, quedando únicamente los fotones que 


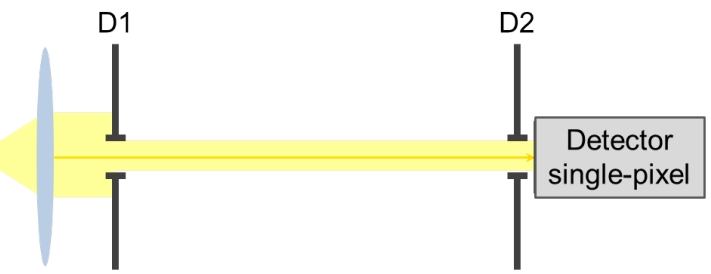

b Fuente de luz

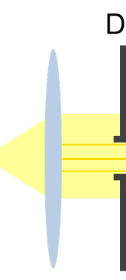

D1

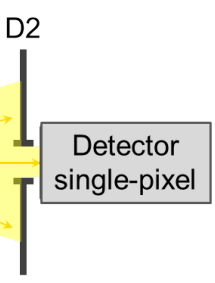

Medio de

scattering

Figura 4.7 - Esquema experimental para el cálculo del porcentaje de fotones balísticos que pasan a través del difusor. a. Detección de la potencia de luz incidente. b. Detección de la potencia de luz transmitida.

se han desviado poco o nada, es decir, los fotones snake y balísticos. Éstos fotones son los que utiliza la cámara single-pixel para muestrear el objeto, es decir, son los responsables de proyectar los patrones Walsh-Hadamard sobre el objeto.

El porcentaje de fotones balísticos y snake transmitido por el medio difusor se puede calcular como el cociente de las potencias ópticas medidas en los dos pasos antes descritos. Los fotones detectados por el sensor en el segundo paso son los que se han desviado un ángulo menor que el delimitado geométricamente por dos parámetros: la distancia del medio difusor al segundo diafragma y el tamaño del diafragma D2. Estos parámetros se eligen para reproducir las condiciones del experimento de medida. Para ello, el tamaño del segundo diafragma $D 2$ y la distancia entre él y el medio difusor debe determinar un ángulo igual al fijado en cada experimento por la celda unidad en el plano del objeto y la distancia de éste al difusor. En la tabla 4.1 se muestra el porcentaje calculado de fotones balísticos y snake que inciden sobre el objeto. Los números 1 y 2 hacen referencia a los diferentes difusores utilizados en los montajes experimentales.

La importancia del porcentaje de fotones balísticos y snake que atraviesan el medio de scattering radica en que la técnica SPI requiere de la existencia de una componente balística en el sistema de iluminación. Como se ha dicho con anterioridad, esto permite que el objeto sea efectivamente muestreado por los patrones W-H. Sin embargo, la existencia de una componente balística 
Capítulo 4. Imagen de un objeto inmerso en tejido biológico

\begin{tabular}{|c|c|}
\hline Medio de scattering & \% fotones balísticos + snake \\
\hline \hline Lámina difusora holográfica 1 & 1 \\
\hline Lámina difusora holográfica 2 & 1.48 \\
\hline Capa de pechuga de pollo 1 $(2.84 \mathrm{~mm})$ & 0.059 \\
\hline Capa de pechuga de pollo $2(2.92 \mathrm{~mm})$ & 0.058 \\
\hline
\end{tabular}

Tabla 4.1 - Tabla del porcentaje calculado de fotones balísticos y snake que atraviesan cada difusor usado en este capítulo. Para el tejido de pechuga de pollo se indica el grosor de la capa entre paréntesis.

después del segundo difusor, en el sistema de detección, no es importante, ya que la técnica SPI es igualmente capaz de reconstruir la imagen únicamente con fotones difusos, tal como se ha demostrado en el capítulo 3.

La técnica de imagen single-pixel se caracteriza por emplear un sensor sin resolución espacial, y la sensibilidad de éste juega un papel importante en la capacidad para reconstruir imágenes a través de medios de scattering. A continuación, se realiza un estudio de la calidad de la imagen a medida que se disminuye la intensidad de luz incidente. Como indicador cuantitativo de la calidad de la imagen se usará el valor del PSNR de las imágenes reconstruidas. En la figura 4.8 se representa la gráfica resultante del valor de PSNR obtenido variando la intensidad (irradiancia) de luz con la que se ilumina el objeto, es decir, variando la cantidad de fotones en la iluminación. El esquema experimental utilizado para este estudio es el de la figura 4.1. Aquí, se ha utilizado como medio difusor un material similar al vidrio esmerilado, pero con una superficie recubierta de blanco para difuminar la luz de manera uniforme (Edmund \#43-718, mostrado en la figura 4.9p. El ancho de banda de la luz incidente se ha reducido mediante un filtro que deja pasar luz verde (Semrock FF01-559/34, con una longitud de onda central de $559 \mathrm{~nm}$ y un ancho de banda de $34 \mathrm{~nm}$ ). El control de la intensidad de luz incidente se ha conseguido mediante la combinación de filtros grises y dos polarizadores lineales con distintas orientaciones (lo que permite controlar la intensidad de acuerdo con la ley de Malus).

Los niveles de iluminación que aparecen en la gráfica (potencia por unidad de superficie) se corresponden a los que inciden en el sistema formado por el difusor y el objeto. De estos valores de irradiancia sólo el porcentaje de la componente balística que atraviesa el medio difusor llega al objeto con una estructura espacial definida. El cálculo de este porcentaje se ha realizado siguiendo el mismo procedimiento que los resultados de la tabla 4.1 y en este caso se ha obtenido un valor de $0.018 \%$.

Cuando el PSNR baja de un cierto valor umbral, se entiende que la calidad 


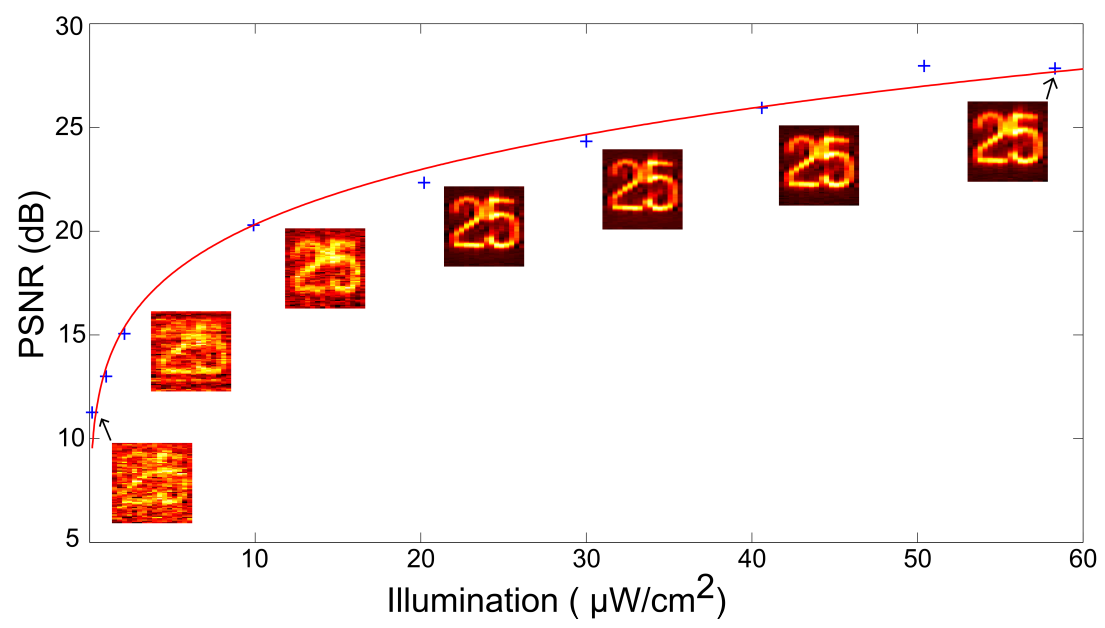

Figura 4.8 - Efecto de la disminución de la intensidad de la luz incidente. PSNR de varias imágenes reconstruidas con distintos niveles de iluminación (la imagen de referencia utilizada es la medida con mayor nivel de iluminación). Por debajo de $10^{-5} \mathrm{~W} / \mathrm{cm}^{2}$ de irradiancia, la reducción en la calidad de la imagen es evidente $(\mathrm{PSNR}<20 \mathrm{~dB})$. La gráfica incluye algunas de las imágenes reconstruidas (de $64 \times 64$ píxeles) para ilustrar la evolución de la calidad de imagen.

de la imagen se ha degradado de forma considerable. En el caso presentado en la figura 4.8, este umbral es $20 \mathrm{~dB}$. Para intensidades de unas cuantas decenas de $\mu W / \mathrm{cm}^{2}$, el PSNR corresponde a imágenes de calidad aceptable (PSNR > $20 \mathrm{~dB})$. La magnitud medida con el detector viene expresada en $W / \mathrm{cm}^{2}$. La energía de un fotón se expresa como: $E=h c / \lambda$, de modo que para un fotón de longitud de onda $\lambda=0.559 \mu \mathrm{m}$, su energía equivale $\mathrm{a}^{2}$ $E=2.22 \mathrm{eV}=3.56 \times 10^{-19} \mathrm{~J}$. La energía medida por unidad de área y tiempo $\left(\mathrm{J} / \mathrm{cm}^{2} \mathrm{~s}\right)$ dividida por la energía de un fotón, proporciona el flujo de fotones. Sin embargo, como se ha dicho anteriormente, el valor de irradiancia relevante no es el medido sino el correspondiente a la luz estructurada que llega al objeto. Aplicando el porcentaje de la componente balística después del difusor $(0.018 \%)$ a la irradiancia medida correspondiente a la imagen con PSNR más cercano al valor umbral $\left(9.9 \mu \mathrm{W} / \mathrm{cm}^{2}\right)$, se obtiene que la fracción de luz estructurada contiene $5 \times 10^{9}$ fotones $/ \mathrm{cm}^{2} \mathrm{~s}$. Por tanto, se puede decir que el método single-pixel empleado obtiene imágenes de calidad aceptable cuando muestrea el objeto con cantidades del orden de $10^{9}-10^{10}$ fotones $/ \mathrm{cm}^{2}$ s, con el detector utilizado.

\footnotetext{
${ }^{2}$ Constante de Planck: $h=4.13566733 \times 10^{-15} \mathrm{eV} \cdot \mathrm{s}$; velocidad de la luz: $c \approx 3 \times 10^{8} \mathrm{~m} / \mathrm{s}$; $1 \mathrm{eV}=1.602177 \times 10^{-19} \mathrm{~J}$.
} 
Capítulo 4. Imagen de un objeto inmerso en tejido biológico

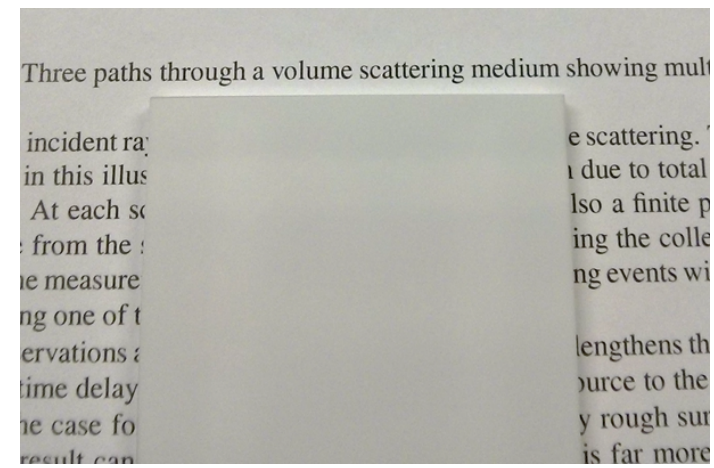

Figura 4.9 - Difusor utilizado para el estudio del PSNR con el nivel de iluminación.

A medida que el nivel de iluminación disminuye, las fluctuaciones aleatorias de la señal detectada aumentan, y el ruido electrónico del detector empieza a enmascarar la señal real. En ese caso, se obtiene un valor muy inexacto de los coeficientes de reconstrucción de la imagen y, por tanto, la calidad de la imagen reconstruida disminuye. La importancia de los resultados de la gráfica de la figura 4.8 toma relevancia cuando se comparan las intensidades utilizadas con las que se usan habitualmente para conseguir imagen a través de tejido biológico por medios ópticos. Por ejemplo, el umbral de daño en la piel se corresponde con una irradiancia de $0.2 \mathrm{~W} / \mathrm{cm}^{2}$ para las condiciones de trabajo empleadas aquí con una fuente de onda contínua [101]. Éste valor es tres órdenes de magnitud más grande que la intensidad máxima aplicada en el estudio de la figura $4.8\left(120.8 \mu \mathrm{W} / \mathrm{cm}^{2}\right)$.

Como se acaba de ver, el método SPI funciona con un número de fotones muy bajo (tres órdenes de magnitud por debajo del umbral de daño en tejido) lo que hace de esta técnica una buena candidata para entornos de imagen biomédica. El inconveniente de un sistema de imagen en transiluminación como el que se ha presentado en este capítulo es que no es útil para aplicaciones en las que la luz no llega a atravesar el medio. Un sistema para aplicar la técnica SPI que trabaje en reflexión tendría un uso más generalizado y sería más apropiado para su aplicación en imagen biomédica. El siguiente capítulo aborda este problema con una aplicación biológica real. 


\section{Capítulo 5}

\section{Sistema single-pixel para aplicaciones oftálmicas: imagen de la retina de un ojo sano y de un ojo artificial con catarata}

El ojo humano constituye nuestro sistema formador de imágenes. Un ojo adulto tiene una forma aproximadamente esférica con un diámetro de 2.4 cm [102. La luz que entra en el ojo es en primer lugar refractada por la córnea, que constituye una fina capa transparente; detrás de la córnea se situa la cámara anterior, llena de un líquido llamado humor acuoso; a continuación el iris, un esfínter muscular con un agujero central cuyo tamaño depende del nivel de contracción del músculo, que actúa como un diafragma. La pupila es la apertura variable en el centro del iris, su tamaño controla la iluminación que llega a la retina y limita los rayos de luz que entran en el ojo, afectando así a la calidad de la imagen sobre la retina. El diámetro de la pupila puede variar desde un tamaño menor de $2 \mathrm{~mm}$ en condiciones de luz muy brillante hasta más de $8 \mathrm{~mm}$ en condiciones de oscuridad. Una vez la luz se ha refractado en la córnea y ha atravesado la pupila, una lente llamada cristalino forma la imagen sobre la retina. El cristalino puede modificar su forma para cambiar su potencia óptica y, por tanto, la del ojo. Esta modificación es la base del mecanismo de acomodación, que permite al ojo enfocar las imágenes en la retina. Entre el iris y el cristalino está la cámara posterior llena de humor acuoso y, entre el cristalino y la retina, la luz atraviesa un gel transparente llamado humor vítreo. La retina humana tiene una zona central llamada fóvea, en la cual los fotorreceptores están densamente empaquetados para proporcionar una alta resolución espacial. Los objetos de una escena pueden estar a distancias diferentes respecto al ojo, por ello, los 


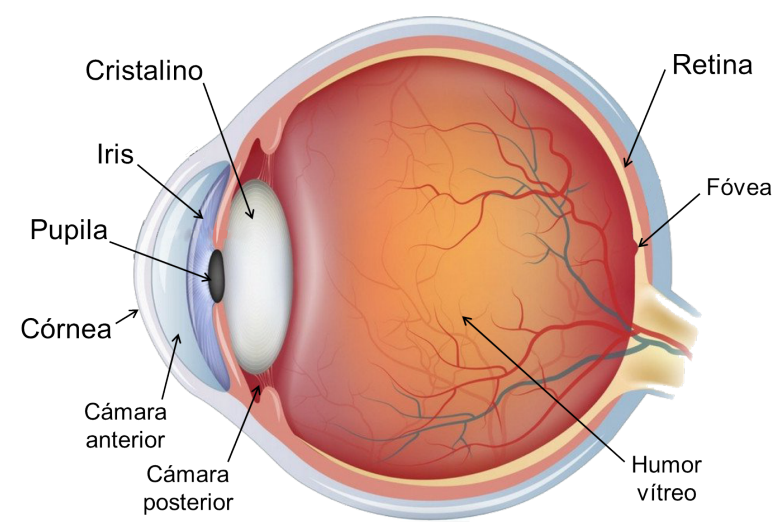

Figura 5.1 - Dibujo de la sección del ojo humano donde aparecen señaladas las partes mencionadas en el texto. Adaptado de 103.

ojos se mueven continuamente para fijar los detalles deseados en la fóvea. Las partes periféricas de la retina tienen una resolución espacial más baja que la fóvea, pero son importantes porque están especializadas en la detección de movimiento y son necesarias para localizar objetos en el campo visual. En la figura 5.1 se puede ver un dibujo de la sección de un ojo humano con sus principales partes señaladas.

Las estructuras del ojo humano son tan complejas y precisas que en su momento hasta Charles Darwin descartó la idea de que fueran fruto de la evolución. Sin embargo, el ojo humano es el resultado de la evolución de una simple zona sensible a la luz compuesta de fotorreceptores. Este ojo primitivo funcionaba mediante mecanismos capaces de transformar la energía óptica de la luz que incidía sobre ellos en energía eléctrica, igual que el funcionamiento de un detector single-pixel. Curiosamente, en la naturaleza existe un género de algas unicelulares, llamado Euglena, que cuenta con este mecanismo para guiarse hacia su alimento. El paso definitivo en la evolución del ojo fue el desarrollo del cristalino. La lente que constituye el cristalino es la que hoy en día se opera para corregir problemas de cataratas. La catarata en un ojo comienza por formar cúmulos que nublan una parte del cristalino y que pueden crecer dejándolo opaco. Ésta es una de las alteraciones oculares más comunes, la causa más frecuente de pérdida de visión en personas mayores de 40 años y la causa principal de ceguera en el mundo.

Muchas enfermedades oculares se diagnostican observando el fondo del ojo, donde se encuentra la retina. Por esta razón existen varios sistemas dedicados a su observación. El oftalmoscopio es uno de los más usados por su sencillez y su bajo coste. Las cámaras modernas de fondo de ojo (retinógrafos) usan la tecnología CCD o CMOS para obtener una imagen, o un vídeo, 
de millones de píxeles de resolución de una parte de la retina 104. Iluminando de forma homogénea el área de la retina que se quiere observar, se pueden obtener imágenes de gran calidad. Si las aberraciones que introduce el ojo se corrigen mediante óptica adaptativa, es posible capturar los detalles de estructuras como el mosaico de fotorreceptores [105, 106]. En un oftalmoscopio de barrido láser (SLO, Scanning Laser Ophthalmoscope) un punto de luz escanea la zona de la retina que se quiere observar [107] y la intensidad reflejada de cada punto se detecta con un sensor sin resolución espacial, como un tubo fotomultiplicador (PMT) [108 o un fotodiodo de avalancha (APD) [109]. Más recientemente, se han desarrollado oftalmoscopios digitales usando dispositivos DMD para escanear líneas de luz sobre la retina y formar la imagen sobre sensores bidimensionales como una cámara convencional [110,111]. Todos los oftalmoscopios descritos anteriormente son dispositivos de última generación y se usan ampliamente como instrumentos médicos para controlar el estado y la alteración del fondo de ojo. Sin embargo, la presencia de catarata en el cristalino del ojo dificulta la obtención de la imagen de la retina con cualquiera de los sistemas anteriores.

En el ámbito de esta tesis la catarata puede tratarse como un medio turbio y, tal como se ha demostrado en los capítulos anteriores, la técnica single-pixel presenta ciertas ventajas cuando se trabaja a través de estos medios. Por esta razón el trabajo presentado en este capítulo tiene como objetivo estudiar la posibilidad de obtener la imagen de la retina de un ojo con catarata mediante la técnica single-pixel.

\subsection{Imagen single-pixel en configuración de reflexión en un ojo artificial}

En primer lugar se ha realizado un experimento para recuperar la imagen de la retina de un ojo artificial con la técnica SPI usando una configuración en reflexión. Hasta ahora se ha demostrado la eficacia de la técnica SPI para obtener la imagen por transmisión de un objeto inmerso en un medio de scattering. El montaje en reflexión permite su aplicación en multitud de situaciones reales, pero la captura de la luz procedente del objeto es más compleja. Por ello, el primer paso es obtener imagen del objeto sin difusor.

El esquema experimental se muestra en la figura 5.2. El sistema óptico combina iluminación estructurada con detección single-pixel en dos caminos de luz separados, basados en una configuración de doble paso [112]. En la etapa de iluminación un haz de luz blanca colimado ilumina la pantalla del DMD, donde se codifica la secuencia de patrones microestructurados de 


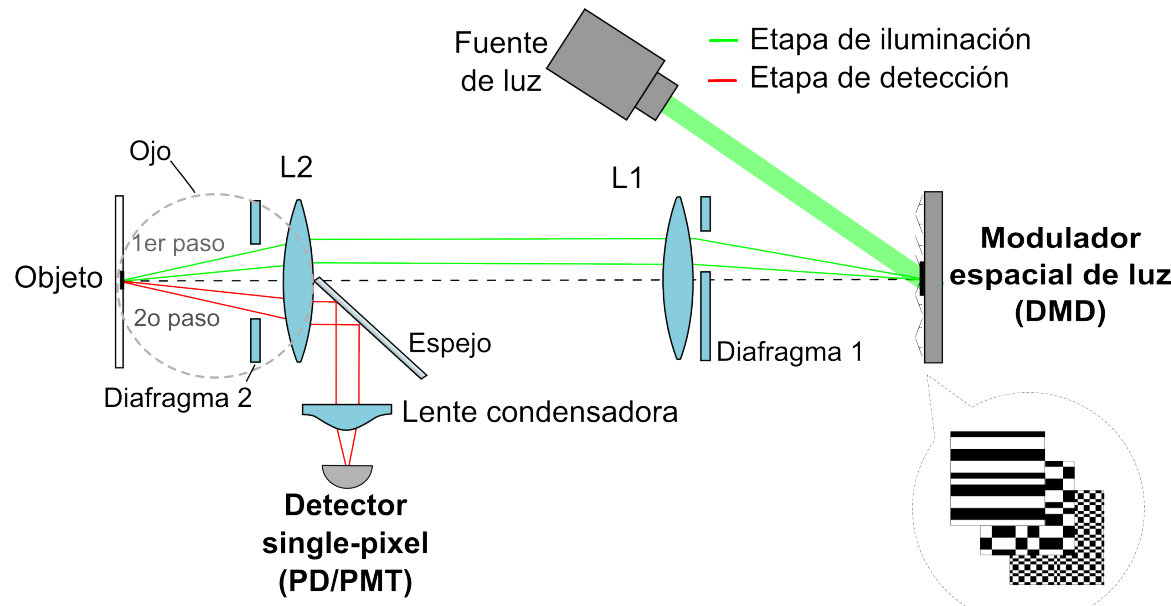

Figura 5.2 - Esquema óptico de doble paso. Las líneas verdes marcan el camino de la luz en la etapa de iluminación: una serie de patrones de luz codificados en el DMD son proyectados, mediante la mitad de la lente L2, sobre el objeto. Las líneas rojas destacan el camino que sigue la luz en la etapa de detección: la luz de backscattering del objeto pasa a través de la otra mitad de la lente L2 y es detectada por un fotodiodo o tubo fotomultiplicador.

muestreo. Un sistema óptico, constituido por las lentes L1 y L2 en una configuración 4-f, proyecta los patrones de luz sobre el objeto. Un diafragma y un espejo localizado antes de que la luz pase por las lentes L1 y L2, respectivamente, obligan a que la luz viaje sólo por la mitad de la lente L2. En la etapa de detección, el espejo selecciona la luz difundida (luz de backscattering) y/o reflejada por el objeto que pasa únicamente por la otra mitad de la lente L2, evitando así que se transmita luz que no proviene del objeto, como reflejos de las lentes. El haz de luz reflejado en el espejo se colecta mediante una lente condensadora que focaliza en el área del detector single-pixel.

El modelo de ojo artificial utilizado es muy simple, consta de un menisco convergente (lente plano-convexa Edmund Optics 49-849) para focalizar la luz e introducir aberración esférica, como la que tiene el ojo humano. Un diafragma actúa como iris con una apertura entre 12 y $18 \mathrm{~mm}$ (en el experimento se ha usado $15 \mathrm{~mm}$ ) situado a $1 \mathrm{~cm}$ de la lente. Una pantalla a la distancia focal de la lente sirve para simular la retina del ojo. Con una distancia focal de unos $50 \mathrm{~mm}$ para la lente convergente se crea un ojo artificial, que posee un tamaño doble del de un ojo humano real, aproximadamente. En la figura 5.2 se muestra el ojo artificial formado por la lente L2, diafragma 2 y objeto. En este modelo de ojo, si un medio difusor se coloca sobre el iris, se simula la posición de un cristalino cataratoso.

La fuente de luz utilizada en el experimento es una lámpara de plasma 


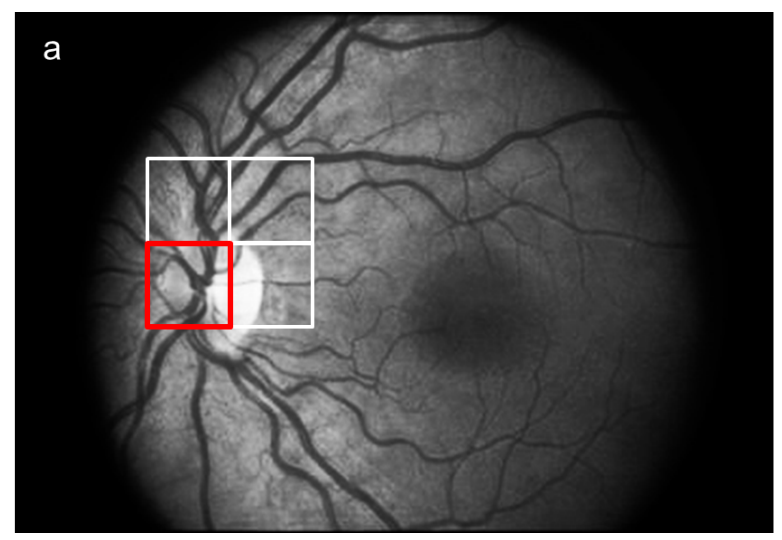

b

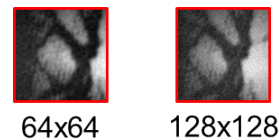

C

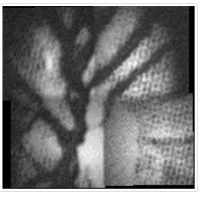

Figura 5.3 - Imágenes obtenidas con el sistema óptico mostrado en la figura 5.2 . El objeto utilizado, una imagen en niveles de gris de la retina de un ojo normal [113] impresa en papel, se muestra en a. El cuadrado rojo y los blancos representan las zonas del objeto de las que se ha obtenido imagen. b. Imágenes reconstruidas con SPI sin medio difusor a dos resoluciones distintas, $64 \times 64$ y $128 \times 128$ píxeles. c. Mosaico de las áreas marcadas en blanco y rojo de la imagen a. Cada imagen por separado tiene $128 \times 128$ píxeles de resolución.

de estado sólido con una fibra óptica (HPLS200 Series Emission Spectrum, Thorlabs). El modulador espacial de luz es un DMD con un tamaño de píxel (microespejo) de $10.8 \mu \mathrm{m}$ de lado (DLP Discovery 4100, Texas Instruments). El área usada para codificar los patrones de muestreo se corresponde con $512 \times 512$ píxeles de la pantalla del DMD. Los patrones utilizados son funciones binarias de la base $\mathrm{W}-\mathrm{H}$ con una resolución de $64 \times 64$ píxeles (cada píxel del patrón está formado por $8 \times 8$ microespejos del DMD) en la mayoría de casos. Con esta resolución de los patrones, la base completa está formada por $N=4096$ patrones distintos. Una lente delgada acromática (L1) con distancia focal $f_{1}=100 \mathrm{~mm}$ y una lente plano-convexa (L2) de distancia focal $f_{2}=50.8 \mathrm{~mm}$ proyectan los patrones de la pantalla del DMD sobre el plano del objeto con una magnificación lateral de 0.5. La lente condensadora (25.4 mm Diameter $\times 25.4 \mathrm{~mm}$ FL Condenser Lens, Edmund) recoge la luz y la focaliza en el área $\left(13 \mathrm{~mm}^{2}\right)$ del fotodiodo (PDA36A-EC Si Amplified Detector, 350-1100 nm, Thorlabs). Un conversor analógico-digital (NI USB-6003, National Instruments) digitaliza la señal proporcionada por el fotodiodo. El detector convencional bidimensional es una cámara IDS UI-1540SE-M-GL con $1280 \times 1024$ píxeles. El software utilizado para controlar el proceso de medida y la reconstrucción de las imágenes se ha desarrollado empleando LabVIEW y Matlab.

Para simular la retina de un ojo, se ha elegido un objeto con muy baja reflectividad. Se ha impreso en papel la imagen de una retina normal en escala 
de grises y a tamaño doble de la de un ojo real. De este modo se ajusta a las dimensiones del ojo artificial que se ha empleado. En la figura 5.3 a se muestra la imagen de retina empleada. El tamaño de las imágenes reconstruidas con el sistema de la figura 5.2 es de $2.8 \mathrm{~mm} \times 2.8 \mathrm{~mm}$ aproximadamente, con lo que sólo se puede reconstruir un área pequeña del objeto. La solución a este posible inconveniente es realizar un "image stitching", es decir, construir una imagen de mayor tamaño combinando en mosaico un conjunto de imágenes de menor tamaño. La figura 5.3 c muestra un stitching de cuatro imágenes recuperadas con la técnica SPI en las posiciones marcadas en blanco sobre la imagen 5.3 a. El programa utilizado para realizar el stitching automático es ImageJ (Fiji), un software libre para el procesado y análisis de imágenes, ampliamente usado en el ámbito de la biomedicina [114].

Con los resultados de la figura 5.3 queda demostrado el buen funcionamiento del sistema de imagen single-pixel en una configuración en reflexión y sin la presencia de medios de scattering. Ahora bien, en este experimento se ha usado un modelo de ojo artificial, con lo que no se han tenido en cuenta los inconvenientes de un ojo vivo, tales como el movimiento involuntario del ojo, la molestia que los pacientes puedan sentir al realizar las imágenes, etc.

\subsection{Imagen single-pixel en configuración de reflexión en un ojo humano in vivo}

Fruto de la colaboración con los investigadores del Laboratorio de Óptica de la Universidad de Murcia (LOUM) fue llevar a cabo el experimento con ojos humanos in vivo. El sistema óptico diseñado para ello se muestra esquemáticamente en la figura 5.4.

La lámpara de luz utilizada para iluminar homogéneamente el DMD es una lámpara xenon de amplio espectro (Hamamatsu L7810-02) que tiene filtrada la radiación ultravioleta (UV). El DMD utilizado (Vialux V7001, controller board V4395, chipset DLP 4100) tiene un tamaño de píxel de 13.68 $\mu \mathrm{m}$ de lado y una matriz de microespejos de $1024 \times 768$. En este experimento también se usan solamente $512 \times 512$ píxeles del centro de la pantalla del DMD y los patrones utilizados para muestrear la retina son los de la base Walsh-Hadamard. El proceso de generación de patrones en la pantalla del DMD comienza con un software desarrollado en $C++$ que envía los patrones al DMD mediante una conexión USB 3.0 y se almacenan en la memoria del DMD. Para conseguir la velocidad máxima en el envío de patrones (22.7 $\mathrm{kHz}$ ) es esencial precargar las imágenes, es decir, los patrones que se van a generar en la pantalla. Los patrones binarios son proyectados a través de las 


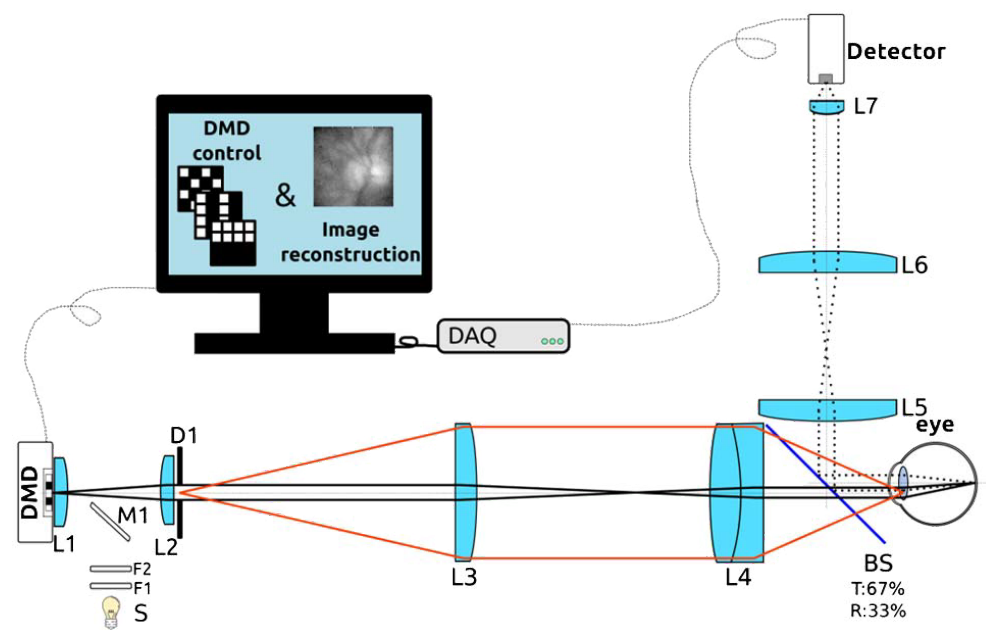

Figura 5.4 - Esquema experimental del oftalmoscopio single-pixel 115.

lentes L1, L2, L3, L4 y la óptica ocular sobre la retina cubriendo un área de 15 grados de campo visual, aproximadamente. La intensidad reflejada por la retina se mide con un tubo fotomultiplicador (SIPM, Excelitas Lynx A33-050-T1-A) a través de las lentes: cristalino, L5, L6 y L7. Estas acciones están sincronizadas, de modo que una señal de trigger del DMD proporciona la información para que el detector mida la intensidad en cada patrón. El diafragma D1 se sitúa centrado justo detrás de la lente L2 y mediante el telescopio formado por L3 y L4 se crea la imagen de este diafragma sobre la pupila del ojo, de modo que definirá el punto de entrada de la luz en el ojo. Esta configuración disminuye el efecto de las aberraciones en la imagen del patrón y también minimiza los efectos de reflejos y backscattering debido al pequeño punto de entrada de luz en el ojo.

Los datos de fotocorriente del tubo fotomultiplicador son transferidos al ordenador (PC i5-4590, quad-core, $3.3 \mathrm{GHz}, 8 \mathrm{~GB} \mathrm{RAM}$ ) mediante un conversor analógico-digital (National Instruments PCIe-6361, tasa de muestreo $2 \mathrm{MS} / \mathrm{s}$ ). Esta alta tasa de muestreo del conversor analógico-digital permite realizar 84 medidas/patrón. Los valores de intensidad medidos para cada patrón son promediados y el valor resultante se guarda como el coeficiente del correspondiente patrón. El sistema óptico junto con el dispositivo de control es capaz de recuperar la imagen y transmitir vídeo en directo. En la tabla 5.1 se muestra un resumen de los valores de la velocidad de adquisición medida en imágenes por segundo (FPS, Frames Per Second) conseguidos en la adquisición y reconstrucción de las imágenes operando en modo vídeo (realtime). Los cálculos matemáticos para reconstruir una imagen son sencillos, sin embargo, la velocidad de vídeo disminuye rápidamente con el aumento de 
resolución, no sólo debido al aumento del número de patrones a medir, sino también debido a la gran cantidad de datos que deben procesarse. Además, en la tabla 5.1 se compara la velocidad de vídeo obtenida en este experimento con la obtenida por otros autores usando la misma técnica de imagen, aunque no estén dedicadas al campo de imagen retiniana.

\begin{tabular}{|l|c|c|c|c|}
\hline$N \times N\left(N^{\prime}\right)$ & $T_{\text {imagen }}(\mathrm{s})$ & $F P S_{\text {teoria }}$ & $F P S_{\text {experimental }}$ & $F P S_{\text {otros }}$ \\
\hline \hline $32 \times 32(2048)$ & 0.09 & 11.10 & 11.10 & $10^{(1)}$ \\
\hline $64 \times 64(8192)$ & 0.36 & 2.77 & 2.76 & $2.5^{(2)}$ \\
\hline $128 \times 128(32768)$ & 1.442 & 0.70 & 0.57 & $0.5^{(3)}$ \\
\hline $256 \times 256(65536)$ & 2.884 & 0.35 & 0.04 & - \\
\hline
\end{tabular}

Tabla 5.1 - Tabla de la velocidad de reconstrucción en FPS obtenida para distintas resoluciones de imagen. En la primera columna se indica la resolución de la imagen en píxeles, $N \times N$, y entre paréntesis el número de patrones utilizados $\left(N^{\prime}\right)$. Para la reconstrucción de imágenes de $256 \times 256$ píxeles se han proyectado sólo los patrones $H^{+}$(véase apéndice B) debido a que la memoria del DMD no admite la totalidad de los patrones. $T_{\text {imagen }}$ es el tiempo necesario para reconstruir una imagen en el montaje mostrado aquí. El valor teórico se basa en la tasa de muestreo máxima del DMD sin realizar el procesado de los datos. El valor experimental incluye el procesado y cálculo de los datos medidos. FPS otros $_{\text {se refiere a medidas realizadas en }}{ }^{(1)}$ [78, 87, 116]; (2) 78 , 116 118]; (3) [119].

Los resultados de la figura 5.5 son imágenes de un ojo real perteneciente a un sujeto joven. Las imágenes 5.5 a y 5.5 c se han obtenido con un tiempo de adquisición de $0.54 \mathrm{~s}$, resolución de $32 \times 32$ píxeles y no se les ha aplicado ningún tipo de procesado. Por otro lado, las imágenes 5.5 b y 5.5 d corresponden a la imagen resultante de promediar 10 fotogramas con las mismas condiciones de medida que las imágenes 5.5 a y 5.5 c, respectivamente. El promedio se ha calculado sin corregir los posibles movimientos oculares y no se ha aplicado procesado de imagen, sólo se han reescalado las imágenes a $128 \times 128$ píxeles. En las imágenes mencionadas se pueden distinguir claramente los principales vasos sanguíneos, que se unen en la cabeza del nervio óptico. Sin embargo, detalles más pequeños no son visibles debido a la falta de resolución espacial y la presencia de ruido. Las imágenes de mayor resolución que se han obtenido promediando fotogramas se muestran en la figura 5.5 e y 5.5 f. Comparando estas dos imágenes con las anteriores, se observan más detalles del mapa del vaso alrededor de la cabeza del nervio óptico. Sin embargo, el tiempo empleado en medir las imágenes aumenta considerablemente cuando la resolución pasa de $64 \times 64$ a $128 \times 128$ píxeles. 

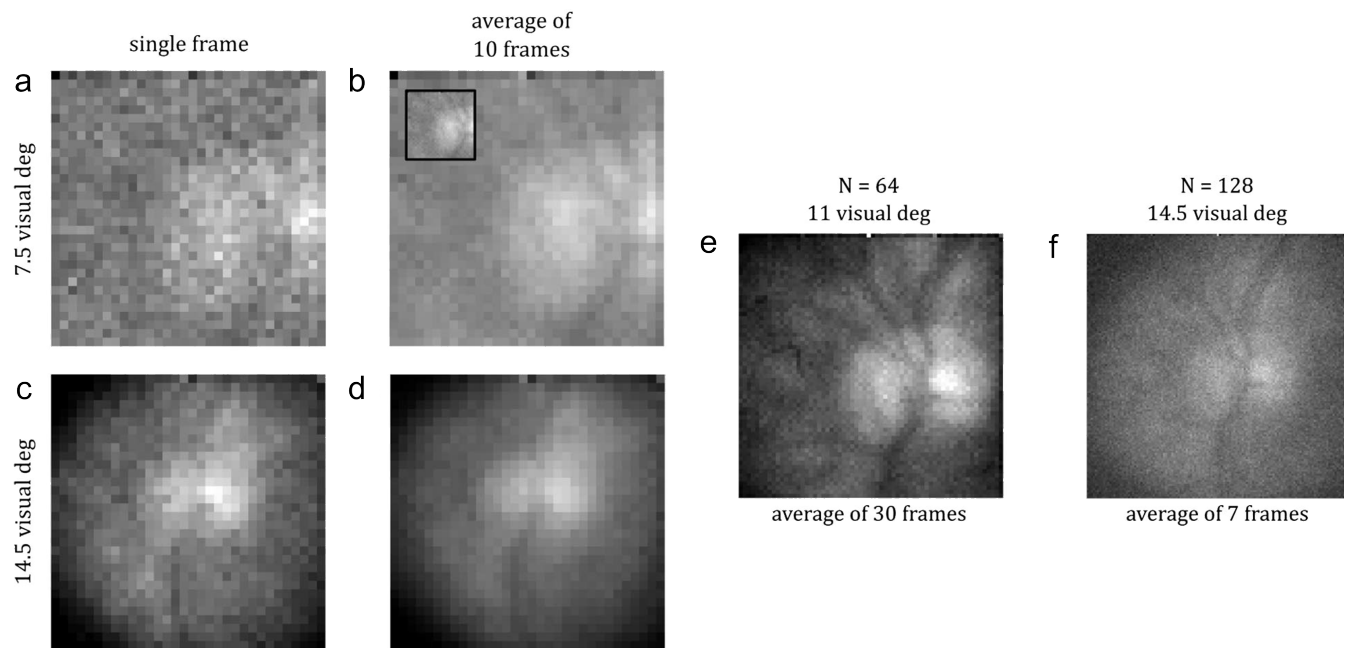

Figura 5.5 - Resultados de imagen de la retina de un ojo humano in vivo [115]. a, b, c y d tienen una resolución de $32 \times 32$ píxeles, pero se han reescalado a $128 \times 128$; la imagen del cuadro insertado en $\mathbf{b}$ corresponde a la imagen en resolución original. $0.54 \mathrm{~s}$ es el tiempo por fotograma empleado en estas imágenes. Los pares a, b y c $\mathbf{c}$ d se corresponden con 7.5 y 14.5 grados visuales, respectivamente. Los pares $\mathbf{a}, \mathbf{c}$ y $\mathbf{b}, \mathbf{d}$ se corresponden con un fotograma y con la media de 10 fotogramas, respectivamente. La imagen e es el resultado de promediar 30 fotogramas de resolución $64 \times 64$ píxeles a 11 grados visuales y reescalar a $128 \times 128$. El tiempo de adquisición es $1.29 \mathrm{~s}$ por fotograma. La imagen $\mathbf{f}$ es el resultado de promediar 7 fotogramas de resolución $128 \times$ 128 píxeles a 14.5 grados visuales. El tiempo de iluminación es $5.15 \mathrm{~s}$ por fotograma. En las últimas 2 imágenes se ha realizado un procesado digital para mejorar el contraste.

En este último caso, los movimientos del ojo son casi inevitables e influyen severamente en el resultado. Para conseguir menores tiempos de medida se pueden usar técnicas de imagen adaptativa [88 o de muestreo compresivo (CS) 44, entre otras.

Hasta ahora se han mostrado resultados de imagen del fondo de un ojo humano in vivo con un área de casi 15 grados visuales. Aunque para un ojo artificial estático se pueden alcanzar velocidades de vídeo a mayor resolución, el principal inconveniente que se encuentra con el ojo in vivo son los movimientos involuntarios durante el proceso de medida. En términos de calidad de imagen y resolución, el sistema empleado no puede competir con los instrumentos de imagen oftálmica que se comercializan actualmente, debido principalmente a la limitación de la tasa máxima de muestreo del DMD. Con los avances futuros en esta tecnología se podrán mejorar estos parámetros. Como se ha comentado anteriormente, el motivo de usar el sistema de la fi- 
gura 5.4 es la ventaja potencial que tienen los sistemas de imagen basados en técnicas de SPI frente a otros sistemas de imagen en presencia de scattering. La idea es aprovechar esta ventaja para la aplicación futura de la técnica en un ojo con catarata.

\subsection{Imagen single-pixel en configuración de reflexión en un ojo artificial con catarata}

Una vez se ha comprobado el funcionamiento de la técnica SPI en reflexión y se ha aplicado a un ojo in vivo, en esta sección se añade un medio turbio al sistema experimental, que en este caso se trata de un ojo artificial con catarata. Debido a la posición del cristalino en el sistema ocular y a los distintos grados de opacidad que puede tener una catarata en el ojo, se realizan dos estudios previos para analizar el efecto del scattering sobre la imagen single-pixel resultante.

Entre el cristalino y la retina de un ojo se encuentra el humor vitreo ocupando la mayor parte del globo ocular, de modo que el cristalino y la retina están separados una cierta distancia, tal como se ha visto al principio de este capítulo (figura 5.1). En un ojo con catarata, el cristalino se vuelve turbio constituyendo un medio de scattering. En este caso, el objeto y el difusor no se encuentran 'pegados' (como fue el caso del capítulo anterior). Es necesario, por tanto, estudiar el efecto de introducir una cierta distancia entre el objeto y el medio turbio en un sistema single-pixel.

En la figura 5.6 se muestran los resultados del estudio de este efecto. El sistema óptico utilizado para proyectar los patrones $\mathrm{W}-\mathrm{H}$ sobre el objeto funciona tal como se muestra en la parte superior de la figura 5.6. El sistema de detección consiste en un fotodiodo y una lente condensadora. El medio de scattering utilizado para este estudio es una lámina difusora comercial (Edmund Optics T54-497) que se va alejando del plano objeto. El gato Cheshire impreso en una lámina transparente se ha dispuesto en el plano objeto y se ha recuperado la imagen de sólo la parte señalada de los ojos en la figura 5.6. En la tabla de la misma figura se comprueba cómo la imagen se degrada a medida que aumenta la distancia entre el difusor y el objeto. El ángulo de dispersión con el que sale un fotón del medio turbio hace que la distancia transversal entre éste y un fotón balístico en el plano de proyección sea mayor a medida que aumenta la distancia axial. Así los fotones snake contribuyen al emborronamiento de la imagen en lugar de contribuir a la proyección de los patrones, y como resutado, la correlación de la imagen en cada posición, x, con la imagen sin difusor va disminuyendo a medida que aumenta la distancia 


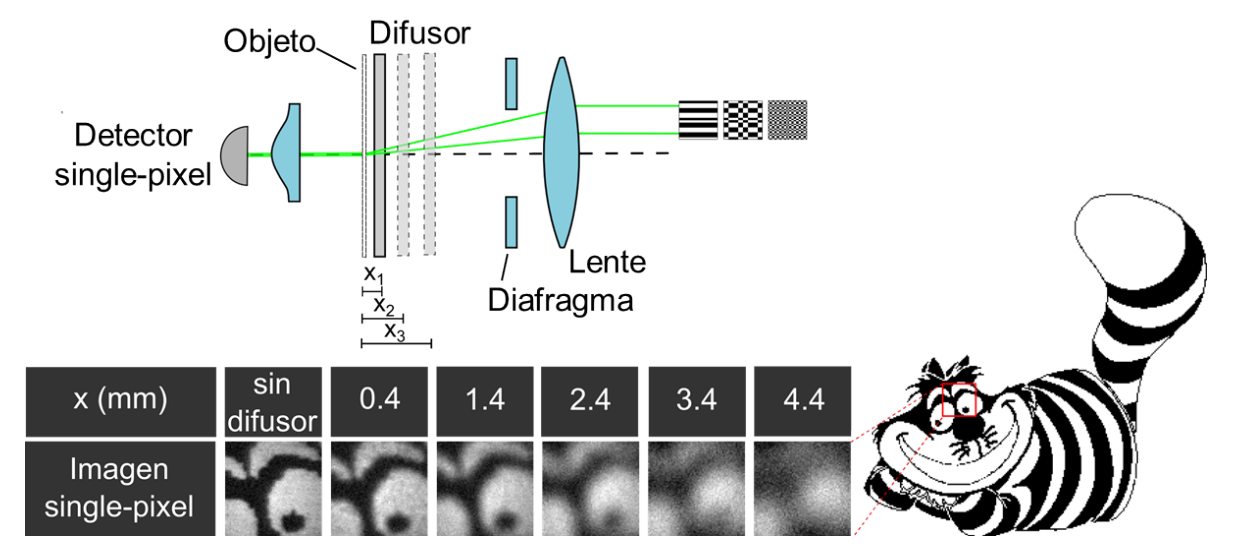

Figura 5.6 - Estudio del efecto de la distancia objeto-difusor. En la parte superior se muestra el esquema experimental usado, los patrones $\mathrm{W}-\mathrm{H}$ son proyectados desde un DMD. En la tabla se aprecia cómo va cambiando la calidad de la imagen a medida que aumenta la distancia, $\mathrm{x}$, del objeto al difusor. La primera imagen de la tabla se corresponde con una reconstrucción single-pixel sin difusor.

del difusor al objeto.

Para comprobar la capacidad de la técnica single-pixel en la recuperación de la imagen de la retina de un ojo artificial con un cristalino cataratoso, se emplea el esquema experimental de la figura 5.7. Los elementos del sistema son los mismos que los de la figura 5.2 excepto por el añadido de un medio de scattering pegado al diafragma 2. Este medio de scattering simula un cristalino cataratoso y consiste en una capa difusora obtenida a partir del polímero que constituye una barra cilíndrica de cola termofusible.

El material utilizado como difusor se ha caracterizado midiendo el valor de su MFP con el método detallado en el material suplementario de la referencia [120]. Se ha medido la componente balística de la luz mediante un proceso simple en el que se ilumina el material difusor con una fuente coherente y colimada; a continuación se pone un pinhole a una cierta distancia para eliminar los fotones difusos y se captura la imagen con una cámara CCD. Con el promedio de varias imágenes se obtiene la intensidad de la componente balística $\left(I_{b}\right)$ para distintos grosores $(z)$ de material difusor, que se han obtenido combinando varias capas del material. Representando $\ln \left(I_{b} / I_{0}\right)$ frente al grosor del difusor $(z)$ se puede obtener el valor del MFP, calculado a partir de la pendiente de la curva que ajusta los puntos experimentales a la ley de Lambert-Beer. En este caso se considera que el medio difusor no tiene absorción o es despreciable frente al scattering, de modo que se puede escribir $l=1 / \mu_{s}$. El valor obtenido del MFP es $l=3.9 \mathrm{~mm}$, lo que significa 


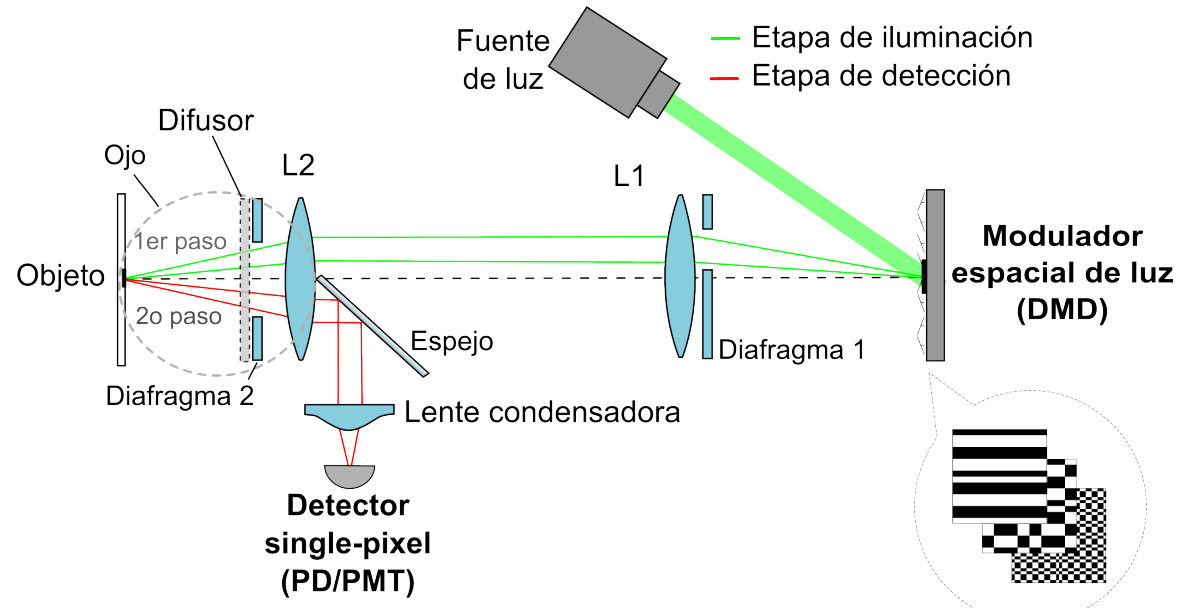

Figura 5.7 - Esquema óptico de doble paso con un medio difusor.

que el haz de fotones propagándose a través de la capa difusora con un grosor de $3.9 \mathrm{~mm}$ experimentará al menos un evento de scattering, resultando en una imagen borrosa cuando se usa una cámara convencional.

Existen distintos grados de opacidad del cristalino según el paciente sufra una catarata temprana o el estado de degradación sea más avanzado (proceso que concluye en una opacidad total del cristalino). El medio de scattering utilizado en este experimento es un material polimérico constitutido por capas difusoras de distinto grosor para simular distintos grados de opacidad del cristalino. El objeto utilizado para recuperar su imagen es un fragmento de papel de periódico en el que hay letras y números en blanco sobre un fondo negro (mostrado en la figura 5.8 a). Es un objeto que tiene baja reflectividad al igual que el empleado para un ojo artificial sin medio turbio (sección 5.1). En la figura 5.8 b se muestra una tabla con imágenes reconstruidas con la técnica SPI para distintos grosores del medio difusor. La cantidad de fotones balísticos disminuye con el grosor del medio, tal como se ha mencionado anteriormente en esta tesis. Además, los fotones balísticos son los que principalmente proyectan los patrones de luz sobre el objeto, por lo que es de esperar que la calidad de la imagen se degrade con la disminución de los mismos. De esto se deduce que el aumento del grosor del medio de scattering resulta en una disminución de la calidad de la imagen, que es precisamente lo que se observa en los resultados experimentales de la figura 5.8 b. Este efecto se suma al producido por la distancia del medio turbio al objeto, visto en las imágenes de la figura 5.6.

En este estudio se ha utilizado el sistema óptico de la figura 5.7 con $15 \mathrm{~mm}$ de diámetro en el diafragma 2. Además, en lugar de usar un fotodiodo como 
a

\begin{tabular}{|c|c|c|c|c|c|c|c|c|}
\hline viliver & $\begin{array}{l}\text { Grosor } \\
(\mathrm{mm})\end{array}$ & $\begin{array}{l}\sin \\
\text { difusor }\end{array}$ & 1.00 & 2.00 & 2.90 & 3.90 & 4.90 & 5.80 \\
\hline & $\begin{array}{l}\text { Imagen } \\
\text { single-pixe }\end{array}$ & 18 & 18 & 18 & 18 & 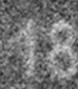 & & \\
\hline
\end{tabular}

Figura 5.8 - Estudio de la imagen obtenida al aumentar progresivamente el grosor de la capa difusora. a. Objeto utilizado experimentalmente; la zona recuadrada en verde es el área usada para proyectar los patrones. b. Tabla de las imágenes reconstruidas por SPI del objeto mostrado en a a través de distintos grosores de capa difusora. La primera imagen de la tabla se ha obtenido sin capa difusora.

detector single-pixel, se ha usado un tubo fotomultiplicador (PMT, Thorlabs PMM01). El propósito de usar un PMT, tanto para este experimento como para el experimento anterior con ojos in vivo, es la posibilidad de medir señales de luz muy débiles. De esta forma se minimiza la molestia que pueda sentir el paciente y el riesgo de daño en los tejidos oculares.
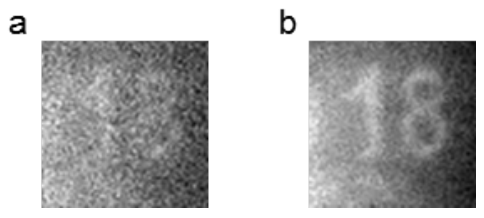

Figura 5.9 - Reconstrucción de la imagen de la retina de un ojo artificial a través de $5.8 \mathrm{~mm}$ de espesor de capa difusora actuando de cristalino cataratoso. a. Reconstrucción de la imagen del objeto sin procesado. b. Imagen obtenida promediando 7 imágenes de la misma zona del objeto.

En los resultados obtenidos para un ojo artificial con catarata se observa que la imagen recuperada con una capa difusora de $5.8 \mathrm{~mm}$ de espesor tiene bastante ruido (véase figura 5.9 a). Por esta razón en la figura 5.9 b se muestra el promedio de 7 imágenes, lo que reduce el ruido y mejora la imagen del objeto. Con estas imágenes queda comprobada la posibilidad de emplear la técnica de imagen single-pixel a través de un medio turbio en una configuración de reflexión.

Existe un valor límite de exposición a la radiación en función del rango espectral utilizado. El valor límite garantiza que si la radiación empleada está por debajo de dicho valor, no habrá daño en los tejidos biológicos. En el experimento presentado en este apartado se ha calculado el valor límite siguiendo la "Guía técnica para la evaluación y prevención de los riesgos relacionados 
con las radiaciones ópticas artificiales" [121], que publica el Ministerio de Empleo y Seguridad Social del Gobierno de España. Para realizar el cálculo en el experimento de ojo articifial se debe tener en cuenta la irradiancia sobre la retina y el tiempo de exposición. Con el DMD utilizado en este experimento, el tiempo de exposición es $300 \mathrm{~s}$. Éste es el tiempo que tarda el sistema en medir las intensidades correspondientes a los 4096 patrones de $\mathrm{W}-\mathrm{H}$ (en el caso de una imagen de $64 \times 64$ píxeles). La irradiancia límite que puede recibir la retina de un ojo humano en el sistema presentado en esta sección y para el tiempo de exposición mencionado es $25.5 \mathrm{~mW} / \mathrm{cm}^{2}$. El hecho de utilizar un detector hipersensible como el PMT permite reducir el nivel de radiación incidente, por lo que en cualquiera de los estudios presentados en este capítulo la irradiancia empleada $\left(1.58 \mathrm{~mW} / \mathrm{cm}^{2}\right.$ como máximo, que son $124 \mu \mathrm{W}$ sobre el área del objeto) está por debajo del límite calculado. Empleando un DMD con más memoria interna, es posible disminuir el tiempo de adquisición hasta $200 \mathrm{~ms}$ 82 (en este caso el límite de irradiancia sería $38.3 \mathrm{~W} / \mathrm{cm}^{2}$ ). Además, si se reduce suficiente el tiempo de adquisición, se pueden promediar varias imágenes para mejorar la imagen final (como se ha hecho en la figura 5.9 b) sin temer por el daño en los tejidos. 


\section{Conclusiones}

En esta tesis se ha analizado el potencial de la técnica Single-Pixel Imaging (SPI) para la obtención de imágenes a través de medios turbios, especialmente tejidos biológicos. Para ello, se han diseñado diferentes sistemas SPI, empleando iluminación estructurada (generada por un SLM) y detección integrada (con un sensor sin resolución espacial). El proceso de detección en SPI presenta una ventaja crucial cuando se trabaja en entornos de scattering: una vez que el objeto ha sido muestrado con los patrones estructurados, la alteración de las trayectorias de la luz por el medio no degradan la calidad de las imágenes obtenidas. El hecho de que sólo sea necesario recolectar la luz, sin preocuparse, además, de formar una imagen, hace de la técnica SPI una buena candidata para afrontar el reto de obtener imágenes a través de medios turbios.

En el capítulo 3, se ha demostrado la transmisión de imágenes a través de un medio difusor situado enfrente del detector de un sistema SPI. Debido al scattering, el campo que incide sobre el detector es un patrón de speckle, lo que en un sistema convencional de imágenes destruye toda la información espacial del objeto que se quiere reconstruir. Sin embargo, en un sistema SPI, la potencia medida en el área del detector (esto es, en un área del patrón de speckle generado por el difusor) va cambiando con los diferentes patrones de iluminación proyectados sobre el objeto. Si el área detectada es lo suficientemente grande (contiene un número grande de granos de speckle) las contribuciones de los patrones son independientes entre sí y el proceso de reconstrucción de la imagen es lineal en intensidades. Esta teoría es igualmente válida para un medio difusor dinámico, puesto que no es necesario tener información a priori del medio, ni caracterizarlo para medir su matriz de transmisión. Las imágenes obtenidas con SPI en el capítulo 3 se han comparado con las obtenidas por métodos convencionales (que simplemente son imágenes de speckle), demostrando así la ventaja de SPI con medios turbios. El sistema desarrollado se ha aplicado con éxito a una muestra biológica a escala microscópica (células de cebolla). La publicación de estos resultados en Optics Express [90] tuvo relevancia, ya que fue la primera vez que se apli- 
caba la técnica SPI a imagen a través de medios turbios. Prueba de ello es la aparición en la portada de la web de la revista Optics Express y varias reseñas en páginas web como OSA Newsroom [122], optics.org [123], BioOptics World [124] o Science Daily [125]; incluso se publicó una pequeña noticia en el periódico Mediterráneo (el 17 de julio de 2014).

En el capítulo 4, con el objeto de representar un escenario más realista que el considerado en el capítulo 3, se ha dispuesto una configuración en transmisión donde el objeto está inmerso en $6 \mathrm{~mm}$ de tejido biológico. Esta configuración tiene en cuenta el efecto de scattering tanto en la etapa de iluminación como en la de detección. El objeto de amplitud se cubre por cada lado con una capa de pechuga de pollo de aproximadamente $3 \mathrm{~mm}$ de grosor. La aplicación de la técnica SPI, iluminando por un lado de la muestra y detectando la luz en transmisión con un fotodiodo, ha permitido reconstruir la imagen del objeto, pese a no tener acceso directo a él por ningún lado. Se ha comprobado que para que la técnica funcione es imprescindible que exista una componente balística de la luz después de la primera capa de tejido, de forma que una fracción de la luz incidente mantenga la estructura espacial de los patrones de muestreo y, al interaccionar con el objeto, produzca fluctuaciones en la intensidad detectada. En el experimento descrito se han realizado dos estudios: el primero tiene que ver con la absorción del tejido en algunas longitudes de onda. Con un análisis espectral se determina cuál es la mejor ventana óptica para el tejido empleado, lo que ayuda a obtener una reconstrucción óptima de la imagen del objeto. El segundo estudio está relacionado con la componente balística necesaria para proyectar los patrones de luz. Conociendo el porcentaje de luz balística que pasa a través del medio difusor y realizando un estudio de la calidad de la imagen a distintas intensidades de luz incidente, se puede obtener la iluminación óptima para una imagen single-pixel de calidad aceptable $\left(10^{9}-10^{10}\right.$ fotones $/ \mathrm{cm}^{2} s$ muestreando el objeto). Al tratarse de tejido biológico, la intensidad siempre debe estar por debajo del umbral de daño, lo que se ha respetado en todos los experimentos del capítulo 4. Estos resultados han sido publicados en Optics Express [98] y han sido reseñados en SPIE Newsroom [126]. En algunos resultados de los capítulos 3 y 4 se ha empleado la técnica de muestreo compresivo (CS) para disminuir el tiempo de medida y por tanto el tiempo de irradiación del medio de scattering (tejido biológico en el caso del capítulo 4). El uso de esta técnica y de otros procedimientos de procesado de señal, que están intrínsecamente ligados a los sistemas SPI, es muy interesante desde el punto de vista biológico, ya que en multitud de casos la dosis de radiación necesaria para la obtención de imágenes es perjudicial para el organismo (por ejemplo, en el caso de las imágenes obtenidas con rayos X o TAC).

En el capítulo 5 se ha diseñado e implementado un sistema SPI que fun- 
ciona como un oftalmoscopio, y que consigue obtener la imagen de la retina de un ojo humano in vivo. Muchas enfermedades oculares se diagnostican observando el fondo del ojo, donde se encuentra la retina, y la ventaja de la técnica SPI de poder usar un detector hipersensible a la luz, como un tubo fotomultiplicador, es una mejora para disminuir la molestia del paciente a la luz incidente y, por supuesto, el riesgo de daño en los tejidos oculares. La principal limitación de la aplicación de SPI a la obtención de imagen de la retina es el tiempo de medida, aunque puede reducirse utilizando métodos de compresión como CS. Este resultado se publicó en la revista Optica [115]. No obstante, la capacidad de los sistemas SPI para obtener imágenes en presencia de scattering hace de ellos una opción prometedora para tomar imágenes de la retina de un ojo con cataratas. La catarata de un ojo hace que el cristalino se comporte como un medio turbio que dificulta tomar imágenes nítidas de la retina. En el último experimento del capítulo 5, se ha desarrollado un sistema SPI por reflexión que permite tomar imágenes a través de un ojo artificial con catarata.

Los procedimientos, sistemas y resultados presentados en esta memoria pueden servir de punto de partida para futuros desarrollos e investigaciones:

a) Reducir el tiempo de medida de las imágenes. Aunque la técnica de SPI tiene un gran potencial, una limitación práctica fundamental es el tiempo que se requiere para la adquisición de datos (que es secuencial) y la reconstrucción compresiva de las imágenes. En este trabajo se ha empleado CS para aliviar este problema. No obstante, un objetivo para mejorar la técnica es optimizar tanto el proceso de medida, haciendo que el DMD trabaje a su máxima velocidad $(22.7 \mathrm{kHz})$, como la velocidad de procesado de datos para resolver algoritmos de compresión. Esto último se puede lograr implementando los algoritmos de reconstrucción en unidades de procesamiento gráfico (GPU), que incrementan significativamente la velocidad de reconstrucción.

b) Aplicar SPI a otros medios de scattering. Un reto de futuro inmediato es también el estudio de la aplicabilidad de la técnica SPI para distintos medios turbios, como por ejemplo niebla o humo (además de tejido biológico). Una buena estrategia es el uso de longitudes de onda más largas, en las que el efecto del scattering disminuye [53, 127].

c) Obtener la imagen con SPI de la retina de un ojo con catarata in vivo. En el ámbito de la oftalmología, los resultados presentados en esta tesis se pueden tomar como base para el diseño de un sistema de SPI que obtenga la imagen de la retina de un ojo con catarata in vivo. Esta medida supone un reto que requiere la optimización de la configuración en reflexión presentada en esta tesis, así como la utilización de un detector con un gran 
rango dinámico, capaz de medir las pequeñas fluctuaciones de intensidad que se puedan producir a medida que varía el patrón de iluminación.

d) Aplicar nuevos algoritmos de reconstrucción para desarrollar sistemas de imagen no convencional. Los sistemas SPI usados en este trabajo son un caso particular de imagen computacional (CI, Computational Imaging), una disciplina que trasciende las técnicas de imagen convencional diseñando de forma simultánea el sistema óptico y los algoritmos de reconstrucción. Juntos, la óptica y los algoritmos pueden alcanzar objetivos que por separado no se podían conseguir [128]. El hecho de que las cámaras SPI necesiten un SLM, las relaciona de manera natural con la imagen computacional y las técnicas de procesado de señal. De este modo, la aplicación, no sólo de CS, sino de multitud de métodos computacionales como matrix completion o maching learning, puede realizarse de forma sencilla y dota a las cámaras SPI de una flexibilidad añadida en comparación con los sistemas tradicionales 129 131. De este modo es posible, además, desarrollar sistemas de imagen multidimensional, tales como imagen de espectroscopía Raman, microscopía de fase, etc. [43, 82].

Estas ideas, además de los nuevos avances que están por venir, indican que el desarrollo de cámaras single-pixel para la obtención de imágenes a través de medios turbios todavía se encuentra en una etapa inicial. Si bien ya se han logrado resultados llamativos, el problema de 'ver' a través de tejido biológico sigue sin estar resuelto, y todo parece indicar que la única manera de superarlo será la combinación de diversas técnicas en paralelo. En este escenario, los métodos basados en SPI son claramente una opción tanto para proporcionar imagen por sí misma como para complementar a otras técnicas de imagen. 


\section{Apéndice A}

\section{Moduladores espaciales de luz}

Un modulador espacial de luz (SLM, Spatial Light Modulator) es un dispositivo que permite controlar la amplitud, la fase o el estado de polarización de la luz que lo atraviesa, tanto espacial como temporalmente. Distintas tecnologías de SLM basadas en efectos electro-ópticos pueden ser utilizadas para generar una imagen. Dos tipos de SLM ampliamente usados son los que utilizan celdas de cristal líquido o espejos como elementos moduladores [132]. El primer grupo está constituido por los moduladores espaciales de luz de cristal líquido (LC-SLM, Liquid Crystal-Spatial Light Modulators). Los píxeles de estos moduladores son celdas de cristal líquido controlables mediante la aplicación de voltajes, y en esta variedad están incluidos los FLC ( $\mathrm{Fe}$ rroelectric Liquid Crystal), los PNLC (Parallel Nematic Liquid Crystal) y los TNLC (Twisted Nematic Liquid Crystal). El segundo grupo de SLMs trabaja por reflexión y sus píxeles son micro-espejos orientables controlados electrónicamente. Dentro de esta categoría se encuentran los DMDs (Digital Micromirror Device) y los moduladores de espejos deformables. El desarrollo de la tecnología de los SLMs ha venido impulsado por la industria electrónica de consumo, ya que estos dispositivos se encuentran en sistemas como los de retroproyección de TV, proyectores frontales y pico-proyectores [133]. Además de la industria de proyección, los SLMs tienen aplicación en telecomunicaciones para codificar señales de luz aumentando el ancho de banda, en espectroscopia Hadamard para el conformado de pulsos ópticos, en el almacenaje óptico de datos, en aplicaciones de óptica adaptativa para la corrección de aberraciones, en el grabado de lentes difractivas, etc. [134. En los últimos años ha aumentado el uso de los moduladores en aplicaciones biomédicas, permitiendo un corte más preciso en la cirugía láser, o la generación de pinzas ópticas para separar o manipular células individualmente [135].

A continuación se describe el funcionamiento de los moduladores TNLC y DMD, que son los utilizados experimentalmente en esta tesis. 


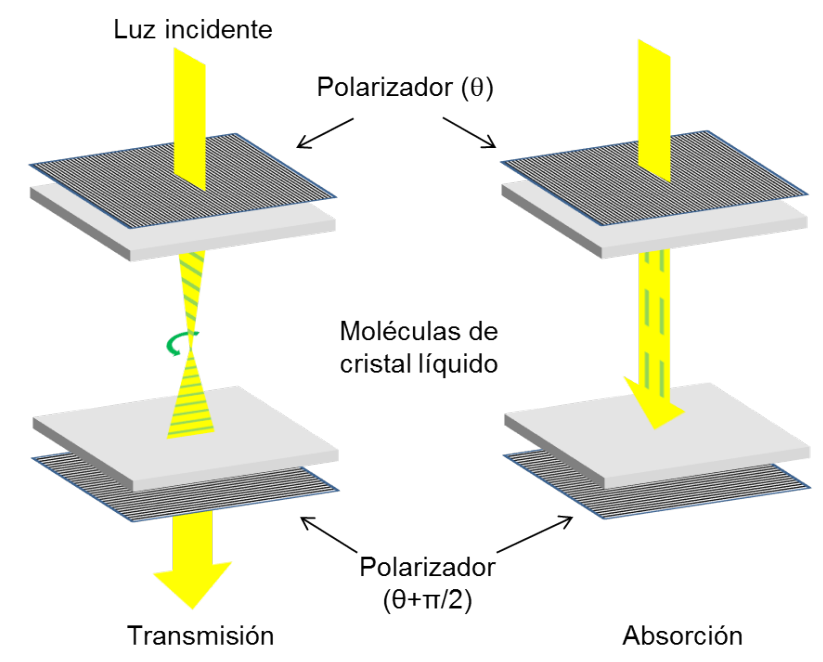

Figura A.1 - Funcionamiento clásico de una celda de TNLC con un giro molecular de $90^{\circ}$ como modulador de intensidad. Dibujo adaptado de [138].

\section{A.1. SLM de cristal líquido}

Los cristales líquidos son materiales orgánicos constituidos por moléculas con estructura en forma de hélice, que presentan una fase intermedia entre los estados sólido y líquido. Tienen características propias de los sólidos cristalinos, ya que las moléculas presentan un cierto grado de orientación, y propiedades intrínsecas de los líquidos como la fluidez. El efecto electro-óptico en los cristales líquidos de tipo nemático $(\mathrm{TN})$ consiste en un giro controlable del plano de polarización de la luz que atraviesa una celda de cristal líquido. $\mathrm{Su}$ estructura molecular helicoidal puede ser alterada por la aplicación de un campo eléctrico externo, lo que induce un cambio en la actividad óptica del material. Si la celda, que típicamente posee un giro molecular de $90^{\circ}$, se sitúa entre dos polarizadores, la variación del voltaje aplicado se traduce en una modulación de la intensidad del haz que emerge del analizador [136]. De esta forma, es posible construir un display de cristal líquido (LCD, Liquid Crystal Display), caracterizado por su bajo consumo, y capaz de proporcionar, mediante la aplicación de pequeños voltajes de control, una modulación de intensidad con un alto contraste y un tiempo de respuesta relativamente corto [137]. El primer uso de las celdas TNLC fue como modulador binario de amplitud para dispositivos electrónicos. Sin embargo, en aplicaciones de proyección se generan estados intermedios que permiten controlar el nivel de intensidad transmitida en cada píxel de la pantalla.

Uno de los SLM que se usan en este trabajo es un modulador de cristal líquido TN LC-R 2500 de Holoeye, basado en una pantalla reflectiva LCoS 
(Liquid Crystal on Silicon), que puede modular en amplitud y fase los frentes de onda de luz coherente. La pantalla tiene una resolución XGA, es decir, $1024 \times 768$ píxeles, y cada uno de estos píxeles mide $19 \mu \mathrm{m}$ de lado. El modulador utiliza matrices activas de LCD (Active Matrix LCD), con las que se consiguen pantallas de cristal líquido de alta resolución. Estas matrices activas tienen un componente electrónico que va unido a cada elemento de la pantalla (píxel) y que permite su control electrónico individual. La velocidad máxima a la que puede cambiar el valor de cada celda es 75 veces por segundo $(75 \mathrm{~Hz})$.

En los experimentos del capítulo 3, este dispositivo se ha usado como modulador binario de amplitud, es decir, los píxeles de los patrones implementados en la pantalla del modulador sólo adoptan dos posibles valores, 0 $(\mathrm{OFF})$ o $255(\mathrm{ON})$. En la figura A.1 se muestra el funcionamiento de una celda de cristal líquido para modular amplitud binaria. El dibujo representa una celda de cristal líquido situada entre dos polarizadores lineales orientados perpendicularmente entre ellos. A la izquierda, la luz incidente queda polarizada linealmente después del primer polarizador; a continuación entra en la celda de cristal líquido de tipo nemático y el plano de polarización gira $90^{\circ}$; finalmente, al salir de la celda, la luz atraviesa de nuevo un polarizador lineal (analizador) girado $90^{\circ}$ respecto al primero. El resultado es que toda la luz incidente atraviesa la celda TNLC, es decir, a ese píxel de la pantalla le corresponde un nivel de gris $g=255$. En cambio, en el esquema de la derecha, la luz dentro de la celda TNLC mantiene la polarización perpendicular al analizador, ya que todas las moléculas se han orientado en la dirección del campo eléctrico aplicado sobre la celda, y ésta se comporta como un medio homogéneo. Por tanto, en este segundo caso el píxel tiene un nivel de gris $g=0$. Controlando el giro de polarización en cada celda (píxel) de la pantalla se consiguen valores de $\mathrm{g}$ intermedios, y de esta manera se forma una imagen sobre la pantalla del modulador.

\section{A.2. SLM de microespejos}

El dispositivo DMD es un SLM que tiene su superfcie dividida en cientos de miles de microespejos, distribuidos en forma de matriz rectangular. Cada microespejo puede adoptar dos posiciones distintas, que determinan la dirección en que se desvía la luz. Estas dos configuraciones estables (habitualmente $+12^{\circ}$ y $-12^{\circ}$ ) dan lugar a los estados ON y OFF. Para que la luz reflejada por el DMD en el estado ON emerja perpendicular a la superfcie del modulador, la inclinación del haz de luz colimado incidente debe ser de $24^{\mathrm{o}}$, tal como se puede observar en la figura A.2. 


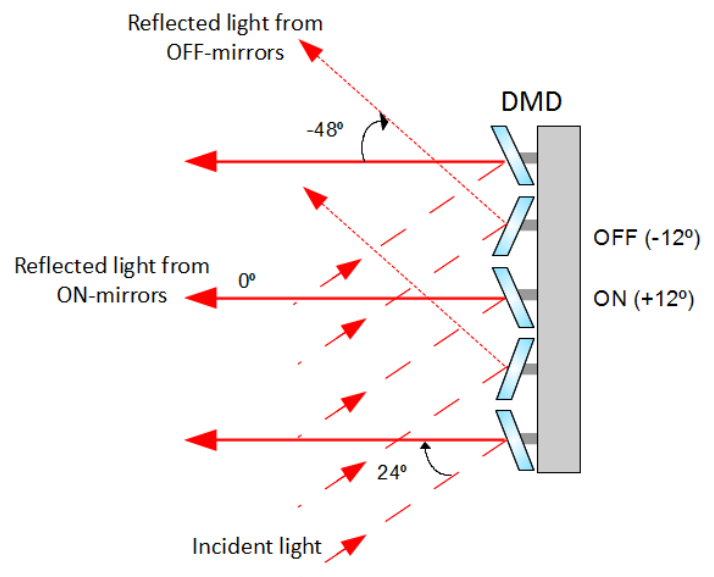

Figura A.2 - Representación esquemática de las direcciones de refexión de la luz a la salida de un DMD 42 .

Cada uno de estos microespejos se dispone sobre una celda de memoria CMOS SRAM (Static Random Access Memory), encima de un soporte que puede girar por medio de una bisagra. Dicho soporte está fijado sobre electrodos, de modo que aplicando una tensión eléctrica se consigue generar una fuerza de atracción o repulsión entre el espejo y la base, obteniendo las dos configuraciones posibles mostradas en la figura A.3.

El DMD lleva incorporado una placa digital (controlador ALP, Accesory Light Modulator Package), para poder determinar la posición de cada espejo de forma individual y automatizada mediante el pertinente sofware informático. Con esto se consigue superponer patrones (en este caso patrones de Walsh-Hadamard) sobre el objeto. El DMD tiene una velocidad de refresco extremadamente rápida (con una frecuencia que puede llegar a valores del orden del $\mathrm{kHz}$ ), lo cual resulta crucial para capturar imágenes secuenciales de forma eficiente.

En esta tesis se han empleado dos dispositivos DMD para los experimentos realizados. En las secciones 5.1 y 5.3 se usa el DMD con una matriz de espejos de $1920 \times 1080$, donde cada espejo mide $10.8 \mu \mathrm{m}$ de lado. El segundo DMD, usado en los experimentos del capítulo 4 y en la sección 5.2 , tiene una matriz de $1024 \times 768$ microespejos y el área de cada espejo es $13.68 \mu \mathrm{m} \times 13.68 \mu \mathrm{m}$. La frecuencia de muestreo máxima para ambos DMDs es la misma (22.7 $\mathrm{kHz}$ ); sin embargo, la capacidad de memoria para cargar las imágenes que se quieren proyectar es mayor en el segundo DMD.

En los dispositivos SLM se puede elegir el tamaño del píxel de la imagen, 


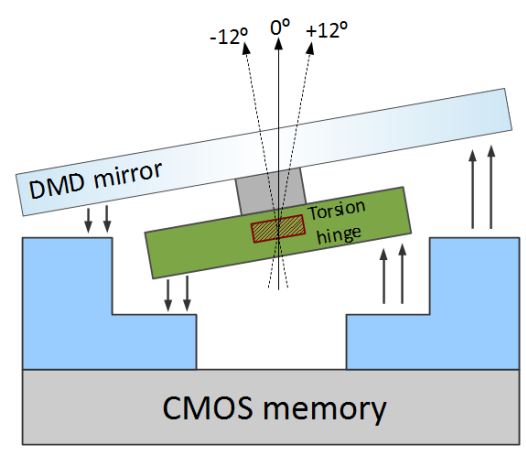

Figura A.3 - Corte transversal de uno de los microespejos que conforman el dispositivo DMD (en estado OFF) 42 .

de forma que éste puede ser, bien un espejo o un conjunto de espejos en el DMD, o bien una celda o un conjunto de ellas en el TNLC. En los experimentos de esta tesis generalmente se usa una región central de $512 \times 512$ microespejos. En esta tesis la resolución elegida es de $32 \times 32,64 \times 64$ o $128 \times 128$ píxeles, agrupando los píxeles del SLM de 16 en 16, de 8 en 8 o de 4 en 4, respectivamente. Se trabaja con resoluciones bajas para evitar las complicaciones informáticas asociadas al procesado de matrices de dimensión elevada, que son propias de la toma de imágenes de alta resolución. Otro motivo por el que se usan bajas resoluciones es que el tiempo de adquisición de la imagen con la técnica SPI aumenta con la resolución. En la tabla A.1 se muestra una comparativa de los tiempos de adquisición de ambos moduladores, TNLC y DMD, para las resoluciones de imagen usadas.

\begin{tabular}{|l|c|c|}
\hline \multicolumn{1}{|c|}{$N \times N\left(N^{\prime}\right)$} & TNLC $(75 \mathrm{~Hz})$ & DMD $(22.7 \mathrm{kHz})$ \\
\hline \hline $32 \times 32(2048)$ & $27 \mathrm{~s}$ & $90 \mathrm{~ms}$ \\
\hline $64 \times 64(8192)$ & $1.8 \mathrm{~min}$ & $361 \mathrm{~ms}$ \\
\hline $128 \times 128(32768)$ & $7.3 \mathrm{~min}$ & $1.4 \mathrm{~s}$ \\
\hline
\end{tabular}

Tabla A.1 - Tabla del tiempo de medida necesario para obtener una imagen a máxima velocidad de muestreo del SLM. Se comparan los dos tipos de SLM utilizados, TNLC y DMD. En la primera columna se indica la resolución de la imagen en píxeles, $N \times N$, y entre paréntesis el número de patrones necesarios con la técnica SPI propuesta en esta tesis $\left(N^{\prime}=2 N^{2}\right.$, véase apéndice B.

Los tiempos presentados en la tabla A.1 pueden reducirse usando métodos de compresión. Tal como se comenta a lo largo de esta tesis, Compressive 
Sensing (véase apéndice C) es el que se ha usado en algunos de los experimentos presentados. 


\section{Apéndice B}

\section{Patrones de Walsh-Hadamard}

Los patrones de muestreo utilizados en las experiencias realizadas en esta tesis son funciones 2D pertenecientes a la base de Walsh-Hadamard (W-H). Esta base debe su nombre, por un lado, a la matriz de Hadamard y, por otro lado, a las funciones Walsh. La matriz de Hadamard es cuadrada y está formada por elementos de valor $+1 \mathrm{y}-1$. Todas las filas (y columnas) de la matriz son ortogonales entre sí, es decir, el producto de una matriz de Hadamard y su traspuesta es proporcional a la matriz identidad:

$$
H_{N} \cdot H_{N}^{T}=N \cdot I_{N}
$$

donde $H_{N}$ es una matriz de Hadamard de dimensión $N \times N, I_{N}$ es la matriz identidad de la misma dimensión y $T$ denota traspuesta [139]. Entre las diferentes maneras de generar matrices de Hadamard destaca la construcción de Sylvester, que obtiene las matrices Hadamard de orden 1, 2, 4, 8, 16, ... recursivamente a partir de $H_{1}=(1)$ y de la siguiente ecuación [140]:

$$
H_{2 n}=\left(\begin{array}{cc}
H_{n} & H_{n} \\
H_{n} & -H_{n}
\end{array}\right)
$$

donde $n=2^{m}$, siendo $m=1,2,3, \ldots$.

Las funciones de Walsh son un conjunto completo y ortogonal de funciones rectangulares. Estas funciones están formadas por elementos de valor $+1 \mathrm{y}$ -1 coincidiendo con las filas de las matrices de Hadamard. Las funciones de Walsh tienen una interpretación frecuencial, de forma que la frecuencia es el número de cambios de signo que hay a lo largo de cada fila, tal como se muestra en la figura B.1. Las funciones de Walsh pueden seguir diferentes órdenes frecuenciales: el orden de Walsh o secuencial (el mostrado en la figura B.1), y el orden de Hadamard o natural (el que siguen las filas de las matrices de Hadamard). Por ejemplo, en la matriz $\mathrm{H}_{4}$ las frecuencias de las filas son 


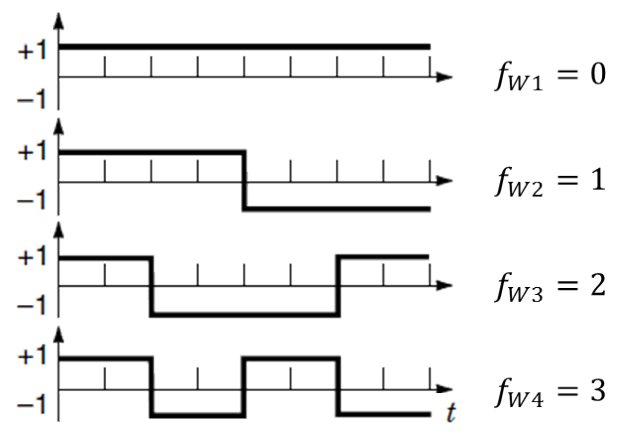

Figura B.1 - Conjunto de las 4 primeras funciones Walsh en orden secuencial (u orden de Walsh) 139.

$f_{H 1}=0, f_{H 2}=3, f_{H 3}=1$ y $f_{H 4}=2$ respectivamente:

$$
H_{4}=\left(\begin{array}{cccc}
+1 & +1 & +1 & +1 \\
+1 & -1 & +1 & -1 \\
+1 & +1 & -1 & -1 \\
+1 & -1 & -1 & +1
\end{array}\right)
$$

De este modo el conjunto de las filas de la matriz de Hadamard se puede considerar como una base de funciones 1D rectangulares, que son funciones de Walsh. En este contexto la matriz Hadamard realiza la descomposición de una función en un conjunto de funciones rectangulares de manera similar a como lo hace la transformada de Fourier en un conjunto de funciones sinusoidales [141].

$\mathrm{Al}$ igual que una imagen $2 \mathrm{D}$ se puede expresar como un vector $1 \mathrm{D}$ en tratamiento de imágenes digitales, los vectores 1D correspondientes a las funciones de Walsh tienen una representación en 2D que se llama funciones o patrones Walsh-Hadamard (W-H). En el ejemplo para $N=4$ (ecuación B.3) cada fila de la matriz $H_{4}$ es una función de Walsh y cada función de Walsh se puede representar como una función $\mathrm{W}-\mathrm{H}$ del siguiente modo:

$$
\begin{aligned}
& W_{1}=\left(\begin{array}{llll}
+1 & +1 & +1 & +1
\end{array}\right) \Longleftrightarrow \mathrm{WH}_{1}=\left(\begin{array}{ll}
+1 & +1 \\
+1 & +1
\end{array}\right) \\
& W_{2}=\left(\begin{array}{llll}
+1 & -1 & +1 & -1
\end{array}\right) \Longleftrightarrow \mathrm{WH}_{2}=\left(\begin{array}{ll}
+1 & -1 \\
+1 & -1
\end{array}\right) . \\
& W_{3}=\left(\begin{array}{llll}
+1 & +1 & -1 & -1
\end{array}\right) \Longleftrightarrow \mathrm{WH}_{3}=\left(\begin{array}{ll}
+1 & +1 \\
-1 & -1
\end{array}\right) . \\
& W_{4}=\left(\begin{array}{llll}
+1 & -1 & -1 & +1
\end{array}\right) \Longleftrightarrow \mathrm{WH}_{4}=\left(\begin{array}{ll}
+1 & -1 \\
-1 & +1
\end{array}\right) .
\end{aligned}
$$




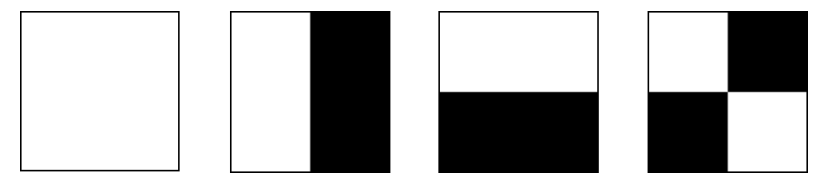

Figura B.2 - Representación de las funciones Walsh-Hadamard obtenidas a partir de la matriz $H_{4}$ como imágenes de $2 \times 2$ píxeles. Los valores 1 están representados en blanco y los valores -1 en negro. En orden de izquierda a derecha se corresponden con $\mathrm{WH}_{1}, \mathrm{WH}_{2}, \mathrm{WH}_{3}$ y $\mathrm{WH}_{4}$.

Los patrones $\mathrm{W}-\mathrm{H}$ tienen dimensión $\sqrt{N} \times \sqrt{N}$, tal como se ve en el conjunto de ecuaciones B.4. Estas funciones bidimensionales, representadas en la figura B.2, son las que se implementan en el SLM para realizar las medidas single-pixel. Los SLM empleados en esta tesis se usan sólo como moduladores de intensidad $(0,1)$, lo que hace que la implementación de los patrones $\mathrm{W}-\mathrm{H}$ no sea inmediata. Como el proceso de medida utilizado es lineal, cualquier función de $\mathrm{W}-\mathrm{H}$ se puede expresar como la resta de dos funciones complementarias:

$$
\mathrm{WH}=\mathrm{WH}^{+}-\mathrm{WH}^{-},
$$

donde $\mathrm{WH}^{+}$se construye a partir de $\mathrm{WH}$ reemplazando los -1 por 0 y $\mathrm{WH}^{-}$es la matriz complementaria de $\mathrm{WH}^{+}$. Estas funciones binarias sí que se pueden implementar fácilmente con un modulador espacial de amplitud. De esta forma la medida de una función de Walsh-Hadamard superpuesta al objeto consiste en recoger con un fotodetector los valores de intensidad $\left(I^{+}, I^{-}\right)$para cada subpatrón $\left(\mathrm{WH}^{+}, \mathrm{WH}^{-}\right.$, respectivamente) y calcular el valor que correspondería al patrón original WH mediante $I=I^{+}-I^{-}$. No obstante, este método implica doblar el número de medidas a realizar en SPI para la reconstrucción de la imagen (véase tabla A.1 del apéndice A).

Una forma sencilla de disminuir el tiempo de adquisición a la mitad es tomar únicamente las medidas de intensidad con los patrones $\mathrm{WH}^{+}$. Para obtener los valores de intensidad correspondientes a WH se tendría que realizar una sencilla operación con las intensidades $I^{+}$. Puesto que $\mathrm{WH}^{+}$y $\mathrm{WH}^{-}$son complementarias con valores de 0 y 1 , la suma de ambas es una matriz en la que todos sus elementos son 1s (matriz $J$ ), de forma que se puede escribir:

$$
\mathrm{WH}^{+}+\mathrm{WH}^{-}=J .
$$

A partir de las ecuaciones B.5 y B.6 se puede deducir $\mathrm{WH}=2 \mathrm{WH}^{+}-$ $J$. Traduciéndolo a las medidas experimentales en intensidad quedaría $I=$ $2 I^{+}-J$, donde $I^{+}$son los valores de intensidad medidos con un fotodetector para cada superposición de los patrones $\mathrm{WH}^{+}$y el objeto, mientras que $J$ 


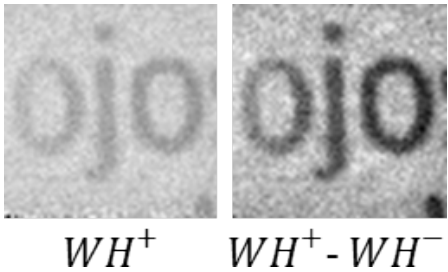

Figura B.3 - Derecha: imagen reconstruida con $\mathrm{WH}^{+}$. Izquierda: imagen reconstruida con $\mathrm{WH}^{+}-\mathrm{WH}^{-}$. Ambas imágenes tienen $64 \times 64$ píxeles.

es el valor medido para el patrón en el que todos los valores son 1, es decir, un patrón todo blanco. Esta opción de medir $I^{+}$funciona satisfactoriamente cuando se tienen unas condiciones de iluminación óptimas. Sin embargo, en condiciones de bajo nivel de luz, el ruido introducido por el detector, la fuente de luz o el entorno (la luz de un LED cercano o la pantalla del PC) pueden tener un gran impacto en la imagen reconstruida, tal como se observa en la figura B.3. Por otro lado, con las dos medidas $\left(I^{+}, I^{-}\right)$se elimina el efecto de las fluctuaciones temporales que pueda tener la fuente de iluminación, mientras que midiendo sólo $I^{+}$esto no sería posible.

Otra forma de reducir el número de medidas es, como se ha mencionado en varias ocasiones a lo largo de esta tesis, la aplicación de algoritmos adaptativos o técnicas de compresión como CS. 


\section{Apéndice $\mathrm{C}$}

\section{Teoría de Compressive Sensing}

En la sociedad actual, inmersa en la era digital, es habitual el almacenamiento y la transmisión de imágenes comprimidas en formatos tales como JPEG, JPEG2000 u otros. Las técnicas para comprimir consisten en representar las imágenes en una base diferente a la base natural, donde se requieren menos coeficientes para expresar la imagen sin pérdida sustancial de información. Si la imagen se puede expresar en una base con sólo un número reducido de coeficientes, inferior a la dimensión de la imagen, entonces se dice que la imagen es sparse en esta base. Citando a David Brady, profesor de la Universidad de Duke, "if it is possible to compress measured data, one might argue that too many measurements were made". Teniendo esta afirmación presente, la teoría de Compressive Sensing (CS) explora la estimación de imágenes compresibles realizando menos medidas que la dimensión de las imágenes 142 144].

Recuperando la notación de la sección 2.3, se puede decir que el conjunto de medidas del objeto $\mathbf{x}$ sobre un conjunto de funciones se puede escribir como

$$
\mathbf{y}=\mathbf{\Phi} \mathbf{x}
$$

donde cada fila de la matriz de medida $\boldsymbol{\Phi}$ se corresponde con una función de una base. Si $\Psi$ es otra base donde la imagen es sparse, se puede escribir la ecuación C.1 como

$$
\mathrm{y}=\Phi \Psi \alpha
$$

donde $\boldsymbol{\alpha}$ es un vector sparse, es decir, que tiene pocos elementos que sean distintos de cero.

Cuando el número de medidas $\left(N^{\prime}\right)$ es menor que la dimensión de la imagen, el sistema de ecuaciones correspondiente a la ecuación C.2 es compatible indeterminado y tiene infinitas soluciones. Para afrontar esta situación, se 
puede plantear el siguiente problema de optimización

$$
\boldsymbol{\alpha}_{e}=\min \gamma(\boldsymbol{\alpha}) \text { de tal manera que } \quad \mathbf{y}=\boldsymbol{\Phi} \boldsymbol{\Psi} \boldsymbol{\alpha}
$$

donde $\boldsymbol{\alpha}_{e}$ es la imagen estimada, y donde se minimiza una función determinada $\gamma(\boldsymbol{\alpha})$, denominada función objetivo, restringida al cumplimiento de la ecuación $\mathrm{y}=\boldsymbol{\Phi} \boldsymbol{\Psi} \alpha$.

La teoría de CS tiene como objetivos:

1. Diseñar la matriz de medida $\boldsymbol{\Phi}$.

2. Garantizar que el problema de optimización tenga una alta probabilidad de solución única.

El profesor Candés en el año 2006 presentó un trabajo enunciando un teorema que garantiza la reconstrucción de la imagen bajo tres requisitos [145]: que la imagen sea sparse en la base $\boldsymbol{\Psi}$, que la matriz de medida $\boldsymbol{\Phi}$ sea un subconjunto aleatorio de elementos de una base, y que las bases $\boldsymbol{\Phi}$ y $\boldsymbol{\Psi}$ sean incoherentes en el sentido que se detalla a continuación.

La coherencia entre la base usada para muestrear el objeto $(\boldsymbol{\Phi})$ y la base usada para reconstruir el objeto $(\boldsymbol{\Psi})$ se define como

$$
\mu(\boldsymbol{\Phi}, \boldsymbol{\Psi})=\sqrt{N} \max _{k, j}\left|\left\langle\phi_{k} \psi_{j}\right\rangle\right|,
$$

donde $1 \leq k, j \leq N$.

La coherencia cuantifica la mayor correlación entre dos elementos cualesquiera de $\boldsymbol{\Phi}$ y $\boldsymbol{\Psi}$. El rango de valores posible es $\mu(\boldsymbol{\Phi}, \boldsymbol{\Psi}) \in[1, \sqrt{N}]$. El caso de máxima coherencia se da cuando las dos bases comparten un vector, entonces $\mu(\boldsymbol{\Phi}, \boldsymbol{\Psi})=\sqrt{N}$. Cuando la coherencia es mínima $(\mu(\boldsymbol{\Phi}, \boldsymbol{\Psi})=1)$, se dice que las bases $\boldsymbol{\Phi}$ y $\boldsymbol{\Psi}$ son incoherentes.

El teorema de Candés [85] puede enunciarse de la siguiente forma

"Si un objeto es $k$-sparse en $\boldsymbol{\Psi}$ (tiene $k<N$ coeficientes no nulos), si la matriz de medida se compone por un conjunto aleatorio de vectores de la base, y si se cumple que

$$
N^{\prime} \geq k C \mu^{2}(\boldsymbol{\Phi}, \boldsymbol{\Psi}) \log N
$$

donde $C$ es una constante positiva, entonces la imagen estimada a partir de

$$
\boldsymbol{\alpha}_{e}=\arg \min \|\boldsymbol{\alpha}\|_{l_{1}} \text { de tal manera que } \mathbf{\Phi} \Psi \boldsymbol{\alpha}=\mathbf{y},
$$

representa la imagen de objeto $\boldsymbol{\alpha}$ con una alta probabilidad" [44].

La función objetivo utilizada en el problema de optimización para la estimación de la imagen es la norma $l_{1}\|\boldsymbol{\alpha}\|_{l_{1}}=\sum_{i=1}^{N}\left|\alpha_{i}\right|$, donde $\alpha_{i}$ es un coeficiente de x. Según la ecuación C.5 se puede decir que cuanto más incoherentes son las bases de medida $\boldsymbol{\Phi}$ y $\boldsymbol{\Psi}$, menos medidas es necesario realizar para recuperar la imagen. 
En presencia de ruido, el problema de optimización puede replantearse como

$$
\boldsymbol{\alpha}_{e}=\arg \min \|\boldsymbol{\alpha}\|_{l_{1}} \quad \text { de tal manera que } \quad\|\boldsymbol{\Phi} \boldsymbol{\Psi} \boldsymbol{\alpha}-\mathbf{y}\|_{l_{2}} \leq \epsilon
$$

siendo la norma $l_{2},\|\boldsymbol{\alpha}\|_{l_{2}}=\sum_{i=1}^{N}\left|\alpha_{i}\right|^{2}$. En las referencias 85, 145 se puede encontrar una explicación más detallada sobre los fundamentos matemáticos de la técnica de CS, así como otras herramientas de optimización que se pueden aplicar para conseguir el objetivo fundamental de la teoría de CS, que es recuperar la señal a partir de un número reducido de medidas lineales inferior al establecido por el teorema de Nyquist. 


\section{Bibliografía}

[1] Agustín González-Cano. Alhacén: una revolución óptica. ARBOR Ciencia, Pensamiento y Cultura, 191(775):a262, oct 2015.

[2] United Nations. Resolución aprobada por la Asamblea General el 20 de diciembre de 2013: Año Internacional de la Luz y las Tecnologías Basadas en la Luz, 2015.

[3] Hannu Karttunen, Pekka Kröger, Heikki Oja, Markku Poutanen, and Karl J. Donner. Fundamental Astronomy. Springer Berlin Heidelberg, Berlin, Heidelberg, 5th editio edition, 2017.

[4] Ralph Weissleder. Scaling down imaging: molecular mapping of cancer in mice. Nature Reviews Cancer, 2(1):11-18, jan 2002.

[5] Vasilis Ntziachristos, Jorge Ripoll, Lihong V. Wang, and Ralph Weissleder. Looking and listening to light: the evolution of whole-body photonic imaging. Nature biotechnology, 23(3):313-320, 2005.

[6] Ralph Weissleder and Mikael J. Pittet. Imaging in the era of molecular oncology. Nature, 452(7187):580-589, apr 2008.

[7] Melinda Wenner. The most transparent research. Nature Medicine, 15(10):1106-1109, oct 2009.

[8] Vasilis Ntziachristos. Going deeper than microscopy: the optical imaging frontier in biology. Nature Methods, 7(8):603-614, aug 2010.

[9] Kwanghun Chung, Jenelle Wallace, Sung-Yon Kim, Sandhiya Kalyanasundaram, Aaron S Andalman, Thomas J Davidson, Julie J Mirzabekov, Kelly a Zalocusky, Joanna Mattis, Aleksandra K Denisin, Sally Pak, Hannah Bernstein, Charu Ramakrishnan, Logan Grosenick, Viviana Gradinaru, and Karl Deisseroth. Structural and molecular interrogation of intact biological systems. Nature, 497(7449):332-337, may 2013. 
[10] Nicholas G. Horton, Ke Wang, Demirhan Kobat, Catharine G. Clark, Frank W. Wise, Chris B. Schaffer, and Chris Xu. In vivo three-photon microscopy of subcortical structures within an intact mouse brain. $\mathrm{Na}$ ture Photonics, 7(3):205-209, mar 2013.

[11] https://www.radiologyinfo.org/sp/info.cfm?pg=safety-xray, 2017.

[12] Robert H. Webb. Confocal optical microscopy. Reports on Progress in Physics, 59(3):427-471, mar 1996.

[13] D. Huang, E. Swanson, C. Lin, J. Schuman, W. Stinson, W. Chang, M. Hee, T. Flotte, K. Gregory, C. Puliafito, and J. Fujimoto. Optical coherence tomography. Science, 254(5035):1178-1181, nov 1991.

[14] Fritjof Helmchen and Winfried Denk. Deep tissue two-photon microscopy. Nature methods, 2(12):932-40, dec 2005.

[15] J. Tang, R. N. Germain, and M. Cui. Superpenetration optical microscopy by iterative multiphoton adaptive compensation technique. Proceedings of the National Academy of Sciences, 109(22):8434-8439, may 2012.

[16] Martin J. Booth. Adaptive optical microscopy: the ongoing quest for a perfect image. Light: Science \& Applications, 3(4):e165-e165, apr 2014.

[17] Juan M. Bueno, Martin Skorsetz, Raquel Palacios, Emilio J. Gualda, and Pablo Artal. Multiphoton imaging microscopy at deeper layers with adaptive optics control of spherical aberration. Journal of Biomedical Optics, 19(1):11007, 2014.

[18] Joseph N. Mait, Gary W. Euliss, and Ravindra A. Athale. Computational imaging. Advances in Optics and Photonics, 10(2):409, jun 2018.

[19] Ryoichi Horisaki, Ryosuke Takagi, and Jun Tanida. Learning-based imaging through scattering media. Optics Express, 24(13):13738, jun 2016.

[20] James Sharpe. Optical Projection Tomography as a Tool for 3D Microscopy and Gene Expression Studies. Science, 296(5567):541-545, apr 2002 .

[21] Lihong V. Wang. Multiscale photoacoustic microscopy and computed tomography. Nature Photonics, 3(9):503-509, sep 2009. 
[22] Claudio Vinegoni, Chrysoula Pitsouli, Daniel Razansky, Norbert Perrimon, and Vasilis Ntziachristos. In vivo imaging of Drosophila melanogaster pupae with mesoscopic fluorescence tomography. Nature Methods, 5(1):45-47, jan 2008.

[23] Stefan Rotter and Sylvain Gigan. Light fields in complex media: Mesoscopic scattering meets wave control. Reviews of Modern Physics, 89(1):015005, mar 2017.

[24] Ivo. M. Vellekoop and Allard. P. Mosk. Focusing coherent light through opaque strongly scattering media. Optics Letters, 32(16):2309, aug 2007.

[25] Sébastien M. Popoff, Geoffroy Lerosey, Mathias Fink, A. Claude Boccara, and Sylvain Gigan. Controlling light through optical disordered media: transmission matrix approach. New Journal of Physics, 13(12):123021, dec 2011.

[26] Moonseok Kim, Wonjun Choi, Youngwoon Choi, Changhyeong Yoon, and Wonshik Choi. Transmission matrix of a scattering medium and its applications in biophotonics. Optics Express, 23(10):12648, may 2015.

[27] Isaac Freund, Michael Rosenbluh, and Shechao Feng. Memory effects in propagation of optical waves through disordered media. Physical Review Letters, 61(20):2328-2331, nov 1988.

[28] Benjamin Judkewitz, Roarke Horstmeyer, Ivo M. Vellekoop, Ioannis N. Papadopoulos, and Changhuei Yang. Translation correlations in anisotropically scattering media. Nature Physics, 11(8):684-689, aug 2015.

[29] Ori Katz, Eran Small, and Yaron Silberberg. Looking around corners and through thin turbid layers in real time with scattered incoherent light. Nature Photonics, 6(8):549-553, 2012.

[30] Jacopo Bertolotti, Elbert G. van Putten, Christian Blum, Ad Lagendijk, Willem L. Vos, and Allard P. Mosk. Non-invasive imaging through opaque scattering layers. Nature, 491(7423):232-234, nov 2012.

[31] Ori Katz, Pierre Heidmann, Mathias Fink, and Sylvain Gigan. Noninvasive single-shot imaging through scattering layers and around corners via speckle correlations. Nature Photonics, 8(10):784-790, oct 2014. 
[32] Youngwoon Choi, Taeseok Daniel Yang, Christopher Fang-Yen, Pilsung Kang, Kyoung Jin Lee, Ramachandra R. Dasari, Michael S. Feld, and Wonshik Choi. Overcoming the Diffraction Limit Using Multiple Light Scattering in a Highly Disordered Medium. Physical Review Letters, 107(2):023902, jul 2011.

[33] Ivo M. Vellekoop and Christof M. Aegerter. Scattered light fluorescence microscopy: imaging through turbid layers. Optics Letters, 35(8):1245, apr 2010.

[34] Claire M. Watts, David Shrekenhamer, John Montoya, Guy Lipworth, John Hunt, Timothy Sleasman, Sanjay Krishna, David R. Smith, and Willie J. Padilla. Terahertz compressive imaging with metamaterial spatial light modulators. Nature Photonics, 8(8):605-609, jun 2014.

[35] John Hunt, Tom Driscoll, Alex Mrozack, Guy Lipworth, Matthew Reynolds, David Brady, and David R. Smith. Metamaterial Apertures for Computational Imaging. Science, 339(6117):310-313, jan 2013.

[36] Gregory A. Howland, Daniel J. Lum, Matthew R. Ware, and John C. Howell. Photon counting compressive depth mapping. Optics Express, 21(20):23822, oct 2013.

[37] Pere Clemente, Vicente Durán, Enrique Tajahuerce, Pedro Andrés, Vicent Climent, and Jesús Lancis. Compressive holography with a singlepixel detector. Optics Letters, 38(14):2524, jul 2013.

[38] Lluís Martínez-León, Pere Clemente, Yutaka Mori, Vicent Climent, Jesús Lancis, and Enrique Tajahuerce. Single-pixel digital holography with phase-encoded illumination. Optics Express, 25(5):4975, mar 2017.

[39] Yaron Bromberg, Ori Katz, and Yaron Silberberg. Ghost imaging with a single detector. Physical Review A, 79(5):053840, may 2009.

[40] Pere Clemente, Vicente Durán, Víctor Torres-Company, Enrique Tajahuerce, and Jesús Lancis. Optical encryption based on computational ghost imaging. Optics Letters, 35(14):2391, jul 2010.

[41] Yuehao Wu, Iftekhar O. Mirza, Gonzalo R. Arce, and Dennis W. Prather. Development of a digital-micromirror-device-based multishot snapshot spectral imaging system. Optics Letters, 36(14):2692, 2011. 
[42] Fernando Soldevila, Esther Irles, Vicente Durán, Pere Clemente, Mercedes Fernández-Alonso, Enrique Tajahuerce, and Jesús Lancis. Singlepixel polarimetric imaging spectrometer by compressive sensing. Applied Physics B, 113(4):551-558, dec 2013.

[43] Richard A. DeVerse, Robert M. Hammaker, and William G. Fateley. An improved Hadamard encoding mask for multiplexed Raman imaging using single channel detection. Journal of Molecular Structure, 521(13):77-88, mar 2000.

[44] Marco F. Duarte, Mark A. Davenport, Dharmpal Takhar, Jason N. Laska, Ting Sun, Kevin F. Kelly, and Richard G. Baraniuk. Single-pixel imaging via compressive sampling. IEEE Signal Processing Magazine, 25(2):83-91, mar 2008.

[45] Anton Van Pamel, Colin R. Brett, Peter Huthwaite, and Michael J. S. Lowe. Finite element modelling of elastic wave scattering within a polycrystalline material in two and three dimensions. The Journal of the Acoustical Society of America, 138(4):2326-2336, oct 2015.

[46] Jørgen B. Andersen, Theodore S. Rappaport, and Susumu Yoshida. Propagation measurements and models for wireless communications channels. IEEE Communications Magazine, 33(1):42-49, 1995.

[47] John Rarity. Entangled telecommunications. Nature Photonics, 4(6):342-343, jun 2010.

[48] Louise K. Harra. Looking closer at the Sun. Science, 346(6207):305306 , oct 2014 .

[49] Woody Turner. Sensing biodiversity. Science, 346(6207):301-302, oct 2014.

[50] Ashwin N. Sridhar, Archie Hughes-Hallett, Erik K. Mayer, Philip J. Pratt, Philip J. Edwards, Guang-Zhong Yang, Ara W. Darzi, and Justin A. Vale. Image-guided robotic interventions for prostate cancer. Nature Reviews Urology, 10(8):452-462, aug 2013.

[51] https://www.flickr.com/photos/kamenskiyan/15479977676/in/photolistpzUW3Q-qWU3gq/.

[52] https://structurae.net/photos/206278-pedestrian-bridge-acrossvolkhov. 
[53] Valery Tuchin. Tissue Optics. SPIE, 1000 20th Street, Bellingham, WA 98227-0010 USA, sep 2007.

[54] Fabrizio Martelli, Samuele Del Bianco, Andrea Ismaelli, and Giovanni Zaccanti. Light Propagation through Biological Tissue and Other Diffusive Media: Theory, Solutions, and Software. SPIE, 1000 20th Street, Bellingham, WA 98227-0010 USA, dec 2009.

[55] Antonio Miguel Caravaca-Aguirre. Light Control for Non-Invasive and Minimally Invasive Imaging. $\mathrm{PhD}$ thesis, University of Colorado Boulder, 2016.

[56] Chris Dunsby and Paul M. W. French. Techniques for depth-resolved imaging through turbid media including coherence-gated imaging. Journal of Physics D: Applied Physics, 36(14):R207-R227, jul 2003.

[57] Joseph W. Goodman. Speckle Phenomena in Optics: Theory and Applications. Roberts and Company, Englewood, 2007.

[58] Tomáš Čižmár. Exploiting multimode waveguides for in vivo imaging. SPIE Newsroom, sep 2015.

[59] David J. Stephens and Victoria J. Allan. Light Microscopy Techniques for Live Cell Imaging. Science, 300(5616):82-86, apr 2003.

[60] Warren R. Zipfel, Rebecca M. Williams, and Watt W. Webb. Nonlinear magic: multiphoton microscopy in the biosciences. Nature Biotechnology, 21(11):1369-1377, nov 2003.

[61] Milind Rajadhyaksha, R. Rox Anderson, and Robert H. Webb. Videorate confocal scanning laser microscope for imaging human tissues in vivo. Applied Optics, 38(10):2105, apr 1999.

[62] Demirhan Kobat, Michael E. Durst, Nozomi Nishimura, Angela W. Wong, Chris B. Schaffer, and Chris Xu. Deep tissue multiphoton microscopy using longer wavelength excitation. Optics Express, 17(16):13354, aug 2009.

[63] Eric A. Swanson, Joseph A. Izatt, C. P. Lin, James G. Fujimoto, Joel S. Schuman, M .R. Hee, David Huang, and Carmen A. Puliafito. In vivo retinal imaging by optical coherence tomography. Optics Letters, 18(21):1864, nov 1993. 
[64] Joseph M. Schmitt, Michael J. Yadlowsky, and R. F. Bonner. Subsurface Imaging of Living Skin with Optical Coherence Microscopy. Dermatology, 191(2):93-98, 1995.

[65] James G. Fujimoto, Costas Pitris, Stephen A. Boppart, and Mark E. Brezinski. Optical Coherence Tomography: An Emerging Technology for Biomedical Imaging and Optical Biopsy. Neoplasia, 2(1-2):9-25, jan 2000 .

[66] Eusebio Real, José Fernando Val-Bernal, José M. Revuelta, Alejandro Pontón, Marta Calvo Díez, Marta Mayorga, José M. López-Higuera, and Olga M. Conde. Identification of vessel wall degradation in ascending thoracic aortic aneurysms with OCT. Biomedical Optics Express, 5(11):4089, nov 2014.

[67] Joseph A. Izatt, Eric A. Swanson, James G. Fujimoto, Michael R. Hee, and Gabrielle M. Owen. Optical coherence microscopy in scattering media. Optics Letters, 19(8):590, apr 1994.

[68] Christoph G. A. Hoelen, Frits F. M. de Mul, Richard Pongers, and André Dekker. Three-dimensional photoacoustic imaging of blood vessels in tissue. Optics Letters, 23(8):648, apr 1998.

[69] Allard P. Mosk, Ad Lagendijk, Geoffroy Lerosey, and Mathias Fink. Controlling waves in space and time for imaging and focusing in complex media. Nature Photonics, 6(5):283-292, may 2012.

[70] Sébastien M. Popoff, Geoffroy Lerosey, Rémi Carminati, Mathias Fink, A. Claude Boccara, and Sylvain Gigan. Measuring the Transmission Matrix in Optics: An Approach to the Study and Control of Light Propagation in Disordered Media. Physical Review Letters, 104(10):100601, mar 2010.

[71] Donald B. Conkey, Antonio M. Caravaca-Aguirre, and Rafael Piestun. High-speed scattering medium characterization with application to focusing light through turbid media. Optics Express, 20(2):1733, jan 2012.

[72] Alba M. Paniagua-Diaz, Adrian Ghita, Tom Vettenburg, Nick Stone, and Jacopo Bertolotti. Enhanced deep detection of Raman scattered light by wavefront shaping. X(X):1-6, jul 2018. 
[73] Alba M. Paniagua-Diaz. Light in scattering media : active control and the exploration of intensity correlations. PhD thesis, University of Exeter, 2018.

[74] Roderick D. Swift, Richard B. Wattson, John A. Decker, Ralph Paganetti, and Martin Harwit. Hadamard transform imager and imaging spectrometer. Applied Optics, 15(6):1595, jun 1976.

[75] Patrick J. Treado and Michael D. Morris. Hadamard Transform Raman Imaging. Applied Spectroscopy, 42(5):897-901, jul 1988.

[76] Patrick J. Treado and Michael D. Morris. Hadamard transform techniques in photothermal spectroscopy. In AIP Conference Proceedings, volume 191, pages 725-730. AIP, 1989.

[77] Marcel J. E. Golay. Multi-Slit Spectrometry*. Journal of the Optical Society of America, 39(6):437, jun 1949.

[78] Matthew P. Edgar, Graham M. Gibson, Richard W. Bowman, Baoqing Sun, Neal Radwell, Kevin J. Mitchell, Stephen S. Welsh, and Miles J. Padgett. Simultaneous real-time visible and infrared video with singlepixel detectors. Scientific Reports, 5(1):10669, sep 2015.

[79] Vicente Durán, Pere Clemente, Mercedes Fernández-Alonso, Enrique Tajahuerce, and Jesús Lancis. Single-pixel polarimetric imaging. Optics Letters, 37(5):824, mar 2012.

[80] Eva Salvador-Balaguer, Pedro Latorre-Carmona, Carlos Chabert, Filiberto Pla, Jesús Lancis, and Enrique Tajahuerce. Low-cost single-pixel 3D imaging by using an LED array. Optics Express, 26(12):15623, jun 2018.

[81] Yiwei Zhang, Matthew P. Edgar, Baoqing Sun, Neal Radwell, Graham M. Gibson, and Miles J. Padgett. 3D single-pixel video. Journal of Optics, 18(3):035203, mar 2016.

[82] Fernando Soldevila, Vicente Durán, Pere Clemente, Jesús Lancis, and Enrique Tajahuerce. Phase imaging by spatial wavefront sampling. Optica, 5(2):164, feb 2018.

[83] Ángel D. Rodríguez, Pere Clemente, Esther Irles, Enrique Tajahuerce, and Jesús Lancis. Resolution analysis in computational imaging with patterned illumination and bucket detection. Optics Letters, 39(13):3888, jul 2014. 
[84] Michael B. Wakin, Jason N. Laska, Marco F. Duarte, Dror Baron, Shriram Sarvotham, Dharmpal Takhar, Kevin F. Kelly, and Richard G. Baraniuk. An Architecture for Compressive Imaging. In 2006 International Conference on Image Processing, pages 1273-1276. IEEE, oct 2006.

[85] Emmanuel J. Candes and Michael B. Wakin. An Introduction To Compressive Sampling. IEEE Signal Processing Magazine, 25(2):21-30, mar 2008 .

[86] Wen-Kai Yu, Ming-Fei Li, Xu-Ri Yao, Xue-Feng Liu, Ling-An Wu, and Guang-Jie Zhai. Adaptive compressive ghost imaging based on wavelet trees and sparse representation. Optics Express, 22(6):7133, mar 2014.

[87] Neal Radwell, Kevin J. Mitchell, Graham M. Gibson, Matthew P. Edgar, Richard Bowman, and Miles J. Padgett. Single-pixel infrared and visible microscope. Optica, 1(5):285, nov 2014.

[88] Fernando Soldevila, Eva Salvador-Balaguer, Pere Clemente, Enrique Tajahuerce, and Jesús Lancis. High-resolution adaptive imaging with a single photodiode. Scientific Reports, 5(1):14300, nov 2015.

[89] Joseph W. Goodman. Some fundamental properties of speckle*. Journal of the Optical Society of America, 66(11):1145, nov 1976.

[90] Enrique Tajahuerce, Vicente Durán, Pere Clemente, Esther Irles, Fernando Soldevila, Pedro Andrés, and Jesús Lancis. Image transmission through dynamic scattering media by single-pixel photodetection. $O p$ tics Express, 22(14):16945, jul 2014.

[91] Emmanuel J. Candes. http://www.stat.stanford.edu/candes/l1magic.

[92] Pere Clemente, Vicente Durán, Lluís Martínez-León, Vicent Climent, Enrique Tajahuerce, and Jesús Lancis. Use of polar decomposition of Mueller matrices for optimizing the phase response of a liquid-crystalon-silicon display. Optics Express, 16(3):1965, 2008.

[93] Alain Hore and Djemel Ziou. Image Quality Metrics: PSNR vs. SSIM. In 2010 20th International Conference on Pattern Recognition, pages 2366-2369. IEEE, aug 2010.

[94] Rajesh Mehra. Estimation of the Image Quality under Different Distortions. International Journal Of Engineering And Computer Science, 5(17291):17291-17296, jul 2016. 
[95] David Salomon. A Guide to Data Compression Methods. Springer New York, New York, NY, 2002.

[96] Vasilis Ntziachristos, Arjun G. Yodh, Mitchell Schnall, and Britton Chance. Concurrent MRI and diffuse optical tomography of breast after indocyanine green enhancement. Proceedings of the National Academy of Sciences, 97(6):2767-2772, mar 2000.

[97] David A. Boas, Dana H. Brooks, Eric L. Miller, Charles A. DiMarzio, Misha Kilmer, Richard J. Gaudette, and Quan Zhang. Imaging the body with diffuse optical tomography. IEEE Signal Processing Magazine, 18(6):57-75, 2001.

[98] Vicente Durán, Fernando Soldevila, Esther Irles, Pere Clemente, Enrique Tajahuerce, Pedro Andrés, and Jesús Lancis. Compressive imaging in scattering media. Optics Express, 23(11):14424, 2015.

[99] Guillermo Marquez, Lihong V Wang, Shao-Pow Lin, Jon A Schwartz, and Sharon L Thomsen. Anisotropy in the absorption and scattering spectra of chicken breast tissue. Applied Optics, 37(4):798, feb 1998.

[100] Bruce J. Tromberg, Natasha Shah, Ryan Lanning, Albert Cerussi, Jennifer Espinoza, Tuan Pham, Lars Svaasand, and John Butler. NonInvasive In Vivo Characterization of Breast Tumors Using Photon Migration Spectroscopy. Neoplasia, 2(1-2):26-40, jan 2000.

[101] Inc. American National Standards Institute. America National Standard for Safe Use of Lasers, 2007.

[102] Pablo Artal. Image Formation in the Living Human Eye. Annual Review of Vision Science, 1(1):1-17, nov 2015.

[103] http://sciabc.us/nGaGJ Why Squinting Helps Us See Better?, 2017.

[104] Robert D. Moore and George W. Hopkins. CCD camera and method for fundus imaging. U. S. Patent 5140352, 1992.

[105] Junzhong Liang, David R. Williams, and Donald T. Miller. Supernormal vision and high-resolution retinal imaging through adaptive optics. Journal of the Optical Society of America A, 14(11):2884, nov 1997.

[106] Stacey S. Choi, Nathan Doble, Joseph L. Hardy, Steven M. Jones, John L. Keltner, Scot S. Olivier, and John S. Werner. In Vivo Imaging of the Photoreceptor Mosaic in Retinal Dystrophies and Correlations 
with Visual Function. Investigative Opthalmology \& Visual Science, 47(5):2080, may 2006.

[107] Robert H. Webb, George W. Hughes, and Francois C. Delori. Confocal scanning laser ophthalmoscope. Applied Optics, 26(8):1492, apr 1987.

[108] Austin Roorda, Fernando Romero-Borja, William J. Donnelly III, Hope Queener, Thomas J. Hebert, and Melanie C.W. Campbell. Adaptive optics scanning laser ophthalmoscopy. Optics Express, 10(9):405, may 2002.

[109] Brian Vohnsen and Diego Rativa. Ultrasmall spot size scanning laser ophthalmoscopy. Biomedical Optics Express, 2(6):1597, jun 2011.

[110] Matthew S. Muller, Ann E. Elsner, and Glen Y. Ozawa. Non-mydriatic confocal retinal imaging using a digital light projector. volume 8567, page $85670 Y$, mar 2013.

[111] Kari V. Vienola, Mathi Damodaran, Boy Braaf, Koenraad A. Vermeer, and Johannes F. de Boer. Parallel line scanning ophthalmoscope for retinal imaging. Optics Letters, 40(22):5335, nov 2015.

[112] Pablo Artal, Antonio Benito, Guillermo M. Pérez, Encarna Alcón, Álvaro De Casas, Jaume Pujol, and José M. Marín. An Objective Scatter Index Based on Double-Pass Retinal Images of a Point Source to Classify Cataracts. PLoS ONE, 6(2):e16823, feb 2011.

[113] https://ocularis.es/pics/retsana.jpg, 2007.

[114] Caroline A. Schneider, Wayne S. Rasband, and Kevin W. Eliceiri. NIH Image to ImageJ: 25 years of image analysis. Nature Methods, 9(7):671675, jul 2012.

[115] Benjamin Lochocki, Adrian Gambín, Silvestre Manzanera, Esther Irles, Enrique Tajahuerce, Jesus Lancis, and Pablo Artal. Single pixel camera ophthalmoscope. Optica, 3(10):1056, oct 2016.

[116] Nam Huynh, Edward Zhang, Marta Betcke, Simon Arridge, Paul Beard, and Ben Cox. Single-pixel optical camera for video rate ultrasonic imaging. Optica, 3(1):26, jan 2016.

[117] Lenore McMackin, Matthew A. Herman, Bill Chatterjee, and Matt Weldon. A high-resolution SWIR camera via compressed sensing. In 
Bjørn F. Andresen, Gabor F. Fulop, and Paul R. Norton, editors, Infrared Technology and Applications XXXVIII, volume 8353, pages 835303835303-10, may 2012.

[118] Rayko I. Stantchev, Baoqing Sun, Sam M. Hornett, Peter A. Hobson, Graham M. Gibson, Miles J. Padgett, and Euan Hendry. Noninvasive, near-field terahertz imaging of hidden objects using a single-pixel detector. Science Advances, 2(6):e1600190-e1600190, jun 2016.

[119] Ming-jie Sun, Matthew P. Edgar, David B. Phillips, Graham M. Gibson, and Miles J. Padgett. Infrared single-pixel imaging utilising microscanning. Arxiv, 2015.

[120] Amaury Badon, Dayan Li, Geoffroy Lerosey, A. Claude Boccara, Mathias Fink, and Alexandre Aubry. Smart optical coherence tomography for ultra-deep imaging through highly scattering media. Science Advances, 2(11):e1600370-e1600370, nov 2016.

[121] Instituto Nacional de Seguridad e Higiene en el Trabajo (INSHT). Guía técnica para la evaluación y prevención de los riesgos relacionados con las radiaciones ópticas artificiales. Ministerio de Empleo y Seguridad Social, Madrid, 2015.

[122] https://www.osa.org/en-us/about_osa/newsroom/news_releases/2014/ Overcoming Light Scattering: Single-pixel Optical System Uses Compressive Sensing to See Deeper Inside Tissue, 2014.

[123] http://optics.org/news/5/7/8 Overcoming light scattering in biosample imaging, 2014.

[124] https://www.bioopticsworld.com/articles/2014/07/single-pixeloptical-system-with-compressive-sensing-enables-deeper-tissueimaging.html, 2014.

[125] https://www.sciencedaily.com/releases/2014/07/140702111031.htm Overcoming light scattering: New optical system sees deeper inside tissue, 2014.

[126] Vicente Durán, Fernando Soldevila, Esther Irles, Pere Clemente, Enrique Tajahuerce, Pedro Andrés, and Jesús Lancis. Scatter-free imaging through biological tissue. SPIE Newsroom, pages 2-4, jan 2016.

[127] Laura A. Sordillo, Yang Pu, Sebastião Pratavieira, Yury Budansky, and Robert R. Alfano. Deep optical imaging of tissue using the second and 
third near-infrared spectral windows. Journal of Biomedical Optics, 19(5):056004, may 2014.

[128] Laura Waller and Lei Tian. Computational imaging: Machine learning for 3D microscopy. Nature, 523(7561):416-417, jul 2015.

[129] Xing Lin, Yair Rivenson, Nezih T. Yardimci, Muhammed Veli, Yi Luo, Mona Jarrahi, and Aydogan Ozcan. All-optical machine learning using diffractive deep neural networks. Science, 361(6406):1004-1008, sep 2018 .

[130] Navid Borhani, Eirini Kakkava, Christophe Moser, and Demetri Psaltis. Learning to see through multimode fibers. Optica, 5(8):960, aug 2018.

[131] Miles Wernick, Yongyi Yang, Jovan Brankov, Grigori Yourganov, and Stephen Strother. Machine Learning in Medical Imaging. IEEE Signal Processing Magazine, 27(4):25-38, jul 2010.

[132] Neil Savage. Digital spatial light modulators. Nature Photonics, 3(3):170-172, mar 2009.

[133] Grigory Lazarev, Andreas Hermerschmidt, Sven Krüger, and Stefan Osten. LCOS Spatial Light Modulators: Trends and Applications. In Optical Imaging and Metrology, pages 1-29. Wiley-VCH Verlag GmbH \& Co. KGaA, Weinheim, Germany, aug 2012.

[134] Roberto Fernández, Sergi Gallego, Andrés Márquez, Jorge Francés, Víctor Navarro-Fuster, and Inmaculada Pascual. Diffractive lenses recorded in absorbent photopolymers. Optics Express, 24(2):1559, jan 2016.

[135] David G. Grier. A revolution in optical manipulation. Nature, 424(6950):810-816, aug 2003.

[136] Vicente Durán Bosch. Optimización del funcionamiento de un Modulador Espacial de Luz de Cristal Líquido mediante el modelo retardadorrotor. Aplicaciones en Óptica adaptativa. PhD thesis, Universitat de Valencia, 2007.

[137] Jeffrey A. Davis, David B. Allison, Kevin D’Nelly, Michael L. Wilson, and Ignacio S. Moreno. Ambiguities in measuring the physical parameters for twisted-nematic liquid crystal spatial light modulators. Optical Engineering, 38(4):705, apr 1999. 
[138] http://www.appliedmaterials.com/files/styles/large/public/inlineimages/TFT-LCD_Diagrams-475px.jpg?itok=tZ71oFRG.

[139] Mohsen Razzaghi and Jalal Nazarzadeh. Walsh Functions. In Wiley Encyclopedia of Electrical and Electronics Engineering. John Wiley \& Sons, Inc., Hoboken, NJ, USA, dec 1999.

[140] Martin Harwit and Neil J. A. Sloane. Hadamard Transform Optics. Academic Press, London, 1979.

[141] William K. Pratt, J. Kane, and H.C. Andrews. Hadamard transform image coding. Proceedings of the IEEE, 57(1):58-68, 1969.

[142] Emmanuel J. Candes, Justin Romberg, and Terence Tao. Robust uncertainty principles: exact signal reconstruction from highly incomplete frequency information. IEEE Transactions on Information Theory, 52(2):489-509, feb 2006.

[143] Emmanuel J. Candes and Terence Tao. Near-Optimal Signal Recovery From Random Projections: Universal Encoding Strategies? IEEE Transactions on Information Theory, 52(12):5406-5425, dec 2006.

[144] David L. Donoho. Compressed sensing. IEEE Transactions on Information Theory, 52(4):1289-1306, apr 2006.

[145] Emmanuel J. Candès, Justin K. Romberg, and Terence Tao. Stable signal recovery from incomplete and inaccurate measurements. Communications on Pure and Applied Mathematics, 59(8):1207-1223, aug 2006 . 
Artículos publicados 



\title{
Image transmission through dynamic scattering media by single-pixel photodetection
}

\author{
Enrique Tajahuerce, ${ }^{1}$ Vicente Durán, ${ }^{1}$ Pere Clemente, ${ }^{1}$ Esther Irles, ${ }^{1}$ \\ Fernando Soldevila, ${ }^{1}$ Pedro Andrés, ${ }^{2}$ and Jesús Lancis ${ }^{1, *}$ \\ ${ }^{1}$ GROC•UJI, Institut of New Imaging Technologies, Universitat Jaume I, 12070 Castelló, \\ Spain \\ ${ }^{2}$ Departamento de Óptica, Universitat de València, 46100 Burjassot, Spain
}

*lancis@uji.es

\begin{abstract}
Smart control of light propagation through highly scattering media is a much desired goal with major technological implications. Since interaction of light with highly scattering media results in partial or complete depletion of ballistic photons, it is in principle impossible to transmit images through distances longer than the extinction length. Nevertheless, different methods for image transmission, focusing, and imaging through scattering media by means of wavefront control have been published over the past few years. In this paper we show that single-pixel optical systems, based on compressive detection, can also overcome the fundamental limitation imposed by multiple scattering to successfully transmit information. But, in contrast with the recently introduced schemes that use the transmission matrix technique, our approach does not require any a-priori calibration process that ultimately makes the present method suitable to use with dynamic scattering media. This represents an advantage over previous methods that rely on optical feedback wavefront control, especially for short speckle decorrelation times.
\end{abstract}

(C) 2014 Optical Society of America

OCIS codes: (290.4210) Multiple scattering; (110.7050) Turbid media; (110.1758) Computational imaging; (230.6120) Spatial light modulators.

\section{References and links}

1. M. Wenner, "The most transparent research," Nature Medicine 15, 1106-1109 (2009).

2. K. Chung, J. Wallace, S. Y. Kim, S. Kalyanasundaram, A. S. Andalman, T. J. Davidson, J. J. Mirzabekov, K. A. Zalocusky, J. Mattis, A. K. Denisin, S. Pak, H. Bernstein, C. Ramakrishnan, L. Grosenick, V. Gradinaru and K. Deisseroth, "Structural and molecular interrogation of intact biological systems," Nature (London) 497, 332-337 (2013).

3. M. J. Booth, D. Dbarre and A. Jesacher, “Adaptive optics for biomedical microscopy,” Opt. Photon. News 23, 22 (2012).

4. A. P. Mosk, A. Lagendijk, G. Lerosey and M. Fink, "Controlling waves in space and time for imaging and focusing in complex media,” Nat. Photonics 6, 283-292 (2012).

5. I. M. Vellekoop, A. Lagendijk and A. P. Mosk, “Exploiting disorder for perfect focusing," Nat. Photonics 4 , 320-322 (2010)

6. S. M. Popoff, G. Lerosey, M. Fink, A. C. Boccara and S. Gigan, “ Controlling light through optical disordered media: transmission matrix approach,” New J. Phys. 13, 123021 (2011).

7. R. T. Hillman, T. Yamauchi, W. Choi, R. R. Dasari, M. S. Feld, Y. Park and Z. Yaqoob, "Digital optical phase conjugation for delivering two-dimensional images through turbid media," Sci. Rep. 3, (2013). 
8. O. Katz, E. Small, Y. Bromberg and Y. Silberberg,“ Focusing and compression of ultrashort pulses through scattering media," Nat. Photonics 5, 372-377 (2011).

9. D. J. McCabe, A. Tajalli, D. R. Austin, P. Bondareff, I. A. Walmsley, S. Gigan and B. Chatel, “ Spatio-temporal focusing of an ultrafast pulse through a multiply scattering medium," Nat. Commun. 2, 447-5 (2011).

10. S. Popoff, G. Lerosey, M. Fink, A. C. Boccara and S. Gigan, "Image transmission through an opaque materia," Nat. Commun. 1, (2010).

11. J. Katz and J. Sheng, "Applications of Holography in Fluid Mechanics and Particle Dynamics," Annu. Rev. Fluid Mech. 42, 531-555 (2010).

12. J. Bertolotti, E. G. van Putten, C. Blum, A. Lagendijk, W. L. Vos and A. P. Mosk,"Non-invasive imaging through opaque scattering layers," Nature (London) 491, 232-234 (2012).

13. D. B. Conkey, A. M. Caravaca-Aguirre and R. Piestun, "High-speed scattering medium characterization with application to focusing light through turbid media," Opt. Express 20, 1733-1740 (2012).

14. M. Nixon, O. Katz, E. Small, Y. Bromberg, A. A. Friesem, Y. Silberberg and N. Davidson, 'Real-time wavefront shaping through scattering media by all-optical feedback," Nat. Photonics 7, 919-924 (2013).

15. M. Plöschner, B. Straka, K. Dholakia and T. Cizmár, "GPU accelerated toolbox for real-time beam-shaping in multimode fibres," Opt. Express 22, 2933-2947 (2014).

16. Y. Bromberg, O. Katz and Y. Silberberg, "Ghost imaging with a single detector," Phys. Rev. A 79, 053840 (2009).

17. P. Clemente, V. Durán, E. Tajahuerce, V. Torres-Company and J. Lancis, "Single-pixel digital ghost holography," Phys. Rev. A 86, 041803 (2012).

18. M. F. Duarte, M. A. Davenport, D. Takhar, J. N. Laska, T. Sun, K. F. Kelly and R. G. Baraniuk, "Single-Pixe Imaging via Compressive Sampling,” IEEE Signal Process. Mag. 25, 83-91 (2008).

19. F. Magalhães, F. M. Araújo, M. V. Correia, M. Abolbashari and F. Farahi, "Active illumination single-pixel camera based on compressive sensing," Appl. Opt. 50, 405-414 (2011).

20. E. J. Candes and M. B. Wakin, “An Introduction To Compressive Sampling," IEEE Signal Process. Mag. 25, 21-30 (2008).

21. B. Sun, M. P. Edgar, R. Bowman, L. E. Vittert, S. Welsh, A. Bowman and M. J. Padgett, "3D Computational Imaging with Single-Pixel Detectors," Science 340, 844-847 (2013).

22. G. A. Howland and J. C. Howell, "Efficient High-Dimensional Entanglement Imaging with a CompressiveSensing Double-Pixel Camera," Phys. Rev. X 3, 011013 (2013).

23. V. Studer, J. Bobin, M. Chahid, H. S. Mousavi, E. Candes and M. Dahan, "Compressive fluorescence microscopy for biological and hyperspectral imaging," Proc. Natl. Acad. Sci. USA 109, E1679-E1687 (2012).

24. J. Hunt, T. Discroll, A. Mrozack, G. Lipworth, M. Reynolds, D. Brady and D. R. Smith, "Metamaterial Apertures for Computational Imaging," Science 339, 310-313 (2013).

25. Y. Choi, C. Yoon, M. Kim, W. Choi and W. Choi, "Optical Imaging With the Use of a Scattering Lens," IEEE J. Sel. Top. Quantum Electron. 20, 6800213 (2014).

26. T. Cizmar and K. Dholakia, "Exploiting multimode waveguides for pure fibre-based imaging," Nature Commun. 3, 1027 (2012).

27. S. M. Popoff, G. Lerosey, R. Carminati, M. Fink, A. C. Boccara and G. Gigan, "Measuring the Transmission Matrix in Optics: An Approach to the Study and Control of Light Propagation in Disordered Media," Phys. Rev. Lett. 104, 100601 (2010).

28. J. W. Goodman, "Some fundamental properties of speckle," J. Opt. Soc. Am. 66, 1145-1150 (1976).

29. E. J. Candes, http://www.stat.stanford.edu/ candes/l1magic.

\section{Introduction}

In a conventional imaging experiment, a lens maps every input pixel of an object to its conjugated output pixel at the sensor. Input and output measurement modes correspond to highly specific and localized information and all modes are simultaneously measured with an optical array detector, being transfer of information physically limited, in the ideal case, by diffraction. However, in a scattering medium the relationship between input and output pixels suffers the effects of light propagation by multiple scatterers. As a result, the spatial information of an input mode is scrambled and coupled through all output modes. Alternatively, an output pixel retains a tiny fraction of the optical field coming from every input mode and the interference between the different light fields generates an image that looks like a speckle field. Indeed, the ability of a lens to provide a clear image of an object is critically limited, even when a very thin layer of a scattering material is placed in the light path.

Scattering is the dominant extinction process that limits the imaging depth range inside bi- 
ological tissue [1]. Although optical clearing techniques based on tissue manipulation has recently resulted in a see-through tissue [2], manipulation of photons provides a parallel avenue to control light-matter interactions without alteration of the biological material. Fine control of wave fields with current megapixel programmable spatial light modulators is by far the most employed approach. Examples of such technology are adaptive optics [3] and, more recently, control of disorder [4]. Transmission matrix characterization or feedback control based on iterative methods has allowed to undo the modifications that a scattering medium performs on the incoming wavefront by wavefront shaping [5-9] and seeing through static scattering media has also been demonstrated with this approach $[10,11]$. Additionally, the angular correlation exhibited by speckle patterns within a small range of angles has been exploited for non-invasive imaging of a fluorescent object completely embedded in an opaque scattering medium [12]. Some recent attempts to extend the above techniques to steady focusing light through a slowly evolving dynamic medium are based on the use of faster spatial light modulators or by alloptical feedback $[13,14]$. In this direction, recent advances in both DMD technology and GPU processing allow to compute the transmission matrix in tens of milliseconds [15]. However the dynamic nature of scattering in living tissue still remains an open question. Micrometerscale translations of the scatter centres generate a decorrelated speckle field on the millisecond timescale, which makes dificult to follow the changing state of the medium for current feedback control techniques.

Image transmission through dynamic scattering media requires a paradigm shift to remove the use of feedback algorithms. Here we address this challenge. To do this, we use computational imaging of projected patterns with measurements being captured sequentially by a single-pixel sensor. The programmed patterns are used as generalized measurement modes where the object information is expressed. The same principle enables retrieval of the spatial information of an object with the use of a single-pixel detector in ghost $[16,17]$ and compressive imaging $[18,19]$. In the latter case, the development of data collection strategies based on compressive sampling allows image compression to be performed at the sensing stage [20]. Applications that benefit from the advantages of single-pixel cameras are, among others, 3D imaging [21], entanglement imaging [22], fluorescence microscopy [23] or imaging at regions of the electromagnetic spectrum where current pixelated sensors are unavailable [24]. In this work we demonstrate that the presence of a scattering medium between the object and the light detector, even in the dynamically varying case, does not invalidate the operation principle of the proposed single-pixel scheme. Notably, scrambling of light due to disorder mixes information from all the regions of the sample but does not destroy the object information that can be retrieved from the generalized modes. As we will show later, we emphasize that this statement is accurate even if the medium is dynamic. Image transmission through disordered media has an immediate impact in the case of multimode fibers, which are subject to mode coupling. This crosstalk effect behaves in a similar way to a disordered medium. In this sense, an increment of the imaging capabilities of multimode fibers has been achieved by exploiting the properties of highly scattering media with a 'single-pass' architecture [25]. This approach, conceptually similar to that presented in Ref. [10], implies a precise calibration of the scattering effects and assumes a static medium. Both limitations are overcome by our single-pixel-sensor method.

\section{Operation principle}

To demonstrate our technique for image transmission through a scattering medium with a single-pixel camera, we refer to the diagram illustrated in Fig. 1(a). First, we consider the situation of static scattering. The sample (in this example a binary version of the famous Cheshire Cat in Alice's Adventures in Wonderland) is sequentially illuminated with a set of microstructured projecting patterns, which are codified onto a spatial light modulator. The light transmitted 
through the sample undergoes strong scattering so that any object is completely hidden, as is shown in Fig. 1(b). For each pattern, an optical sensor without spatial resolution averages the signal generated by the noise-like light distribution that covers its active surface. Each photodetected signal corresponds to a fraction of the light arising from the inner product between the sample and the projecting pattern and contains information of the whole sample thanks to light scrambling imposed by the scattering medium. Given that the sensor averages a sufficient number of speckle grains and that the number of input patterns is suitable, the information arising from the different modes is decorrelated and equally weighted. This fact guarantees that their contributions become independent for incoherent imaging and that the image-retrieval process can be formulated as a sequential measurement of the coefficients of the object intensity in the input basis (see Section 5). Notably, most of the coefficients of the object expressed in the function basis do not contribute in a significant way to image retrieval (see Fig. 1(c)). This means

a

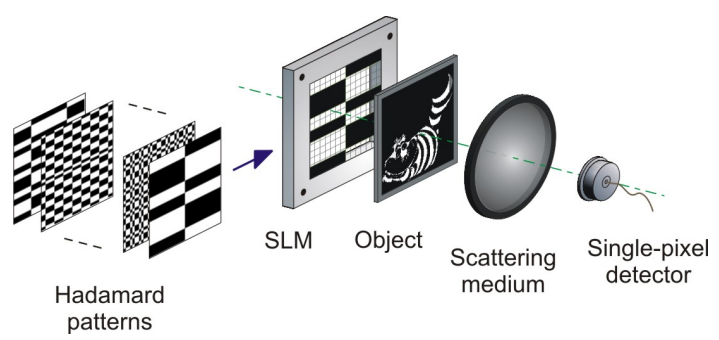

$\mathrm{b}$

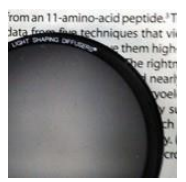

$\mathrm{C}$

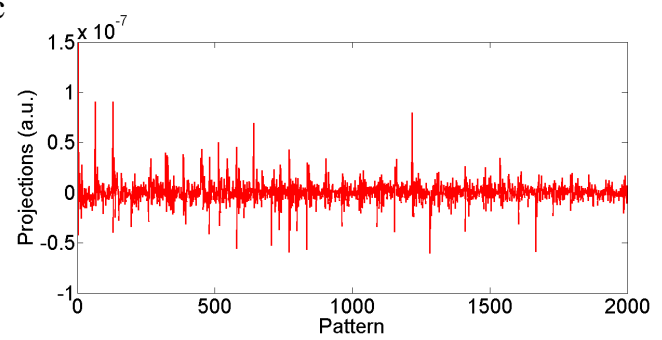

Fig. 1. Schematic diagram of the experimental set-up. (a) Set of microstructured patterns is projected onto the sample, which is placed in front of the scattering layer. The transmitted light undergoes strong scattering and a fraction is recorded by a photodiode. Within single-pixel imaging schemes, we need to project several patterns to form the image with measurements captured sequentially. (b) Photograph of the scattering layer covering partially a text located at a distance $10 \mathrm{~mm}$ from the diffuser. In this way we show that the portion of the text under the diffuser is completely hidden. (c) Plot of two thousand projections derived from the photodetected signal in terms of the input modes.

that the signal is sparse and compressive sensing can be used at the sampling stage by selecting in a random way the projecting patterns. In Section 3 we include a detailed study about the applicability of compressive sensing to our technique.

In our experiments, the Walsh-Hadamard basis is used to express the object $\mathbf{x}^{\text {in }}$ as a linear combination, $\mathbf{x}^{i n}=\sum_{i} E_{i}^{i n} \mathbf{H}_{i}(i=1, \ldots, N)$. A Walsh-Hadamard matrix of order $n$, denoted by $\mathbf{H}_{i}(n)$, is an $N=n \times n$ matrix with entries that satisfies $\mathbf{H}_{i}^{T}(n) \mathbf{H}_{i}(n)=n \mathbf{I}(n)$, where $\mathbf{I}(n)$ is the identity matrix and $\mathbf{H}_{i}^{T}(n)$ stands for the transposed matrix. Hadamard matrices form an orthonormal basis of matrices that was first proposed by researchers in statistics and is considered to be the optimum weighting design for extracting information from random noise. A shifted and rescaled version of $\mathbf{H}_{i}(n)$ generates a binary pattern taking on the values 0 or 1 , which can 
be simply encoded onto a spatial light modulator as an intensity pattern.

The scattering medium placed after the object is characterized at the macroscopic scale through the transmission matrix $\mathbf{K}$ with complex coefficients $k_{m n}$. The individual element $k_{m n}$ connects the $n$th input Hadamard mode with the $m$ th output measurement mode expressed in the canonical basis [27]. We assume that the matrix-coefficient statistics follows from the classical random walk phenomenon, as each $k_{m n}$ results from the sum of contributions from many elementary pathways inside the medium that connect incoming and outgoing modes. As a result, the complex phasor $k_{m n}$ is said to be a circular complex Gaussian variate and the transmission matrix amounts to a random matrix of independent identically distributed entries of Gaussian statistics [28]. The outgoing optical field corresponding to the $m$ th output mode is given by $E_{m}^{\text {out }}=\sum_{n} k_{m n} E_{n}^{\text {in }}$ and the field intensity from the $m$ th mode is $I_{m}^{\text {out }}=\left|\sum_{n} k_{m n} E_{n}^{\text {in }}\right|^{2}$. The input modes add together on an amplitude basis and the signal is affected by strong correlations between the signals provided by the different input Hadamard modes. In addition, the measurement in our scheme of single-pixel detection is given by the summation of the signals provided by the output canonical modes that cover the active surface of the sensor, i.e., $I^{\text {out }}=\sum_{m} I_{m}^{\text {out }}(m=1, \ldots, S)$. However, the averaging over the photodetector surface forces the cross terms that couple different input modes to vanish and their contributions become uncorrelated and equally weighted so that the modes now add together on an intensity basis, i.e., $I^{\text {out }}=\sum_{m} I_{m}^{\text {out }} \propto \sum_{n}\left|E_{n}^{i n}\right|^{2}$. Consequently, the sequential projection of the different Hadamard modes onto the input object allow us at the detection level to measure separately any image expansion coefficient $\left|E_{n}^{i n}\right|^{2}$. This result, derived in the Section 5, is extremely crucial for the validity of our proposed disorder-assisted single-pixel image-retrieval method and states that the incoherent nature of single-pixel imaging is preserved even through disordered media.

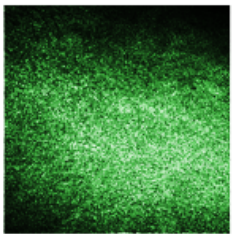

b

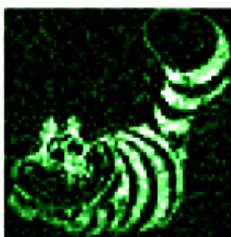

Fig. 2. Seeing through scattering media with a single-pixel camera. (a) The Cheshire Cat is placed in front of a scattering layer that completely hides it. We show the image of the object as seen by a charge-coupled-device camera (Stingray-F-145 with square pixel size of $6.45 \times 6.45 \mu^{2}$ ). The image contains not information at all on the shape of the object. (b) Image of the retrieved object from the photodetected values recorded by the photodiode. The good quality of the reconstructed image confirms that disorder-assisted imaging can indeed recover fine details of the object even though a sensor without spatial resolution is used.

Applying the above ideas to our test object, we obtained the results shown in Fig. 2. The Cheshire Cat was directly codified onto the spatial light modulator with an image size of $N=$ $128 \times 128$ pixels. The number of Walsh-Hadamard patterns was $M=0.2 N$. We used a diodepumped laser at $532 \mathrm{~nm}$ (Oxxius slim-532) coupled to a single mode optical fiber. The beam was expanded and modulated by a liquid crystal reflective spatial light modulator (Holoeye LC-R 2500, with XGA pixel pitch of $19 \mu \mathrm{m}$ ) inserted between an appropriate combination of polarizers. The scattering layer was a commercial diffuser (Edmund Optics T54-497). After passing through the diffuser, the light was partially guided by a lens to the photodiode (Thorlabs DET36A with active area size of $3.6 \times 3.6 \mathrm{~mm}^{2}$ ) to measure the fraction of the transmitted light intensity and an analog-to-digital converter digitized the photodetected signal. We found that 
the scattering layer completely hides the presence of the object so that the image recorded by a charge-coupled device camera is simply a speckle pattern (see Fig. 2(a)). On the contrary, the reconstructed image from computational imaging of projected patterns with single-pixel detection showed an excellent resemblance with the original object (see Fig. 2(b)).

\section{Compressive imaging through a static scattering layer}

\subsection{Compressive sensing}

In the framework of single-pixel imaging, the imaging process in intensity is formulated as

$$
\mathbf{y}=\mathbf{M I}^{i n}=\left(\begin{array}{ccc}
H_{1}^{11} & \cdots & H_{1}^{n n} \\
\vdots & \ddots & \vdots \\
H_{N}^{11} & \cdots & H_{N}^{n n}
\end{array}\right) \mathbf{I}^{i n},
$$

where the sampling matrix $\mathbf{M}$ is here a row-wise array of the Walsh-Hadamard modes and $\mathbf{I}^{i n}=\left|\mathbf{x}^{i n}\right|^{2}$ denotes the sampled intensity corresponding to the unknown object (expressed in the canonical basis) arranged in a column vector of dimension $N$. The components of the vector $\mathbf{y}$ are the projecting coefficients $\left|E_{n}^{\text {in }}\right|^{2}$.

The object is recovered off-line from the projections $\left|E_{n}^{i n}\right|^{2}$ by solving the algebraical problem described in Eq. (1). To form a completely determined set of measurements, the rank of the sampling matrix $\mathbf{M}$ must equal the object data dimension $N$, as has been written in Eq. (1). However, compressive sensing allows the reconstruction of sparse signals $\mathbf{I}^{\text {in }}$ although the number of measurements $M$ be lower than the number of pixels of the sampled object, i.e., $M<<N$. This image sampling mechanism overcomes the fundamental tradeoff in imaging between speed and resolution and allows to speed up computational imaging. The point is that a sparse signal has only a small part of coefficients with a significant value when transformed in the appropriate base of functions. Therefore, many of the modes of the base provide little to no useful information and can be removed without substantial loss of image quality. Although it is not known at the sensing stage what coefficients have appreciable amplitude, compressive sensing algorithm recovers an undersampled signal $\mathbf{I}_{\text {rec }}^{\text {in }}$ that approaches the exact signal $\mathbf{I}^{\text {in }}$ with high probability from random undersampling of the matrix M. From a mathematical point of view, the system is undetermined and the object is recovered by solving the optimization problem $\min \left(\left\|\mathbf{I}^{i n}\right\|_{l_{1}}\right)$ such that $\mathbf{y}(M)=\mathbf{M}_{u s} \mathbf{I}^{i n}(N)$. In the above equation $\mathbf{M}_{u s}$ is the undersampled version of the sampling matrix $\mathbf{M}$, with dimension $M \times N$, and $\left\|\mathbf{I}^{i n}\right\|_{l_{1}}$ is the $l_{1}$-norm of the object represented in an appropriate basis (in our case, the Walsh-Hadamard basis), which reflects the inherent sparsity that exists in natural objects. Given a sufficiently large number of samplings, the problem is rigorously solvable and the recovered signal $\mathbf{I}_{\text {rec }}^{\text {in }}$ approaches the exact signal $\mathbf{I}^{i n}$. If only $k$ Hadamard projections of the signal $\mathbf{I}^{i n}$ have a significant value, the number of helpful sampling modes scales as $M \geq k \log N$ [20] and the compression ratio is given by $C R=N / M$.

\subsection{Application to a microscopic sample}

To test the quality of the images recovered by compressive sensing through a turbid medium, we conducted a series of experiments with the optical implementation shown in Fig. 3(a). The laser source and the photodiode were those employed in the preceding section. The object was a sample of stained onion cells, the Walsh-Hadamard patterns had $64 \times 64$ pixels and the optics of the system was adapted to adjust the spatial scale of the projecting patterns to the sample by use of an optical relay containing a microscope objective (Nikon $4 \times$ and $N A=0.1$ ). We used the diffuser shown in Fig. 1(b) and included in the optical system the Stingray CCD camera. The sample was hidden by the scattering layer so that the image recorded by the CCD 
camera was a speckle pattern, as is shown in the small intensity map in Fig. 3(a). The code employed for compressive sensing was the function 11 eq-pd of the $l_{1}$-magic software package, which solves the standard basis pursuit problem using a primal-dual algorithm [29]. The quality of the undersampled image was tested using the standard peak signal-to-noise ratio, $P S N R=10 \log \left(I_{\max }^{2} / M S E\right)$, where $I_{\max }$ is the maximum pixel intensity value of the reference image and $M S E=\left(\frac{1}{N}\right)\left\|\mathbf{I}_{r e f}^{i n}-\mathbf{I}_{r e c}^{i n}\right\|^{2}$ stands for the mean square error between the undersampled image, $\mathbf{I}_{r e c}^{i n}$, and the image recovered from the whole measurement set, $\mathbf{I}_{r e f}^{i n}$. Figure 3(b) illustrates that the time required for the sensing stage could be reduced by a factor of 2 while the PSNR is still higher than $20 \mathrm{~dB}$, which indicates high image fidelity. This is relevant to speed up the image retrieval. Moreover, for faster operation, the slow liquid crystal spatial light modulator can be replaced by a digital micromirror device or any equivalent component. Considering that the maximum full-image frame rate of commercially available digital micromirror devices is $22.7 \mathrm{kHz}$, the capture of images of $64 \times 64$ pixels at the sensing stage could operate at a frame rate of $10 \mathrm{~Hz}$. Even in this situation, the above imaging rate is still unsatisfactory to overcome the dynamic nature of real scattering media whose speckle decorrelations are on the millisecond order.

\section{Image reconstruction through dynamic scattering media}

Our method is also valid to recover the image through a scattering medium that changes its temporal properties due to the movement of the scattering centres. The critical point here is that our technique works without the need of a signal feedback. For a dynamic scattering medium, new realizations of the random walk are created as the time goes by and, as a consequence, the speckle intensity at any point on the detector plane changes with time, and the transmission matrix too. However, our approach addresses this situation in a rather different way. As long as the statistical properties of the medium remain stationary and the number of speckle grains impinging on the active area of the sensor is high enough, the photodetected current does not change with time and, as a result, the sample is reconstructed regardless of the diffuser movement (see Fig. 4(a)). In our experiment the diffuser was a polypropylene cover characterized by its orange peel texture. The diffuser was moved by means of a stream of air and a USAF resolution chart acted as the sample. The chaotic movement of the diffuser mimicked a dynamic scattering medium generating variable speckle. The key point was that the photodiode performed a spatial intensity integration in such a way that, under the above assumptions, the value of every measurement provided by the non-pixelated detector was effectively the same as in the static state. Figure 4(b) shows a snapshot of the dynamic speckle pattern after the moving diffuser. This image was recorded by use of a charge-coupled device camera like in Fig. 3(a). A plot of the measured intensity as a function of time for a single pixel of the camera is compared with that corresponding to a small region of $64 \times 64$ pixels. The uniformity of the intensity level in the latter case is clearly noticed and is the basis of our implementation.

\section{Discussion}

Here we examine in greater detail the impact of the statistical properties of the scattering medium in the retrieved image process. As discussed before, the medium is characterized at the macroscopic scale through the transmission matrix $\mathbf{K}$ with complex coefficients $k_{m n}$. The individual quantity $k_{m n}$ connects the $n$th input Hadamard mode with the $m$ th output measurement mode expressed in the canonical basis. The measurement in our scheme of single-pixel detection is given by the summation of the signals provided by the different output modes that cover the active surface of the sensor, say $S$ modes. Thus, when the media is fed with a complex 
a

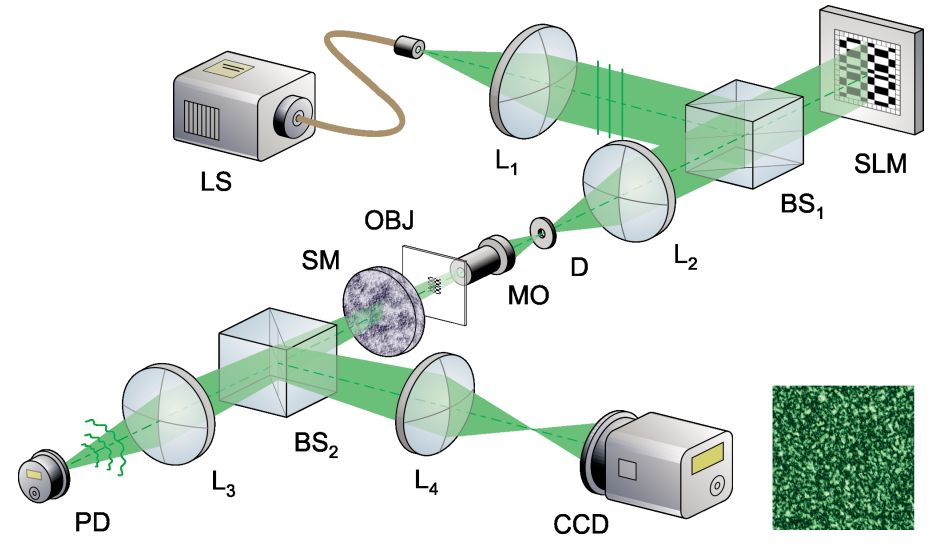

$\mathrm{b}$

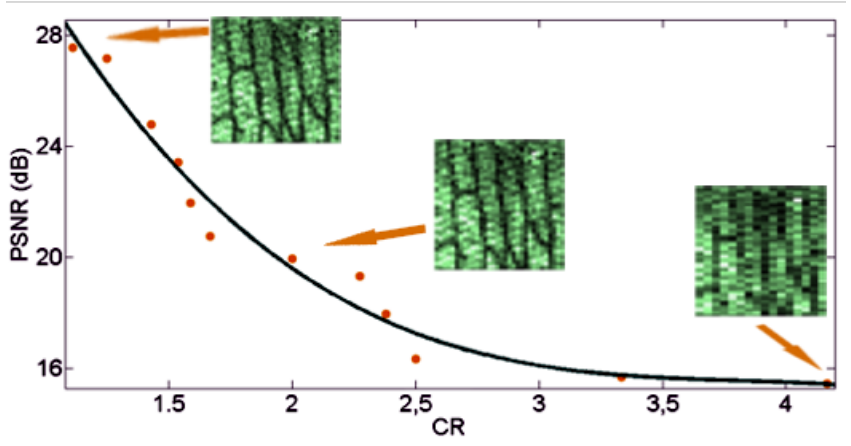

Fig. 3. Disorder-assisted compressive microscopy. (a) Schematic diagram of the optical setup. $L S$ laser source; $L$ lens; $B S$ beam splitter; $S L M$ programmable spatial light modulator; $D$ iris diaphram; $M O$ microscope objective; $O B J$ sample (stained onion cells); $S M$ scattering medium; $C C D$ charge-coupled device camera; $P D$ Photodiode. (b) Plot of the quality of the recovered images in $\mathrm{dB}$ as a function of the compression ratio. We show as insets the image of the onion cells retrieved from the photodetected signals generated by a randomized selection ( $24 \%$ and $50 \%$ ) of the 4096 input modes, along with the unsampled image $(C R=1)$ for comparison.

signal that consists of $N$ input modes, the photodetected signal is given by

$$
I^{\text {out }}=\sum_{m=1}^{S} I_{m}^{\text {out }}=\sum_{m=1}^{S}\left|\sum_{n=1}^{N} k_{m n} E_{n}^{\text {in }}\right|^{2}=\sum_{m=1}^{S} \sum_{n=1}^{N}\left|k_{m n}\right|^{2}\left|E_{n}^{i n}\right|^{2}+\sum_{m=1}^{S} \sum_{n=1}^{N} \sum_{\substack{n^{\prime}=1 \\ n^{\prime} \neq n}}^{N} k_{m n} k_{m n^{\prime}}^{*} E_{n}^{i n} E_{n^{\prime}}^{i n *}
$$

It is convenient to define $A_{n}=\sum_{m}\left|k_{m n}\right|^{2}$ and $B_{n n^{\prime}}=\sum_{m} k_{m n} k_{m n^{\prime}}^{*}$ to shorten the above expression, so that the output signal can be rewritten as

$$
I^{\text {out }}=\sum_{n=1}^{N} A_{n}\left|E_{n}^{i n}\right|^{2}+\sum_{\substack { n=1 \\
\begin{subarray}{c}{n^{\prime}=1 \\
n^{\prime} \neq n{ n = 1 \\
\begin{subarray} { c } { n ^ { \prime } = 1 \\
n ^ { \prime } \neq n } }\end{subarray}}^{N} B_{n n^{\prime}} E_{n}^{i n} E_{n^{\prime}}^{i n *}
$$

\#205980 - \$15.00 USD (C) 2014 OSA 
a

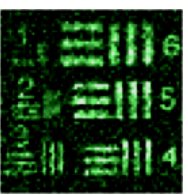

b

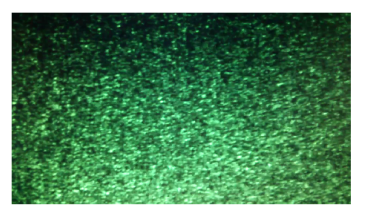

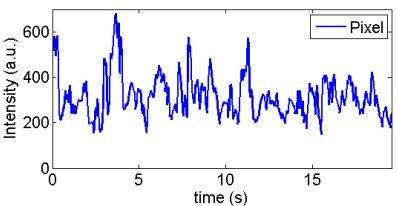

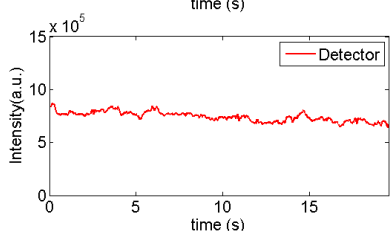

Fig. 4. Image reconstruction through a dynamic scattering medium. (a) Image of the sample (a typical resolution chart) reconstructed from the photodetected signal showing the successful image retrieving ability of our single-pixel imaging setup through a moving diffuser. (b) Snapshot of the speckle field generated by the object placed in front of a moving diffuser. At the right side we plot the detected signal with an integration time smaller than the typical temporal drift of the speckle grains corresponding to both a pixel of the camera (top) and a region of $64 \times 64$ pixels (bottom).

Due to the scattering statistics, roughly speaking the averaging over the photodetector surface forces to cancel the cross terms that couple the $B_{n n^{\prime}}$ contributions from the different input modes, or more precisely, the contribution of the coefficients $B_{n n^{\prime}}$ is negligible with respect to that of the coeffcients $A_{n}$. Instead, the $A_{n}$ contributions nearly become equally weighted for all $n$. Consequently,

$$
I^{\text {out }} \propto \sum_{n=1}^{N}\left|E_{n}^{i n}\right|^{2} .
$$

The input modes now add together on an intensity basis, as in conventional single-pixel imaging, which is at the core of our computational imaging method. At this point, and concerning Eq. (4), two additional comments are relevant. On one hand, the projection of the $n$th Hadamard mode onto the input plane allows us at the detection level to evaluate separately the corresponding squared object expansion coefficient, $\left|E_{n}^{i n}\right|^{2}$. On the other hand, compressive sensing reduces the number of sequentially projected patterns we need to recover the object information from $N$ to $M<N$ modes randomly selected. We tested experimentally the above hypotheses by sequentially launching several Hadamard patterns onto the spatial light modulator and detecting the output intensity with the charge-coupled-device camera used in Fig. 3(a). The size of the speckle grains recorded by the camera (see inset in Fig. 3(a)) was estimated from the full width at half maximum (FWHM) of the autocorrelation signal to be about $12.9 \mu \mathrm{m}$. Next the active area of the matrix sensor was limited to $64 \times 64$ pixels. In the experiment, 1500 Hadamard modes were sequentially displayed onto the spatial light modulator and the signal corresponding to the $64 \times 64$ output modes was separately recorded for every input mode. The histogram of the $\left|k_{m n}\right|$-values is shown in Fig. 5(a). The results fit nicely to the assumed random walk model for the scatterers. From the above experimental counts, we numerically calculate the value of the parameters $A_{n}$ and $B_{n n^{\prime}}$. Their corresponding statistical distributions are shown in Figs. 5(b) and (d), respectively. In the latter case, in order to compute the $B_{n n^{\prime}}$ coefficients, we allocate a random uniform phase distribution between 0 and $2 \pi$ to the $\left|k_{m n}\right|$ measured elements.

Two findings are clear from the histograms in Figs. 5(b) and (d). First, the $A_{n}$ values are clearly clustered around a certain value $\langle A\rangle$. In mathematical terms, the quotient between the standard deviation $\sigma_{A}$ and the mean value of the histogram turns out to be 0.13 , in good agree- 


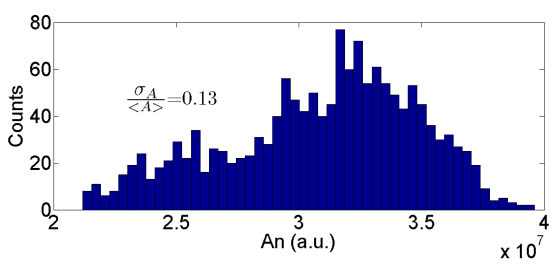

d

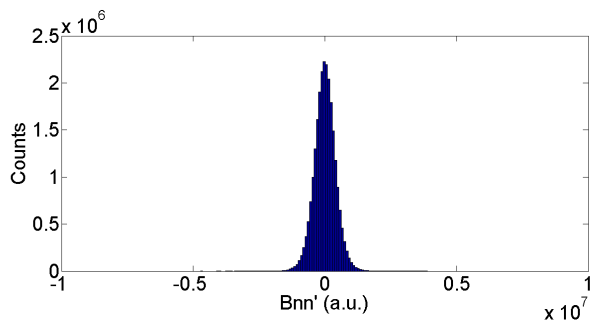

Fig. 5. Charting the statistical properties of the scattering layer. (a) Histogram of the absolute value of the transmission matrix elements assessed by experimental means. The plot fairly matches the Rayleigh distribution, as we expected. (b) Histogram of the summations $A_{n}$ evaluated from the data in (a). The small ratio between the standard deviation $\sigma_{A}$ and the mean value $\langle A\rangle$ ensures that the integrated contributions coming from the different input modes are nearly equally weighted. (c) Relative dispersion of the $A_{n}$ contributions in terms of the number of output modes integrated by the area of the sensor. (d) Histogram of the summations $B_{n n^{\prime}}$ evaluated from the data in (a) assigning randomly a uniform phase distribution between 0 and $2 \pi$. Note that in order to make easier the comparison of results, the scale of the abscissa axis in the graphs (b) and (d) is the same.

ment with the nearly zero value we expected. Likewise, the $B_{n n^{\prime}}$ coefficient histogram (a nearly Gaussian distribution) is centred at origin, shows positive and negative values, and is far away to intersect the $A_{n}$ coefficient distribution. The combination of all the above facts validates the assumptions we guessed to derive Eq. (4) from Eq. (3). Figure 5(c) shows that the relative dispersion of the $A_{n}$ contributions increases when the number of output modes integrated by the detector is smaller and smaller. The stagnation value $(0.13$ in Fig. $5(b))$ can be reduced by increasing the number of input modes taken into account. In our experiments in Fig. 3, the number of modes inside the active surface of the photodiode was about $10^{5}$, which is clearly enough to assume decorrelation between the different input modes.

\section{Conclusions}

We have demonstrated that computational techniques combined with single-pixel sensing enables image reconstruction behind arbitrary scattering media, in contrast to charge-coupled device cameras, where the pixelated structure of the sensor returns a noise-like speckle pattern. Our approach does not require a previous calibration of the disordered media and permits to retrieve images when we deal with dynamic scatterers. In contrast with techniques based on measuring the transmission matrix, our technique does not need to characterize the scattering medium, but operates on an intensity basis, thereby computing intensity distributions instead of complex fields. Moreover, the use of compressive sensing is limited to scenes that are sparse on the chosen basis. Different scenes may need different compression ratios (up to 1), which could entail higher acquisition times depending on the object under study. Our implementation is a 
first step to tackle the general problem of imaging objects completely embedded in a scattering medium. In parallel, our disordered-assisted single-pixel configuration shows straightforward applications for image transmission through multimode fibers or to look around corners. In addition, the operation principle of single-pixel imaging offers an ideal framework for using dedicated sensors, such as fiber spectrometers, beam polarimeters, and avalanche photodiodes, which can be employed to measure new physical imaging dimensions (wavelength, polarization, low-light intensity level, ...) of the sample under scrutiny.

\section{Acknowledgments}

We thank Víctor Torres-Company at the Chalmers University and Peter Török at the Imperial College of London for useful discussions and for reading the manuscript. This work was supported in part from MINECO (grants CSD2007-00013 and FIS2010-15746), Generalitat Valenciana (grants PROMETEO2012-021 and ISIC 2012/013), and the Universitat Jaume I (P1-1B2012-55). E.I. and F.S. were partially supported by a Generalitat Valenciana research fellowship. 



\title{
Compressive imaging in scattering media
}

\author{
V. Durán,,${ }^{1, *}$ F. Soldevila, ${ }^{2}$ E. Irles, ${ }^{2}$ P. Clemente, ${ }^{2}$ E. Tajahuerce, ${ }^{2}$ P. \\ Andrés $^{3}$ and J. Lancis ${ }^{2}$ \\ ${ }^{1}$ Microtechnology and Nanoscience Department (MC2), Chalmers University of Technology, \\ SE 41296, Gothenburg, Sweden \\ ${ }^{2}$ GROC.UJI, Institute of New Imaging Technologies, Universitat Jaume I, 12070 Castelló, \\ Spain \\ ${ }^{3}$ Departamento de Óptica, Universitat de València, 46100 Burjassot, Spain \\ *vandres@chalmers.se
}

\begin{abstract}
One challenge that has long held the attention of scientists is that of clearly seeing objects hidden by turbid media, as smoke, fog or biological tissue, which has major implications in fields such as remote sensing or early diagnosis of diseases. Here, we combine structured incoherent illumination and bucket detection for imaging an absorbing object completely embedded in a scattering medium. A sequence of low-intensity microstructured light patterns is launched onto the object, whose image is accurately reconstructed through the light fluctuations measured by a single-pixel detector. Our technique is noninvasive, does not require coherent sources, raster scanning nor time-gated detection and benefits from the compressive sensing strategy. As a proof of concept, we experimentally retrieve the image of a transilluminated target both sandwiched between two holographic diffusers and embedded in a $6 \mathrm{~mm}$-thick sample of chicken breast.
\end{abstract}

(C) 2015 Optical Society of America

OCIS codes: (110.1758) Computational imaging; (110.0113) Imaging through turbid media; (110.7050) Turbid media.

\section{References and links}

1. F. Helmchen and W. Denk, "Deep tissue two-photon microscopy," Nat. Methods 2, 932--940 (2005).

2. L. Wang, P. P. Ho, C. Liu, G. Zhang, and R. R. Alfano, "Ballistic 2-d imaging through scattering walls using an ultrafast optical kerr gate," Science 253, 769-771 (1991).

3. D. Huang, E. A. Swanson, C. P. Lin, J. S. Schuman, W. G. Stinson, W. Chang, M. R. Hee, T. Flotte, K. Gregory, and C. A. Puliafito, "Optical coherence tomography," Science 254, 1178-1181 (1991).

4. M. P. Rowe, E. N. Pugh, J. S. Tyo, and N. Engheta, "Polarization-difference imaging: a biologically inspired technique for observation through scattering media," Opt. Lett. 20, 608--610 (1995).

5. V. Tuchin, Tissue Optics (SPIE, 2007).

6. D. Razansky, M. Distel, C. Vinegoni, R. Ma, N. Perrimon, R. W. Köster, and V. Ntziachristos, "Multispectral opto-acoustic tomography of deep-seated fluorescent proteins in vivo," Nat. Photonics 3, $412--417$ (2009).

7. C. Vinegoni, C. Pitsouli, D. Razansky, N. Perrimon, and V. Ntziachristos, "In vivo imaging of Drosophila melanogaster pupae with mesoscopic fluorescence tomography," Nat. Methods 5, 45-47 (2008).

8. V. Ntziachristos, J. Ripoll, L. V Wang, and R. Weissleder, "Looking and listening to light: the evolution of whole-body photonic imaging," Nat. Biotechnol. 23, 313--320 (2005).

9. J. Bertolotti, E. G. van Putten, C. Blum, A. Lagendijk, W. L. Vos, and A. P. Mosk, "Non-invasive imaging through opaque scattering layers," Nature 491, 232--234 (2012).

10. O. Katz, P. Heidmann, M. Fink, and S. Gigan, "Non-invasive single-shot imaging through scattering layers and around corners via speckle correlations," Nat. Photonics 8, 784--790 (2014).

11. M. F. Duarte, M. A. Davenport, D. Takhar, J. N. Laska, K. F. Kelly, and R. Baraniuk, "Single-pixel imaging via compressive sampling,” IEEE Sign. Process. Mag. 25, 83--91 (2008).

12. J. Shapiro, "Computational ghost imaging," Phys. Rev. A 78, 061802 (2008). 
13. P. Clemente, V. Durán, E. Tajahuerce, V. Torres-Company, and J. Lancis, "Single-pixel digital ghost holography," Phys. Rev. A 86, 041803 (2012).

14. J. Hunt, T. Driscoll, A. Mrozack, G. Lipworth, M. Reynolds, D. Brady, and D. R. Smith, "Metamaterial apertures for computational imaging," Science 339, 310-313 (2013).

15. C. M. Watts, D. Shrekenhamer, J. Montoya, G. Lipworth, J. Hunt, T. Sleasman, S. Krishna, D. R. Smith, and W. J. Padilla, "Terahertz compressive imaging with metamaterial spatial light modulators," Nat. Photonics 8, 605-609 (2014).

16. D. J. Cuccia, F. Bevilacqua, A. J. Durkin, and B. J. Tromberg, "Modulated imaging: quantitative analysis and tomography of turbid media in the spatial-frequency domain," Opt. Lett. 30, 1354-1356 (2005).

17. D. J. Cuccia, F. Bevilacqua, A. J. Durkin, F. R. Ayers, and B. J. Tromberg, "Quantitation and mapping of tissue optical properties using modulated imaging," J. Biomed. Opt. 14, 024012 (2009).

18. E. Tajahuerce, V. Durán, P. Clemente, E. Irles, F. Soldevila, P. Andrés, and J. Lancis, "Image transmission through dynamic scattering media by single-pixel photodetection," Opt. Express 22, 16945 (2014).

19. E. J. Candes and M. Wakin, "An introduction to compressive sampling,” IEEE Signal Process. Mag. 25, 21-30 (2008).

20. N. J. A. Sloane, Hadamard Transform Optics (Academic, 1979).

21. G. Marquez, L. V Wang, S. P. Lin, J. A Schwartz, and S. L. Thomsen, "Anisotropy in the absorption and scattering spectra of chicken breast tissue," Appl. Opt. 37, 798--804 (1998).

22. B. J. Tromberg, N. Shah, R. Lanning, A. Cerussi, J. Espinoza, T. Pham, L. Svaasand, and J. Butler, "Non-invasive in vivo characterization of breast tumors using photon migration spectroscopy," Neoplasia 2, 26-40 (2000).

23. http://users.ece.gatech.edu/ justin/l1magic/ .

24. M. T. Figueiredo, R. D. Nowak, and S. J. Wright, "Gradient projection for sparse reconstruction: application to compressed sensing and other inverse problems,” IEEE J. Sel. Top. Signal Process. 1, 586--597 (2007).

25. F. Soldevila, E. Irles, V. Durán, P. Clemente, M. Fernández-Alonso, E. Tajahuerce, and J. Lancis, "Single-pixel polarimetric imaging spectrometer by compressive sensing," Appl. Phys. B 113, 551--558 (2013).

\section{Introduction}

The most widespread principle for high-resolution imaging through inhomogeneous media is the isolation of photons that have not experienced scattering. This idea is at the heart of so diverse approaches such as scanning multiphoton microscopy [1] or imaging techniques based on time-resolved [2], coherence-gated [3] and polarization-sensitive detection [4]. The penetration depth of these methods, irrespective of their operation principle, is limited by the fact that the intensity of the unscattered light decreases exponentially with distance. As a consequence, imaging inside a turbid medium begins to be difficult or unfeasible at penetration depths larger than the transport mean free path, the mean distance that photons travel before they become diffuse [5]. Imaging techniques that model the random propagation of diffuse photons, such as multispectral optoacoustic tomography [6] or hybrid fluorescence molecular tomography [7], can reach greater penetration depths ( $>1 \mathrm{~cm}$ in tissue), but they only enable macroscopic imaging due to their relatively low resolution [8]. Recently it has been demonstrated a non-invasive approach that uses diffuse photons while preserving optical resolution. This method is based on the angular correlation ("memory effect") inherent to the speckle patterns generated by photon scattering [9]. However, current implementations are restricted to thin scattering media [10], since the memory-effect range is inversely proportional to the medium thickness.

In this paper, we present a "scattering-free" wide-field imaging approach based on the concept of single-pixel camera [11-15]. It combines a variable structured illumination, coming from an incoherent light source, and non-pixelated "bucket" photodetection. Spatially modulated illumination has been previously used in diffuse optical imaging (DOI) for quantitative mapping of the scattering properties of an inhomogeneous medium $[16,17]$. Such a DOI approach assumes a transport model-based analysis to describe diffuse photon propagation (forward problem) and provides results after an elaborate reconstruction algorithm (inverse problem). Instead of this, our method relies on the "image-bearing" light component that preserves the illumination structure along the propagation path. The interaction between this component, which is masked by a strong diffuse background, and an absorbing object embedded in the scattering medium produces a fluctuating bucket signal. The object image is simply reconstructed 
from the correlations between the measured light fluctuations and the sequentially generated illumination patterns. In this way, a detailed characterization of the scattering parameters of the medium is not required.

Our technique uses non-diffuse photons at the illumination stage, but takes advantage of the total photon flux at the detection step. This feature distinguishes our single-pixel camera from time-gating or coherence imaging techniques, where the useful signal is composed exclusively of "image-bearing" photons arriving at the detector after passing through a scattering medium. In this case, the strong decay of this useful signal in a round trip dramatically limits the medium thickness. In contrast, our approach can work despite weakly scattered photons transmitted by the object eventually become diffuse on the way out. Recently, we have demonstrated that single-pixel detection of diffuse photons is crucial for image transmission through scattering media, even when they are dynamic [18]. However, in our previous experiments we considered an illumination stage that was free of scattering. Here, we overcome this strong limitation, demonstrating non-invasive imaging of an absorbing object completely embedded in an inhomogeneous medium. Such an advance represents a significant step towards the use of single-pixel imaging in more realistic scenarios, especially in biophotonics applications.

As a proof of concept, we present experimental results for an object hidden by a couple of holographic diffusers. To test the potentiality of our approach for imaging in tissue, the above diffusers are replaced by two $3 \mathrm{~mm}$-thick layers of chicken breast. For such a tissue thickness, multiple scattering is the predominant effect. Image reconstructions inside the "diagnostic window" (from $650 \mathrm{~nm}$ to $1000 \mathrm{~nm}$ ) are presented. In order to harness the advantages offered by single-pixel imaging, we apply compressive sensing to speed up the data acquisition process.

\section{Single-pixel imaging in scattering media}

Our single-pixel scheme is sketched in Fig. 1(a). Spatially and temporally incoherent light coming from a white-light source impinges onto a digital micromirror device (DMD), which is composed of an array of electronically controlled micromirrors that can tilt between two angular directions. The DMD produces a set of illumination patterns, which are projected by an optical relay system onto a high-contrast object embedded in a non-absorbing inhomogeneous medium. The light that hits the object consists of two superimposed components: a strong diffuse halo, the result of averaging many uncorrelated and noninterfering speckle patterns generated by the incoherent source, plus a forward-scattered weak signal, which is a "ghost" illumination pattern with a spatial structure similar to the light pattern "sculpted" by the DMD (Fig. 1(b)). Finally, in our transillumination geometry, the light emerging from the back portion of the scattering medium is concentrated by a collecting lens onto the large active surface of a bucket detector, here a photodiode (PD).

The purpose of the above optical system is to obtain the correlation between the weak structured patterns sampling the object and the tiny fluctuations that appear in the bucket signal. Such a correlation allows one to get rid of the prevalent noisy background interacting with the object due to scattering. As the DMD projects onto the object a sequence of $M$ masks $\left\{I_{i}(\mathbf{x})\right\}$ $(i=1, \ldots, M)$, the intensity at each position $\mathrm{x}$ of the object fluctuates from one pattern to the next. On its turn, the bucket detector measures a signal $\left\{Y_{i}\right\}$, where each $Y_{i}$ is a photocurrent proportional to the total light power emerging from the sample for the $i$-th mask. The image $T(\mathbf{x})$ is then built from the spatially resolved cross-correlation $T(\mathbf{x})=\sum_{i} \Delta I_{i}(\mathbf{x}) \Delta Y_{i}$ between the pattern-to-pattern intensity fluctuations, $\Delta I_{i}=I_{i}(\mathbf{x})-\langle I(\mathbf{x})\rangle$, and those registered by the bucket detector, $Y_{i}-\langle Y\rangle$. Interestingly, for a given illumination pattern, the bucket detector provides a weighted-sum of the fluctuations arising from all the pixels of the pattern and the weights of this sum correspond to the object's transmission at each spatial position. Hence, when the pattern-to-pattern fluctuations that occur at each pixel are correlated with the photocurrent sig- 
nal provided by the bucket detector, the strength of the correlation is proportional to the object's transmission at the corresponding position. This result is not affected by the diffuse background, since it is uncorrelated with the "ghost" structured pattern that impinges onto the object.

Throughout the paper, we consider a reconstruction basis formed by a set of 2D WalshHadamard matrices $\left\{I_{i}(\vec{x})_{i=1}^{N}\right\}$ which entries are either +1 or -1 . The entire reconstruction basis can be expressed through a Hadamard matrix $\mathrm{H}$,

$$
H=\left(\begin{array}{ccc}
I_{1}\left(x_{1}\right) & \cdots & I_{1}\left(x_{N}\right) \\
\vdots & \ddots & \vdots \\
I_{N}\left(x_{1}\right) & \cdots & I_{N}\left(x_{N}\right)
\end{array}\right)
$$

where each row of $\mathrm{H}$ is a Walsh-Hadamard matrix rearranged in the form of a $1 \times N$ vector. Note that $I_{i}\left(x_{j}\right)$ denotes the element of the $i$-th component of the Walsh-Hadamard basis placed at the position $x_{j}$. Taking into account the definition of the Hadamard matrices, it is straightforward to demonstrate that

$$
H \cdot H^{T}=N I_{d}
$$

where $I_{d}$ is the identity matrix of rank $N$. If we represent the amplitude transmission function of the object by a $N \times 1$ vector, $T$, the sequence of measurements taken by the bucket detector is given by

$$
Y=H \cdot T,
$$

The cross-correlation (at zero-shift) between the pattern-to-pattern fluctuations and those registered in the bucket detector signal is given by

$$
\operatorname{corr}[\Delta I(x), \Delta Y]=\sum_{i=1}^{N} \Delta I_{i}(x) \Delta Y_{i}
$$

where $\Delta I_{i}(x)=I_{i}(x)-\langle I(x)\rangle$ and $\Delta Y=Y_{i}-\langle Y\rangle$. Here, the symbol $\langle\cdot\rangle \stackrel{\text { def }}{=} \frac{1}{N} \sum_{i}$ denotes an ensemble average over the entire set of measurements and the position $x$ takes $N$ discrete values. From the properties of the Walsh-Hadamard matrices, $\sum_{i}^{N} I_{i}(x)$ results to be a vector composed of zeros, with the exception of the first component, which takes the value $N$. This exception is due to the fact that the first Walsh-Hadamard matrix is composed exclusively by ones. Aside from this, the only term in the above cross-correlation is $\sum_{i=1}^{N} I_{i}(x) Y_{i}=H^{T} \cdot Y$ and, in accordance with Eqs. (3) and (2), $H^{T} \cdot Y=N T$. As a consequence,

$$
\operatorname{corr}[\Delta I(x), \Delta Y]=N T^{*},
$$

where $T^{*}$ is a version of the object's image whose first "pixel" has an additional constant term proportional to $N$, which can be easily corrected. In conclusion, the cross-correlation expressed in Eq. (5) allows, except for an irrelevant scale factor, retrieving the object's transmission $T$.

In our approach, the object is completely embedded in a scattering medium. The light impinging onto the object is composed of a weak structured component that has a strong superimposed diffuse background. Such a noisy background, in principle, does not prevent the measurement of the bucket signal fluctuations that leads to the image reconstruction. Let us consider the measured data as the sum of a signal $S$ plus a random noise $n, Y=S+n$. The cross-correlation expressed in Eq. (4) can then be written as

$$
\operatorname{corr}[\Delta I(x), \Delta Y]=\operatorname{corr}[\Delta I(x), \Delta S]+\sum_{i=1}^{N} I_{i}(x)\left(n_{i}-\langle n\rangle\right),
$$


As $I$ and $n$ are completely uncorrelated to each other,

$$
\sum_{i=1}^{N} I_{i}(x) n_{i}=\left(\sum_{i=1}^{N} I_{i}(x)\right)\left(\sum_{i=1}^{N} n_{i}\right)=N^{2}\langle I(x)\rangle\langle n\rangle,
$$

Substituting Eq. (7) in Eq. (6) gives

$$
\operatorname{corr}[\Delta I, \Delta Y]=\operatorname{corr}[\Delta I, \Delta S]+\left(N^{2}-N\right)\langle I(x)\rangle\langle n\rangle,
$$

Taking into account that the ensemble average of the Walsh-Hadamard matrices is null,

$$
\operatorname{corr}[\Delta I, \Delta Y]=\operatorname{corr}[\Delta I, \Delta S],
$$

that is, the cross-correlation between $\Delta I$ and the fluctuations of the bucket signal $\Delta S$ is insensitive to the diffuse background noise. Therefore, the object's image can be recovered provided that the sequence of fluctuations $\Delta S$ (which are originated by the structured illumination) can be resolved by the employed detector.

Our approach can be reformulated into the framework of computational single-pixel imaging, where the $N$-pixel image $T$ of an object is recovered from its $M$ incoherent projections in a proper function basis. This formulation leads to the algebraic problem $Y=\Theta \cdot T$, where $\Theta$ is a matrix constructed by arranging in successive rows each illuminating pattern. To form a completely determined set of measurements, the rank of $\Theta$ must equal the object's data dimension. Our procedure requires the sequential delivery of $N$ illumination patterns, so the refreshing rate of the DMD limits the system temporal resolution (i.e., the time necessary to acquire one image). To speed up the data acquisition, we can take advantage of the ground-breaking theory of compressive sensing (CS), which makes it possible to recover an $N$-pixel image from $M<N$ measurements [19], as shown in Sec. 3 . Another aspect to be considered is the choice of the multiplexing masks, key to achieve a high-fidelity imaging. We implement patterns derived from the Hadamard matrices [15], which have been proven to improve by a factor $\sqrt{N}$ the signal-to-noise ratio (SNR) provided by standard raster-scanning [20]. In addition, the efficiency of our scheme benefits from the use of a single-element detector to simultaneously detect all the photons transmitted by the object, instead of spreading them out over an array of sensors in a pixelated device.

\section{Methods and experimental results}

We used the experimental setup shown schematically in Fig. 1(a). The light source was a highpower Xe lamp (Model 66002, Oriel Corporation). The SLM was a DMD with a pixel pitch of $13.7 \mu \mathrm{m}$ (DLP Discovery 4200, Texas Instruments). The unit cell of the binary intensity patterns displayed onto the modulator was composed of $4 \times 4$ DMD pixels. Two thin lenses projected the illuminating patterns onto the object and enlarged their size with a lateral magnification of 2.7, so the length of the unit cell became $148 \mu \mathrm{m}$. An optical collecting system formed by two condenser lenses $(25.4 \mathrm{~mm} \times 25.4 \mathrm{~mm}$ FL Condenser Lens, Edmund) ensured that the light was focused within the sensor area $\left(13 \mathrm{~mm}^{2}\right)$ of a photodiode (DET36A Si Biased Detector, Thorlabs). An analog-to-digital converter (NI USB-6003, National Instruments) digitized the photodetected signal. Custom software written in LabVIEW was used to control the measurement process.

To assess the capability of our technique for imaging through scattering media, we retrieved an image of a binary amplitude object sandwiched between two thin holographic diffusers (Edmund Optics \#T48-002 and \#T54-497). The object was a square part of a resolution target (NBS 1963A) with a size of about $1 \mathrm{~cm}$. The projected binary amplitude patterns were a shifted and rescaled version of the Walsh-Hadamard matrices. The number of illumination patterns 


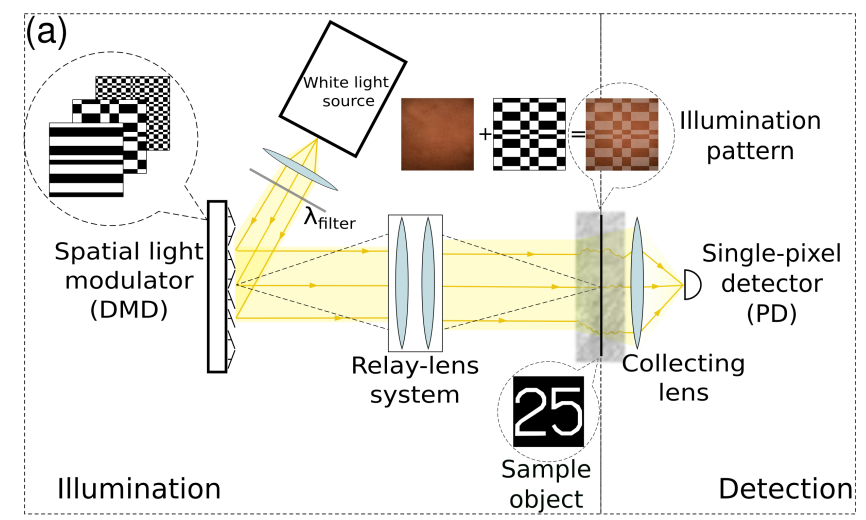

(b)

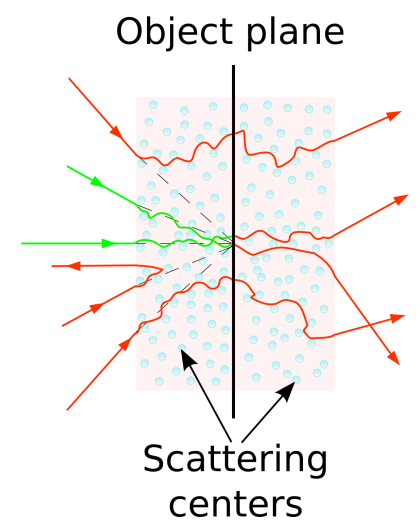

Fig. 1. Operation principle. (a), Schematic of the optical setup. Upper left inset: examples of projected patterns. Upper right inset: weighted superposition of the diffuse background and the illumination pattern. The contribution of the latter has been artificially increased to make it visible. Lower inset: binary amplitude object. (b), A ray light representation corresponding to a bright point of an illumination pattern. For a medium that produces multiple scattering, photons are randomly deviated from the directions they would trace in a homogeneous medium (dashed lines). Those diffuse light rays are red colored in our scheme. This forms a diffuse halo on the object plane, as rays arrive at multiple positions instead of the desired one. However, a fraction of the incoming rays follows a zigzagging path close to the dashed one, even after several interactions with the scattering centres. Those quasi ballistic or snake rays are green colored in our scheme. If such rays are transmitted by the object, they eventually become diffuse rays as a consequence of the second scattering process. Detection consists of collecting all the rays emerging from the ensemble in any direction.

was $N=4096$, so the resolution of the recovered images was $64 \times 64$ pixels. In order to take a conventional picture, we removed both the photodiode and the collecting lens. The object plane was imaged via a photographic objective (Nikkor $28 \mathrm{~mm} \mathrm{f} / 2.8$, Nikon) onto a region of $280 \times 280$ pixels of a digital camera (UI-3480CP-M, Imaging Developmetn Systems). Both conventional and single-pixel pictures are presented in Fig. 2. Figure 2(a) shows the spectrum of our Xe lamp. We used a set of dichroic filters to select three spectral bands in the green (Green Dichroic Filter \#46-139, Edmund), red (Red Dichroic Filter \#30-634, Edmund) and infrared (Colored Glass Filter RDG665, Melles Griot). Even though the conventional images have a 
higher resolution, the halo originated by the thin diffusors makes it impossible to recover any spatial information about the scene. Meanwhile, the single-pixel approach allows us to recover the object information. We also studied the spectral behaviour of the diffusers. As can be seen in Fig. 2(b), our technique is able to recover information in all three bands with very similar quality. As a consequence, it can work with the full spectrum given by the light source.

(a)

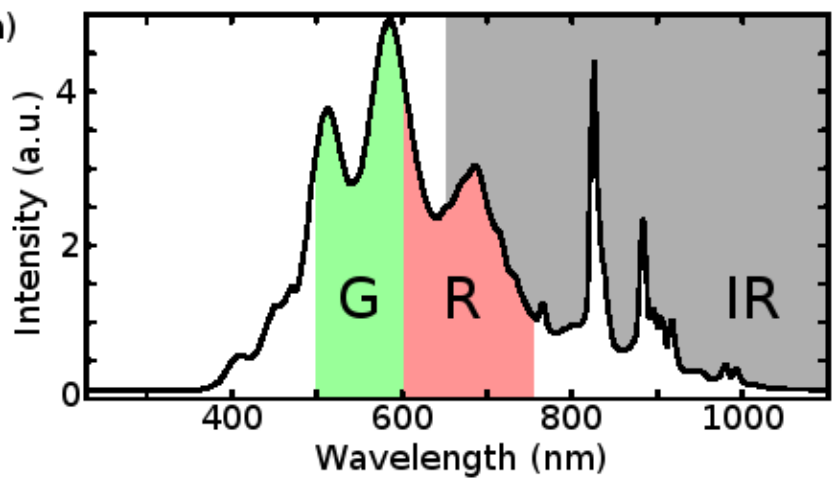

(b)

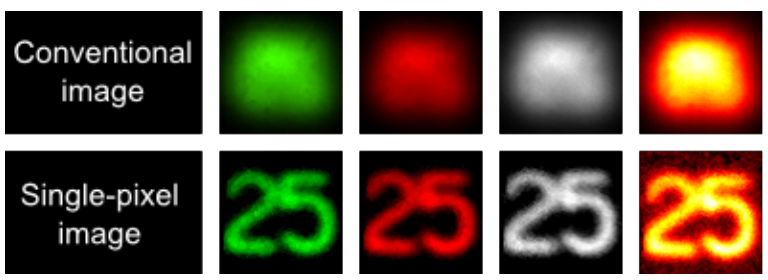

Fig. 2. (a), Power spectrum of the Xe lamp used in the experiments. In order to select different spectral bands, several combinations of dichroic filters were used. (b), Set of pictures captured both with a traditional camera and the single-pixel configuration when the object is sandwiched between two holographic diffusing layers. The pseudocolored picture (last column) corresponds to the full spectrum image (without filters). The other pictures show the results in the green, red and infrared bands, respectively.

Once the method had been proved to work with holographic diffusers, we also tried to recover and object embedded in a volume diffuser. In this experiment, we chose chicken breast tissue as biological scattering medium. The results can be seen in Fig. 3. A reference image for the object is shown in Fig. 3(a). The object was sandwiched between two layers of chicken breast, with a thickness of $2.84 \mathrm{~mm}$ and $2.92 \mathrm{~mm}$, respectively (Fig. 3(b)). No chemical or mechanical processes were applied to the tissue layers. They were placed between two transparent plastic films in order to fix them to the object under study. The image reconstruction is presented in Fig. 3(c). A sample of the measured light fluctuations, corresponding to the first 500 Hadamard patterns, is shown in Fig. 3(d). Such fluctuations make it possible to reconstruct the object image, as can be observed by comparing them with those obtained with the object immersed in air.

The capability of our approach for imaging through tissue along the light source spectrum is analyzed in Fig. 4. In this case, the object was placed between two chicken samples with a thickness of $2.4 \mathrm{~mm}$ and $2.9 \mathrm{~mm}$, respectively. In thick biological tissues photons undergo multiple scattering as they migrate through the medium. This multiple scattering mechanism is quite different from that observed in the thin holographic diffusers. Now, the reduced scattering parameter (the inverse of the transport mean free path) varies across the spectrum. For chicken 

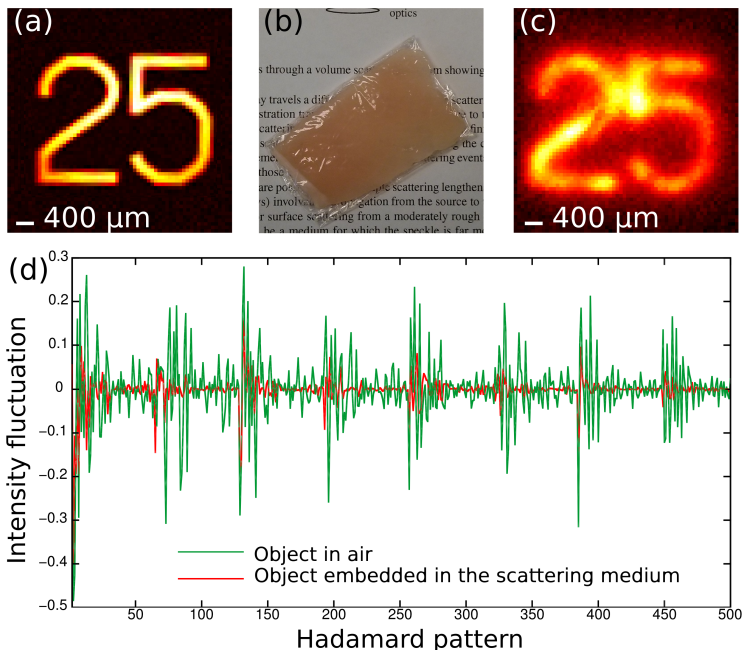

Fig. 3. Imaging inside a biological tissue: experimental results. (a), Single-pixel reconstruction of a binary amplitude object. For this reconstruction, the object was immersed in air. (b), Photograph of one of the 3-mm samples of chicken breast that were used in this experiment. (c), Image reconstruction when the object was embedded in chicken breast. (d), Normalized intensity fluctuations corresponding to the first 500 Hadamard patterns used to recover the object in (a) and (c).

breast, it decreases smoothly with increase in wavelength [21]. As a consequence, the retrieved images degrade progressively towards shorter wavelengths of the visible spectrum, as can be observed in Fig. 4. For the millimeter tissue thickness that we are considering here, multiple scattering dominates over optical absorption, which means that a collimated beam impinging onto the tissue is basically scattered out of the incident light direction [22]. The improvement of image reconstructions from $650 \mathrm{~nm}$ shows the potentiality of our approach for imaging in the tissue optical window $(650-1350 \mathrm{~nm})$, where light reaches its maximum penetration depth [5].
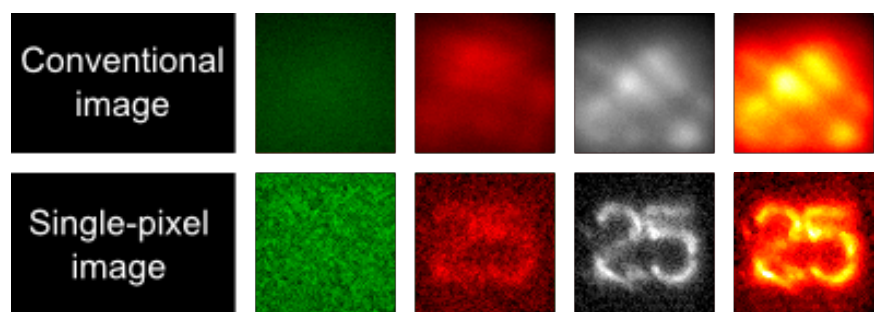

Fig. 4. Spectral study of a biological tissue. From the left to the right column: images for green, red and infrared bands. The reconstruction for the full source spectrum is also shown in the last column (pseudocolored image).

Another feature of our single-pixel camera is that it can take advantage of the theory of CS. By using this technique, we are able to sample the scene by projecting only a fraction of the employed basis of functions. This procedure can speed-up the acquisition process without notably decreasing the quality of the reconstruction. The fundamentals of single-pixel imaging by CS can be briefly presented as follows. Let us consider an object whose $N$-pixel image is arranged in a $N \times 1$ column vector $\mathbf{x}$. This image is supposed to be compressible when it 
is expressed in a basis of functions, $\Psi=\left\{\Psi_{l}\right\}(l=1, \ldots, N)$. From a mathematical point of view, $\mathbf{x}$ can be written as $\mathbf{x}=\Psi \cdot \mathbf{s}$, where $\Psi$ is a $N \times N$ matrix that has the vectors $\left\{\Psi_{l}\right\}$ as columns and $\mathbf{s}$ is the $N \times 1$ vector composed of the expansion coefficients in the above basis. We assume that the image is sparse in $\Psi$, which implies that only a small group of the expansion coefficients is nonzero. In order to determine $\mathbf{x}$, we implement an experimental system that generates a set of $M$ light patterns $\varphi_{m}(m=1, \ldots, M)$ of $N$-pixel resolution. These patterns enable to measure a subset of $M$ projections of the object in the basis function $\Psi$. Mathematically, such a subsampling is expressed through a $M \times N$ sensing matrix $\Phi$, whose rows are elements of the basis $\Psi$. The CS acquisition process can be then written as [19]

$$
\mathbf{y}=\Phi \cdot \mathbf{x}=\Phi \cdot(\Psi \cdot \mathbf{s})=\Theta \cdot \mathbf{s},
$$

where $\mathbf{y}$ is the $M \times 1$ vector formed by the measured projections and the product of $\Phi$ and $\Psi$ gives an $M \times N$ matrix $\Theta$ acting on the $\Psi$ domain. The formalism of CS states that there is a high probability of reconstructing $\mathbf{x}$ when a random subsampling in the $\Psi$ basis is carried out. In other words, the key point is that the matrix $\Theta$ "picks" a subset of the object projections randomly. As Eq. (10) constitutes an underdetermined matrix relation $(M<N)$, it must be resolved by means of a proper reconstruction algorithm. The best strategy to perform this step is based on the minimization of the $l_{1}$-norm of $\mathbf{s}$ subjected to the restriction given by Eq. (10). As the measurements $\mathbf{y}=\left\{y_{m}\right\}$ are affected by noise, the CS recovery process is usually reformulated with inequality constrains $[11,19]$. In this case, the proposed reconstruction $\mathbf{x}^{*}$ is given by $\mathbf{x}^{*}=\Psi \cdot \mathbf{s}^{*}$, where $\mathbf{s}^{*}$ is the solution of the optimization program

$$
\min \left\|\mathbf{s}^{\prime}\right\|_{l_{1}} \text { such that }\left\|\mathbf{y}-\Theta \cdot \mathbf{s}^{\prime}\right\|_{l_{2}}<\varepsilon,
$$

where $\varepsilon$ is an upper bound of the noise magnitude and the $l_{2}$-norm is used to express the measurement restriction.

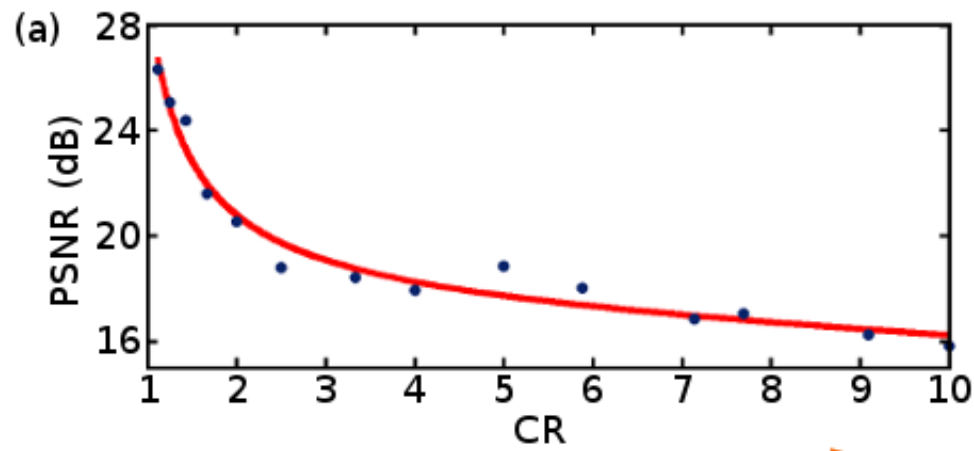

(b)

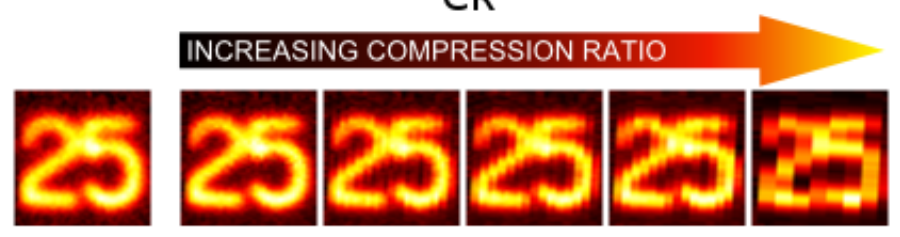

Fig. 5. Compressive sensing study. (a), Plot of the quality of the recovered pictures in $\mathrm{dB}$ as a function of the compression ratio. (b), Comparison between the reference image (without compression) and five of the pictures with different compression ratios. From left to right: reference picture, $C R=2, C R=2.5, C R=3.3, C R=5$ and $C R=10$.

In order to test these ideas, we repeated the first experiment with the holographic diffusers 
with different compression ratios (CR), given by the formula $C R=N / M$. The fidelity of the reconstructed images was estimated by calculating the mean square error (MSE), given by

$$
M S E=\frac{1}{N} \sum_{i, j=1}^{N}\left[I(i, j)-I_{r e f}(i, j)\right]^{2},
$$

where $I(i, j)$ is the lossy image obtained for a given CR and $I_{r e f}(i, j)$ is the non-compressed reference image. The quality of the reconstructed images was quantified by the peak signal-tonoise ratio (PSNR), defined as

$$
P S N R=10 \log \frac{I_{\max }^{2}}{M S E},
$$

where $I_{\max }$ is the maximum possible pixel value of the reference image. Figure 5(a) illustrates that $\mathrm{CR}$ around $50 \%$ can be achieved while the PSNR of the recovered picture remains higher than $20 \mathrm{~dB}$, showing high image fidelity. In Fig. 5(b) we show a comparison between the picture achieved without $\mathrm{CS}$ and a set of pictures recovered with different CR. Without a significant loss in quality, CS can reduce the acquisition time at least by a factor of 2 . The programming code used to obtain the optimal reconstruction was the so-called $l 1 e q-p d$, which solves the standard basis pursuit problem using a primal-dual algorithm [23]. This code includes a collection of MATLAB routines and is a well-tested algorithm for CS problems. However, other selections are possible and, in fact, the search of improved CS algorithms (more robust to data noise, with lower computation time, etc.) is an active area in the field of convex optimization [24].

\section{Conclusions}

In conclusion, we have presented a technique that merges Hadamard illumination and singlepixel photodetection for non-invasive imaging through scattering media. In our approach, images free of scattering noise are reconstructed from the correlation between a set of illumination patterns and the corresponding intensity fluctuations, which are measured by a "bucket" detector. We have obtained results for an absorbing object sandwiched between two opaque scattering layers, as well as for the same object embedded in a millimeter sample of chicken breast tissue, where the light experienced multiple scattering. The spectral behavior of the scattering medium has been analyzed in both cases, demonstrating imaging through tissue slides inside the "therapeutic window". The above goals have been reached without increasing the cost and complexity of the imaging system, as is evidenced by the use of a white-light lamp and an off-the-shelf DMD. In our optical scheme, image resolution and field of view are controlled by the DMD parameters and the data acquisition process can be sped up by the application of compressive sensing. In addition, the freedom to select a proper bucket detector could lead to performing hyperspectral or polarimetric imaging even in the presence of scattering media [25].

\section{Acknowledgments}

This work was supported in part from MINECO (grant FIS2013-40666-P), Generalitat Valenciana (grants PROMETEO2012-021 and ISIC 2012/013), and Universitat Jaume I (P1-1B201255). E.I. and F.S. were partially supported by a Generalitat Valenciana research fellowship. 


\title{
Single pixel camera ophthalmoscope
}

\author{
Benjamin Lochocki, ${ }^{1, *}$ Adrian Gambín, ${ }^{1}$ Silvestre Manzanera, ${ }^{1}$ Esther Irles, ${ }^{2}$ Enrique Tajahuerce, ${ }^{2}$ \\ Jesus Lancis, ${ }^{2}$ and Pablo Artal ${ }^{1}$ \\ 'Laboratorio de Óptica, Universidad de Murcia, Campus de Espinardo (Edificio 34), Murcia 30100, Spain \\ ${ }^{2}$ Institut of New Imaging Technologies, Universitat Jaume I, Castellon 12071, Spain \\ *Corresponding author: benjamin@um.es
}

Received 27 May 2016; revised 22 August 2016; accepted 25 August 2016 (Doc. ID 267182); published 21 September 2016

\begin{abstract}
Ophthalmoscopes to image the retina are widely used diagnostic tools in ophthalmology and are vital for the early detection of many eye diseases. Although there are various effective optical implementations of ophthalmoscopes, new, robust systems may have a future practical importance in cases where ocular media present significant opacities. Here, we present, as a proof of concept, a novel approach for imaging the retina in real time using a single pixel detector combined with spatially coded illumination. Examples of retinal images in both artificial and real human eyes are presented for the first time to our knowledge. (C) 2016 Optical Society of America
\end{abstract}

OCIS codes: (330.4460) Ophthalmic optics and devices; (330.7327) Visual optics, ophthalmic instrumentation; (330.7328) Visual optics, ophthalmic appliances; (110.0110) Imaging systems.

http://dx.doi.org/10.1364/OPTICA.3.001056

Modern flood-illuminated fundus cameras use a CCD or CMOS camera with an array of thousands of pixels to obtain an image, or video, of a part of the retina [1]. Good image quality is achieved by illuminating the full area of interest homogenously. When aberrations are corrected with the use of adaptive optics, even detailed structures of the photoreceptor mosaic can be obtained $[2,3]$. On the other hand, a scanning laser ophthalmoscope (SLO) scans a light spot rapidly across the retina [4]. The reflected intensity of each traversed point is recorded using a spot detector such as a photomultiplier tube (PMT) [5] or an avalanche photodiode (APD) [6]. Subsequently, a high-resolution image of the retina is composed from the acquired data. Most recently, digital light ophthalmoscopes were developed using a digital micromirror device (DMD) to scan lines across the retina, which are imaged either on a line camera or on a two-dimensional (2D) detector array to obtain an image $[7,8]$. All the former described ophthalmoscopes are state-of-the-art devices and widely used as medical instruments for monitoring the condition and alteration of the eye fundus. Here, we introduce another imaging modality, the single pixel camera technique, to the field of ophthalmic imaging. The proposed system images the retina by combining a spatially coded illumination with a single pixel detector in a double-pass configuration. Single pixel imaging gained interest within the last decade and has been successfully applied in biological imaging and microscopy $[9,10]$, infrared imaging [11-13], ultrasonic imaging [14], terahertz imaging [15], and three-dimensional (3D) imaging [16,17], and it has also been used in ghost imaging [18-20]. This type of system avoids the need of a scanning unit, which simplifies the optical system. The additional downscaling to a single pixel detector, instead of a pixel array, might lead to a lower illumination power, which benefits the patient's comfort.

The system (Fig. 1) consists of a DMD (Vialux V7001, controller board V4395, chipset DLP 4100, pixel size: $13.68 \mu \mathrm{m}$, resolution: $1024 \times 768 \mathrm{px})$. Each mirror pixel on the DMD can either guide light into the optical system or deflect it. The DMD is illuminated homogenously with a broadband xenon lamp (Hamamatsu L7810-02) with the UV part of the spectrum blocked. This light source guarantees a stable output over time, which is essential for discriminating minute intensity differences coming from the spatial coding of the later-described pattern.

The illumination is spatially coded by multiple $2 \mathrm{D}$ binary (black and white) patterns based on the Walsh-Hadamard transformation. These patterns are considered to have an optimum weighted design for spatial coding. The number of black and white pixels are equally distributed within each pattern and are preferred to others, e.g., pseudo-random binary patterns $[18,21]$. The so-called Hadamard patterns or masks are generated with an in-house developed software in $\mathrm{C}++$ and sent to the $\mathrm{DMD}$ via a USB 3.0 connection into the DMD's onboard memory. It is essential to pre-load all patterns before displaying them, as this is the only way to reach the maximum DMD frame rate of $22.727 \mathrm{kHz}$. Subsequently, the patterns sequence is initialized within an area of $512 \times 512$ pixels in the center of the DMD. The masks are scaled to match the size on the DMD, meaning e.g., for $N=32$, each pixel of the pattern corresponds to 16 pixels on the DMD. Next, the patterns are imaged through the lenses L1, L2, L3, L4, and the eye's optics onto the retina covering an area of around $15 \mathrm{deg}$ of the visual field. The light intensity reflected from the retina is measured through the crystalline lenses, L5, L6, and L7 with a silicon photomultiplier (SIPM, Excelitas Lynx A-33-050-T1A), the single pixel detector. This is synchronized with the DMD, which triggers the intensity measurement of each projected pattern individually. The diaphragm D1 is placed centrally on the back plane of lens L2, imaged via the telescope formed by lenses L3 and L4 onto the pupil plane, and it therefore defines the beams' entry point. This configuration lowers the impact of 


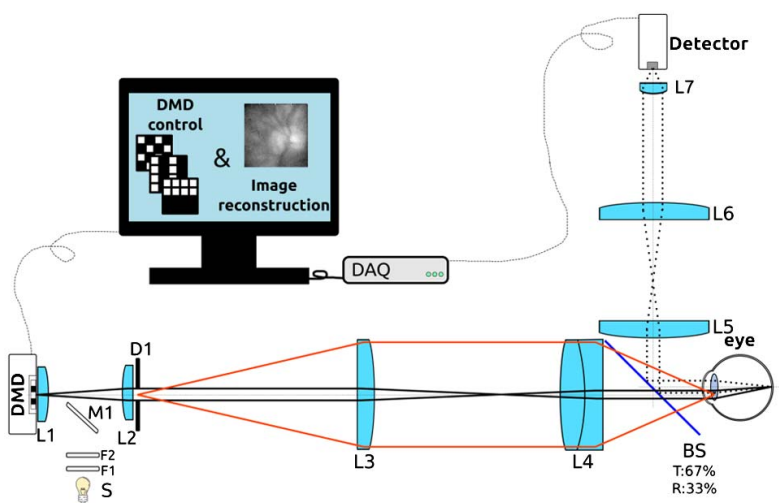

Fig. 1. Schematics of the single-pixel ophthalmoscope. The patterns generated on the DMD are imaged onto the retina. The diaphragm D1 is conjugated to the pupil plane (red line) and defines the entry point. $\mathrm{F} 1$ and F2 are interchangeable ND and bandpass filters.

aberrations on the image of the pattern and minimizes the area of possible backscattering and reflections. The data from the photomultiplier is transferred via an analog-to-digital converter (National Instruments PCIe-6361, sampling rate $2 \mathrm{MS} / \mathrm{s}$ ) to a desktop PC (i5-4590, quad-core, 3.3 GHz, 8 GB RAM). The high sampling rate of the analog-to-digital converter (ADC) allows for 84 measurements per pattern. Not all data points are used for further processing, since data from the start of each pattern measurement is affected by minute mirror wiggling while the mirrors settle. The data received for each pattern are averaged and stored as intensity $y_{i}$ per pattern. A full reconstruction of an image with the resolution $N$ needs the amount of $N^{2}$ patterns to be displayed, meaning for $N=32, n=N^{2}=1024$. Since the mathematical description of the binary Hadamard pattern consists of negative and positive ones $(-1,+1)$, and the DMD is only able to display zeros and positive ones $(0,+1)$, there is a need to display twice the number of patterns, resulting in $n=$ 2048 (equals $2 * N^{2}$ ) for $N=32$. The patterns are displayed in the following order: a positive pattern (resembling patterns with 0 and +1 ) and, subsequently, its inverted complement (patterns with -1 and 0 ). Afterward, the data from the inverted masks are subtracted from the data of the positive masks, resulting in the final data corresponding to the correct mathematical model of the Hadamard patterns $(-1,+1)$. With this displaying order, also used in other studies $[9,10,22]$, noise is almost completely eliminated and the data complements the optimal reconstruction. One might argue that displaying only the positive patterns and subsequently subtracting the average of all intensity measurements would resemble the Hadamard patterns adequately, and, therefore, be sufficient to reconstruct the object, but that only works satisfactorily under optimum illumination conditions. In a low-light environment, noise induced by the photomultiplier, the light source, or the environment (Status LED, PC display) may have a severe impact on the image reconstruction [23]. The reconstruction of the object is done by the use of the following equation:

$$
\text { image }(m, n)=\sum_{i}^{N^{2}} \operatorname{intensity}_{i} \times \operatorname{pattern}_{i}(m, n),
$$

where $\operatorname{pattern}_{i}(m, n)$ denotes the set of matrices of the Hadamard basis with dimensions $N \times N$, consisting of " $+1 \mathrm{~s}$ " and “- 1 s." The intensit $y_{i}$ represents the averaged intensity per pattern after the subtraction of the negative data from the positive data, and $(m, n)$ are discrete spatial coordinates. Note that the values of intensity are the coefficients of the transformation of the image into the WalshHadamard basis, and Eq. (1) just transforms back to the spatial domain. Figure 2 shows the obtained intensity measurements using a model eye with a lens $f_{\text {eye }}=20 \mathrm{~mm}, \varnothing 12.7 \mathrm{~mm}$, and an imprinted letter acting as a retinal surrogate after imaging with a resolution of $N=32$ and a total of 2048 patterns. Figure 2(a) shows the original object with a black square the size of $5 \mathrm{~mm} \times 5 \mathrm{~mm}$ and printed letters with four different grayscale values on a white letter. Figure 2(b) shows the image of the reconstructed object obtained with the maximum DMD frame rate and up-sampled to $128 \times$ 128 pixels without interpolation for better viewing purposes. A detailed image reconstruction is already possible due to the object's simple structure. Figure 2(c) displays the raw intensities, measured 84 times for each of the 2048 patterns. At this point, all the obtained measurements are positive. The final data are shown in Fig. 2(d), after the subtraction and averaging are done; consequently, the computed data contain negative values and vary around the zero baselines. Eventually, this set of data is used to reconstruct an image of the object, as depicted in Fig. 2(b), by performing Eq. (1).

Figure 3 shows additional results using a model eye but imaged with various resolutions, proofing the feasibility of the presented optical system. It is worth to mention that for $N=256$, only all positive patterns $\left(n=N^{2}=65536\right.$; all patterns would result in $\left.n=2 * N^{2}=131072\right)$ are shown due to the restrictions of the DMD's memory, which cannot store more than 87380 binary patterns. In this case, the displaying time only doubles rather than quadrupling (compared to $N=128$, see Table 1), but the reconstructed images are of lower quality, since the noise effects are not compensated effectively.

The images shown in Fig. 3 are reconstructed without any applied image post-processing except for $N=256$, where contrast stretching is applied since the dynamic range was very narrow. The quality of the images could be further improved by lowering the frame rate of the DMD. That might be suitable for measurements with a static object, but during in vivo measurements, subtle eye (a)

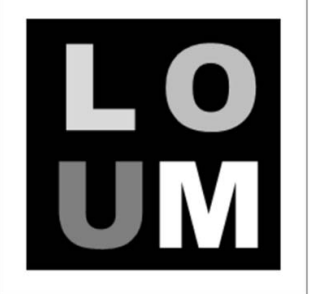

raw data

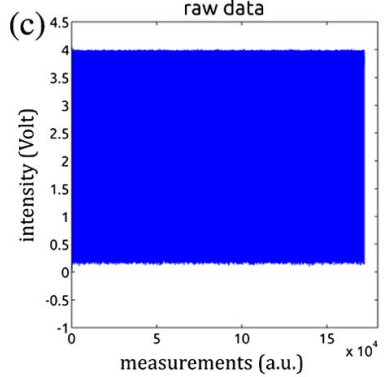

(b)

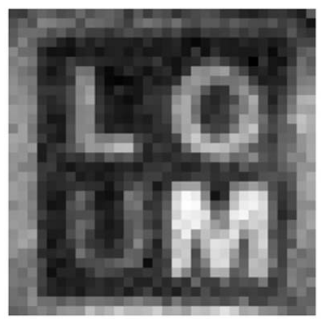

processed data

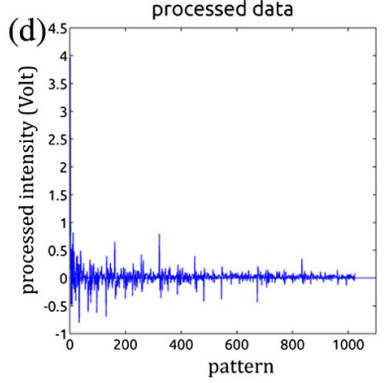

Fig. 2. Top row: (a) original object, black square size is $5 \mathrm{~mm} \times 5 \mathrm{~mm}$ (b) reconstruction for $N=32$. Imaging time $=0.09$ s. Bottom row: (c) full intensity measurements for $N=32 ; 84$ measurements for each of the 2048 patterns, and (d) processed data after subtraction and averaging, resulting in the final 1024 intensity values. 


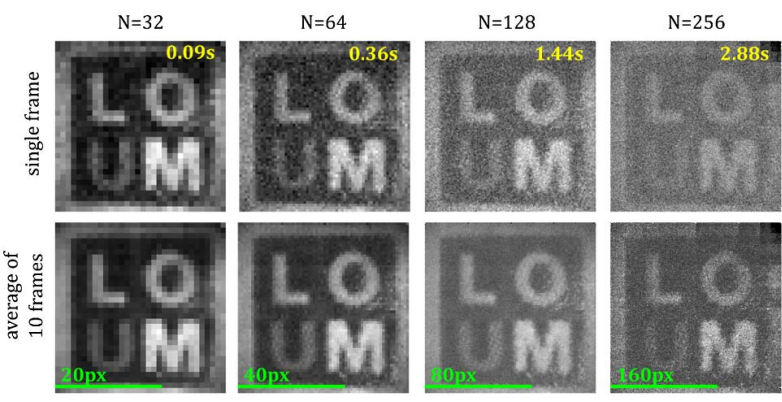

Fig. 3. Results using a model eye (raw images without image postprocessing). Top row: single frames, bottom row: the average of 10 frames. The DMD is set to its maximum display rate. Note: For $N=256$, only the positive patterns were displayed, hence the increased noise and artifacts. Imaging time per frame is indicated.

movements would affect the image quality drastically, since the area of illumination needs to be constant. Furthermore, increasing the imaging time would be contrary to the ophthalmoscope's desired real-time operation capability. One pixel in an $N=32$ reconstruction equals around $0.18 \mathrm{~mm}$. Consequently, doubling $N$ results in halving the pixel size, meaning that when $N=256$, one pixel equals $0.022 \mathrm{~mm}$. The scale bar is indicated within Fig. 3 .

We were able to record images and video streams with the proposed optical instrument. Table 1 shows an overview of the achieved frames per second (FPS) during the continuous acquiring and reconstruction of images when operating in real-time mode. The mathematical calculations to reconstruct an image are simple, but the frame rate drops fast with the increasing resolution not only because of the exponential growth of pattern's size to be displayed, but also due to the vast amount of data that needs to be processed. Additionally, we compared our video rate to those obtained by other groups using the same imaging technique outside the field of retinal imaging.

The following results are obtained in living human eyes while using multiple frame rates of the DMD and the total amount of $n=2 * N^{2}$ patterns. Figure 4(a) presents an initial unprocessed result taken in a young subject volunteer with an illumination time of $0.54 \mathrm{~s}$ and a resolution of $N=32$. The images on the right in Fig. 4 show the average of 10 frames using the same settings as the left ones. Averaging was done without correcting for possible eye movements between each frame. Image postprocessing is not applied, but the image is up-sampled to a size

Table 1. FPS at Maximum DMD Frame Rate for Different Resolutions

\begin{tabular}{lcccc}
\hline $\boldsymbol{N}$ & $\mathbf{3 2}$ & $\mathbf{6 4}$ & $\mathbf{1 2 8}$ & $\mathbf{2 5 6}^{\boldsymbol{a}}$ \\
\hline$n=2 * N 2$ & 2048 & 8192 & 32768 & 65536 \\
Imaging time $(s)$ & 0.09 & 0.360 & 1.442 & 2.884 \\
Theoretical FPS $^{b}$ & 11.10 & 2.77 & 0.70 & 0.35 \\
Experimental FPS $^{c}$ & 11.10 & 2.76 & 0.57 & 0.04 \\
Other groups & $10[10,11,14]$ & $2.5[11,12,14,15]$ & $0.5[22]$ & - \\
\hline
\end{tabular}

The table shows the obtained FPS for various resolutions.

${ }^{a}$ For $N=256$, only positive patterns are shown due to the restriction of the DMD memory.

${ }^{b}$ Theoretical FPS is solely based on the maximum frame rate of the DMD without further data processing.

${ }^{c}$ Obtained experimental FPS including the processing and computation of the data.
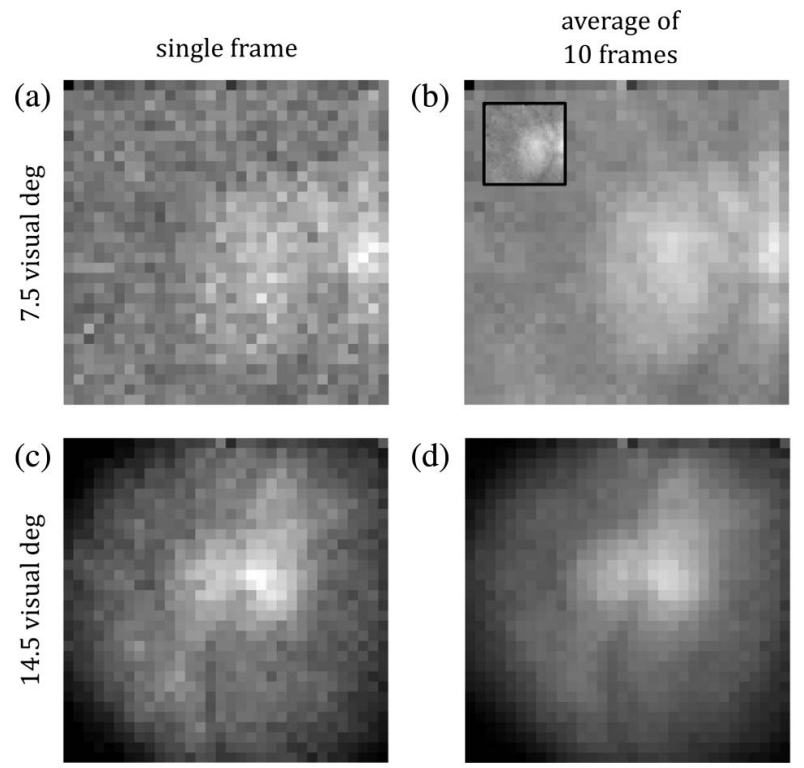

(d)

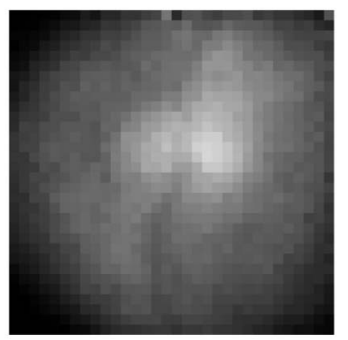

Fig. 4. Reconstructed images of the optical nerve head using $N=32$. Imaging time per frame is $0.54 \mathrm{~s}$. The left side shows one frame; the right side is the average of ten frames. Top row covers an area of around 7.5 and the bottom row around 14.5 visual degrees. All images are up-sampled to a size of $128 \times 128$ pixels. The inset in image (b) displays the image in its original size.

of $128 \times 128$ pixels. The main blood vessels, which join at the optical nerve head, can be distinguished clearly. Further details are not visible due to the lack of resolution and the presence of noise. Higher-resolution images obtained from the averaged video frames (taken from Visualization 1 for $N=64$ and Visualization 2 for $N=128$ ) are shown in Fig. 5.

Compared to the results shown in Fig. 4, more details of the vessel map around the optical nerve head are visible. The improvement is not as good as anticipated, which is due to the increased amount of time it needs to display the full set of patterns, and therefore, eye motions influence the outcome severely. If the subject moves, even subtlely, different areas of interest are illuminated, and this results in useless reflection intensity measurements. Furthermore, with the increase of resolution comes an increased level of noise. Images taken with a resolution of $N=$ 256 are not shown here due to the following reasons: the overall quality is low, as the imaging time for one single frame is around three seconds (at maximum speed) and, therefore, eye movements have a drastic effect on the reconstructed result. Second, with the current hardware, we are not able to project the inverted patterns, which are necessary to compensate for noise effects. As Figs. 4 and 5 show, an increase in resolution does not necessarily improve the image quality, but rather introduces high-frequency noise. This is mainly when finely structured patterns are not projected perfectly onto the retina (due to aberrations) and, therefore, introduce a light haze on the reconstructed image, as shown in Fig. 6. Nevertheless, the extended imaging time combined with a non-constant area of illumination, due to the locomotion of the eye, is the most challenging issue. To reduce the influence of motion artifacts, it is necessary to keep the imaging time as short as possible. For that reason, it is possible to remove masks from the display sequence, since some masks do not provide significant information. The technique of displaying less patterns is known as adaptive imaging or evolutionary compressive sensing $[10,17]$. To 
$\mathrm{N}=64$

11 visual deg

(a)

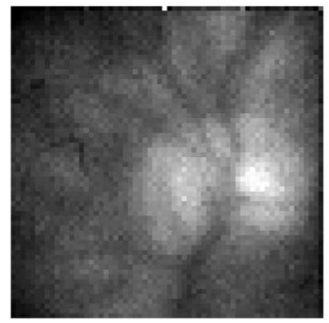

average of 30 frames
$\mathrm{N}=128$

14.5 visual deg

(b)

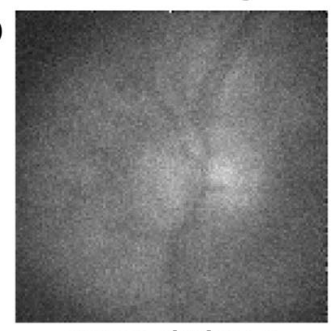

average of 7 frames
Fig. 5. Reconstructed and averaged images of the optical nerve head using a resolution of (a) $N=64$ (11 deg, 30 frames) and (b) $N=128$ (14.5 deg, 7 frames). Illumination times are 1.29 and $5.15 \mathrm{~s}$ per frame. Images are contrast stretched and (a) is scaled to $128 \times 128$ pixels.

gain knowledge about the patterns that can be eliminated, a full set of $2 * N^{2}$ masks needs to be displayed prior to classification. Subsequently, the obtained intensity data are sorted by means of highest responsivity and then loaded into the memory of the DMD to provide instant availability.

Afterward, a threshold is chosen to separate the patterns into useful and dispensable. From there, we are left with two options to gain an advantage of the lower amount of patterns:

(i) Increasing the illumination time per pattern, $T$, hence gaining a longer integration time for the detector area but maintaining the same overall illumination time, $t$, which is not desired.

(ii) Keeping the illumination time per pattern, $T$, constant, results in a lower imaging time per frame.

Figure 6 shows results of the latter adaptive imaging configuration for $100,75,50,30,25$, and $10 \%$ of $2 * N^{2}$ patterns in the model eye setup and a resolution of $128 \times 128$ pixels. As can be seen, displaying less than $30 \%$ of the patterns is sufficient for a good reconstruction of the object but highly dependent on the object's structure and its grade of detail. With fewer patterns displayed, the haze (high-frequency noise) in the reconstructed images disappears and the real-time video frame rate increases significantly. The imaging times per frame are indicated within the images. Another technique that is commonly used with a single pixel detector and a reduced amount of patterns is compressive sensing (CS) $[12,16,21,24,25]$. As it is based on a timeconsuming statistical algorithm, we omit CS for the moment as we put our focus on a real-time optical instrument.

In conclusion, we described a novel instrument, based in a single-pixel detection, for imaging the fundus of an eye in vivo within an area of almost 15 visual degrees. Images and videos taken in a static artificial eye demonstrate its feasibility and

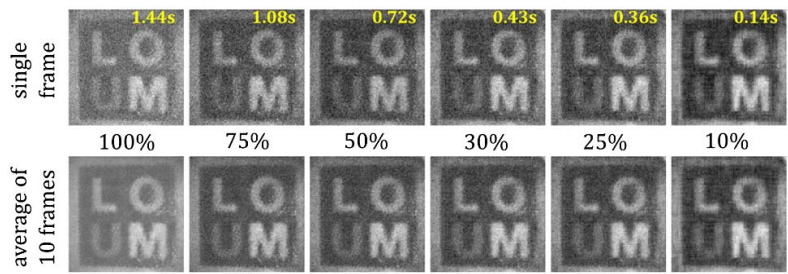

Fig. 6. Adaptive imaging results for $N=128$. The percentage of patterns, which are displayed, and their imaging time per frame are indicated. The first row depicts a single frame, while the bottom row shows an average of 10 frames. The DMD was set to its maximum frame rate. capability, while imaging in vivo remains challenging mainly due to unintentional eye movements during extended illumination times. In terms of image quality and resolution, the obtained results cannot compete with comparable ophthalmic imaging instruments, since the main limitation is the maximum frame rate of the DMD. Future technology improvements and customized hardware might close that gap. In addition, one can expect that this type of single-pixel ophthalmoscope could operate under a larger range of eye conditions, such as increased ocular aberrations or scatter [26], as in the case of cataract patients [27]. Other potential advantages would be to obtain retinal images in spectral bands beyond the current camera technology limits.

Funding. European Research Council (ERC) (ERC-2013AdG-339228 (SEECAT)); Secretaría de Estado de Investigación, Desarrollo e Innovación (SEIDI), Spain (FIS2013-41237-R, FIS2013-40666-P).

\section{REFERENCES}

1. R. D. Moore and G. W. Hopkins, "CCD camera and method for fundus imaging," U.S. patent 5,140,352 (August 18, 1992).

2. J. Liang, D. R. Williams, and D. T. Miller, J. Opt. Soc. Am. A 14, 2884 (1997).

3. S. S. Choi, N. Doble, J. L. Hardy, S. M. Jones, J. L. Keltner, S. S. Olivier, and J. S. Werner, Invest. Ophthalmol. Vis. Sci. 47, 2080 (2006).

4. R. H. Webb, G. W. Hughes, and F. C. Delori, Appl. Opt. 26, 1492 (1987).

5. A. Roorda, F. Romero-Borja, W. Donnelly III, H. Queener, T. J. Hebert, and M. C. W. Campbell, Opt. Express 10, 405 (2002).

6. B. Vohnsen and D. Rativa, Biomed. Opt. Express 2, 1597 (2011).

7. M. S. Muller, A. E. Elsner, and G. Y. Ozawa, Proc. SPIE 8567, 85670Y (2013).

8. K. V. Vienola, M. Damodaran, B. Braaf, K. A. Vermeer, and J. F. de Boer, Opt. Lett. 40, 5335 (2015).

9. E. Tajahuerce, V. Durán, P. Clemente, E. Irles, F. Soldevila, P. Andrés, and J. Lancis, Opt. Express 22, 16945 (2014).

10. N. Radwell, K. J. Mitchell, G. M. Gibson, M. P. Edgar, R. Bowman, and M. J. Padgett, Optica 1, 285 (2014).

11. M. P. Edgar, G. M. Gibson, R. W. Bowman, B. Sun, N. Radwell, K. J. Mitchell, S. S. Welsh, and M. J. Padgett, Sci. Rep. 5, 10669 (2015).

12. L. McMackin, M. A. Herman, B. Chatterjee, and M. Weldon, Proc. SPIE 8353, 835303 (2012).

13. H. Peng, Z. Yang, D. Li, and L. Wu, Proc. SPIE 9795, 979520 (2015).

14. N. Huynh, E. Zhang, M. Betcke, S. Arridge, P. Beard, and B. Cox, Optica 3, 26 (2016).

15. R. I. Stantchev, B. Sun, S. M. Hornett, P. A. Hobson, G. M. Gibson, M. J. Padgett, and E. Hendry, Sci. Adv. 2, e1600190 (2016).

16. W.-K. Yu, X.-R. Yao, X.-F. Liu, L.-Z. Li, and G.-J. Zhai, Appl. Opt. 54, 363 (2015).

17. M.-J. Sun, M. P. Edgar, G. M. Gibson, B. Sun, N. Radwell, R. Lamb, and M. J. Padgett, Nat. Commun. 7, 12010 (2016).

18. J. H. Shapiro, Phys. Rev. A 78, 1 (2008).

19. Y. Bromberg, O. Katz, and Y. Silberberg, Phys. Rev. A 79, 053840 (2009).

20. B. Sun, S. S. Welsh, M. P. Edgar, J. H. Shapiro, and M. J. Padgett, Opt. Express 20, 16892 (2012).

21. M. F. Duarte, M. A. Davenport, D. Takhar, J. N. Laska, T. Sun, K. F. Kelly, and R. G. Baraniuk, IEEE Signal Process. Mag. 25(2), 83 (2008).

22. M. Sun, M. P. Edgar, D. B. Phillips, G. M. Gibson, and M. J. Padgett, "Infrared single-pixel imaging utilising microscanning," arXiv:1511.02637 (2015).

23. L. Streeter, G. R. Burling-Claridge, M. J. Cree, and R. Künnemeyer, Appl. Opt. 48, 2078 (2009).

24. C. M. Watts, D. Shrekenhamer, J. Montoya, G. Lipworth, J. Hunt, T. Sleasman, S. Krishna, D. R. Smith, and W. J. Padilla, Nat. Photonics 8, 605 (2014).

25. V. Duran, F. Soldevila, E. Irles, P. Clemente, E. Tajahuerce, P. Andres, and J. Lancis, Opt. Express 23, 14424 (2015).

26. P. Artal, Adv. Opt. Photonics 6, 340 (2014).

27. P. Artal, A. Benito, G. M. Pérez, E. Alcón, Á. de Casas, J. Pujol, and J. M. Marín, PLoS One 6, e1682 (2011) 